Portland State University

PDXScholar

$6-4-2020$

\title{
Long Term Changes to the Lower Columbia River Estuary (LCRE) Hydrodynamics and Salinity Patterns
}

Aqeel Al-bahadily

Portland State University

Follow this and additional works at: https://pdxscholar.library.pdx.edu/open_access_etds

Part of the Water Resource Management Commons

Let us know how access to this document benefits you.

Recommended Citation

Al-bahadily, Aqeel, "Long Term Changes to the Lower Columbia River Estuary (LCRE) Hydrodynamics and Salinity Patterns" (2020). Dissertations and Theses. Paper 5483.

https://doi.org/10.15760/etd.7357

This Dissertation is brought to you for free and open access. It has been accepted for inclusion in Dissertations and Theses by an authorized administrator of PDXScholar. Please contact us if we can make this document more accessible: pdxscholar@pdx.edu. 
Long Term Changes to the Lower Columbia River Estuary (LCRE) Hydrodynamics and Salinity Patterns

by

Aqeel Al-bahadily

A dissertation submitted in partial fulfillment of the requirements for the degree of

\title{
Doctor of Philosophy
}

in

Civil and Environmental Engineering

\author{
Dissertation Committee: \\ Stefan A. Talke, Chair \\ David A. Jay \\ Joseph Jurisa \\ Gerald Recktenwald
}

Portland State University

2020 


\begin{abstract}
Changing the morphological and hydrological conditions of an estuary can affect the estuarine hydrodynamics. The hydrograph of the Lower Columbia River Estuary (LCRE) and its bathymetry have been altered significantly over the past 150 years, such that the spring-freshet has decreased by $40-50 \%$ while winter flow has increased by $50 \%$. In addition, the inlet width has been narrowed from 9.7 to $3.2 \mathrm{~km}$ by the construction of jetties, and the controlling depth of the navigation channel has been deepened from 6 to $13 \mathrm{~m}$ by continuous dredging. Also, $\sim 70 \%$ of the shallow water habitat has been lost due to diking and wetland reclamation. Finally, the main shipping channel was changed from the north to the south side of the estuary. These system alterations lead to the following question: how have changes since the mid-1800s altered the salinity intrusion, freshwater distribution, transport processes, and water levels in the Lower Columbia River estuary?
\end{abstract}

In this study, I use a 3D hydrodynamic model to gain insights into changes in circulation and salinity intrusion from the mid-1800s to the present. Two models were constructed: one based on bathymetric measurements made between 1869 and 1900, and a second based on bathymetric surveys made from 2008 to 2010. The horizontal resolution is typically $50 \mathrm{~m}$ inside the estuary and $2000 \mathrm{~m}$ offshore, with 36 sigma layers of vertical resolution. The models have been calibrated and verified using field measurements distributed over the lower $40 \mathrm{~km}$ of the estuary. The average skill assessment of the calibration is 0.98 ; the root mean square error is between $0.11 \mathrm{~m}$ and $0.15 \mathrm{~m}$ for water level, 2-4psu for salinity, and $0.25 \mathrm{~m} / \mathrm{s}$ for velocity. 
Analysis of flow bifurcation (water distribution between channels at a junction) showed that morphology, tidal forcing, and water surface slope have played major roles in freshwater distribution in the multi-channel estuary. However, the asymmetry in the water surface slope between the North and the South Channels is what controls the distribution of flow between the two channels. In the historical model, the two channels surface slopes are equal. Therefore, the hydraulic radius and the cross-sectional area control the flow distribution, but the percentage of freshwater in each channel is still a function of river discharge. For the modern model, the percentage of freshwater in the South Channel decreases as the river discharge increases. During spring tide, $88 \%$ of freshwater passes through the South Channel during low river discharge conditions $\left(3,000 \mathrm{~m}^{3} / \mathrm{s}\right)$, while $48 \%$ passes through during high river discharge $\left(15,000 \mathrm{~m}^{3} / \mathrm{s}\right)$. Conversely, in the historical model, the percentage of freshwater in the South Channel increases as the river discharge increases. This implies that the morphological changes in the estuary causes the South Channel to export more freshwater today, as compared to 150 years ago. Finally, model results suggest that $\mathrm{M}_{2}$ amplitude has increased by $10 \%$ in the city of Astoria due exclusively to channel deepening, and about $12.5 \%(\sim 0.11 \mathrm{~m})$ when both channel deepening and river discharge alteration are included.

The LCRE system alteration is modeled to change the average location and the seasonal cycle of salinity intrusion. The simulation results found that average winter-time salinity intrusion has decreased due to a 50\% increase in river discharge. During the annual spring freshet, salinity intrusion has increased because of decreased river flow. Due to changes in river discharge, the seasonality of maximum salinity intrusion has shifted from 
wintertime to late summer/early fall. Channel deepening exerts a strong control on salinity intrusion, and has caused greater landward salinity intrusion landward due to increased stratification. Channel deepening also amplified spring-neap variations in intrusion and altered the sensitivity of intrusion to river discharge. Altogether, the change in freshwater distribution, salinity intrusion, and stratification produced a change in the LCRE system classification. A parameter space classification based on Geyer \& MacCready, (2014), suggests that morphological changes and river discharge alteration have shifted the LCRE from partially mixed $41 \%$ of the time to a salt wedge estuary $34 \%$ of the time.

Finally, the effects of future sea-level rise and a subduction zone earthquake on tidal amplitudes and salinity intrusion are investigated. A future sea-level rise of $0.21 \mathrm{~m}$ will have an insignificant effect on salinity intrusion and tidal variation inside the estuary. On the other hand, sudden land subsidence resulting from a potential M9 earthquake and/or a future $1.5 \mathrm{~m}$ SLR (extreme cases) could produce a substantial effect on tidal amplitudes and circulation. Modeling analyses suggest that either scenario could elevate the major tidal constituent $\left(\mathrm{M}_{2}\right)$ by $0.05 \mathrm{~m}$. Moreover, the maximum value could be moved upstream by $4 \mathrm{~km}$. Combined together, the combined effect of $1.5 \mathrm{~m}$ SLR and sudden land subsidence might raise $\mathrm{M}_{2}$ by $0.11 \mathrm{~m}$ and advance the location of maximum $\mathrm{M}_{2}$ by $10 \mathrm{~km}$ landward. Similarly, salinity intrusion could increase $4 \mathrm{~km}$ as a result of either the SLR or land subsidence cases, and might increase by $10 \mathrm{~km}$ with both scenarios combined. Moreover, both cases have altered the habitat water depth and inundation by increasing the mean depth. 


\section{Acknowledgments}

I would like to thank the Ministry of Higher Education and Scientific Research (MOHESR) in Iraq for funding this research. Also, I wish to express my sincere appreciation and gratitude to my advisors, Professor Stefan Talke and Professor David Jay, for their continuous guidance and support. Special thanks to the staff of the Civil and Environmental Engineering Department at Portland State University for their kindness and assistance. Finally, I wish to acknowledge the support and great love of my family, my wife, and my two lovely daughters. 


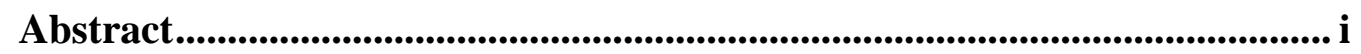

Acknowledgments ................................................................................................. iv

List of Tables ............................................................................................. vii

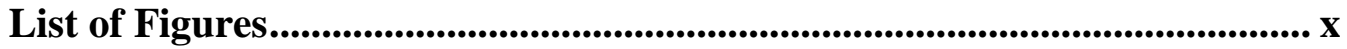

Chapter 1 Overview of Dissertation ................................................................... 1

1.1 Introduction ........................................................................................................... 1

1.2 General ..................................................................................... 1

1.3 Salinity intrusion......................................................................................5 5

1.4 Columbia River Estuary (CRE) ........................................................... 6

1.5 Bathymetry ...................................................................................................................... 7

1.6 River flow................................................................................. 11

1.7 Motivation and research questions ............................................................... 12

Chapter 2 Theory and Literature Review ............................................................... 16

2.1 Introduction ....................................................................................................... 16

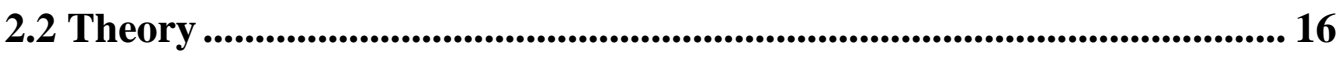

2.3 Literature review ................................................................................................... 30

Chapter 3 Flow Bifurcation in the Lower Columbia River Estuary............... 47

3.1 Introduction ..................................................................................... 47

3.2 Theory and methods .......................................................................................... 49

3.3 Model calibration ....................................................................................6 63

3.4 Results ..................................................................................................69 69

3.5 Conclusions .................................................................................................................. 86

Chapter 4 Changes in the Lower Columbia River Seasonal Cycle of Salinity Intrusion Related to Change in the River Flow Regime and Bathymetry..... 89

4.1 Introduction ......................................................................................................... 89

4.2 Materials and methods ..................................................................................... 94

4.3 Calibration of historical and modern models.......................................... 101 
4.4 Results ........................................................................................................................ 104

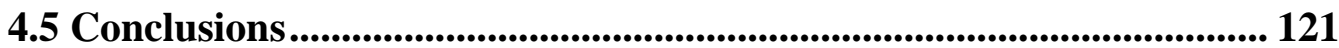

Chapter 5 After the Earthquake and Climate Change: How Sudden Relative Sea-Level Changes May Alter Salinity Intrusion in the Columbia River Estuary? .................................................................................................................. 123

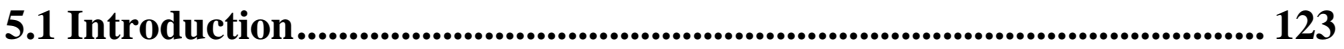

5.2 Theory …….............................................................................................................. 125

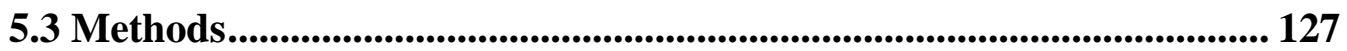

5.4 Results ..................................................................................................................... 132

5.5 Conclusion ............................................................................................................ 141

Chapter 6 Summary and Conclusion ........................................................................ 144

6.1 Summary ............................................................................................................... 144

6.2 Conclusion .............................................................................................................. 145

6.3 Future steps and recommendations .............................................................. 147

References ....................................................................................................................... 149 


\section{List of Tables}

Table 1-1. Columbia River mouth \& navigation channel development by U.S. Army Corp

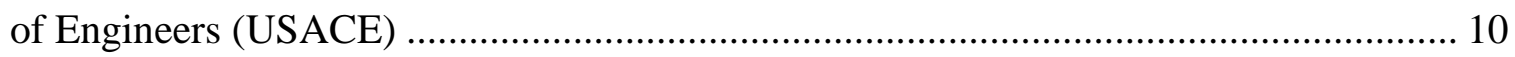

Table 2-1. Salinity intrusion length $\left(\mathrm{X}_{\mathrm{s}}\right)$, river discharge $(\mathrm{Q})$ relation for different estuaries. Where Kmo is a mixing coefficient that uses the whole water column depth as an effective mixing length scale, while KmBL uses the bottom boundary layer height. .................... 36

Table 2-2. Hydrologic modeling for the Columbia River above The Dalles [after Bureau of

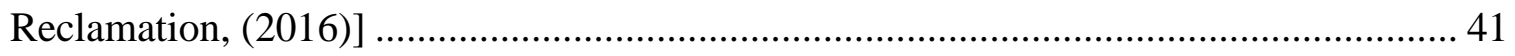

Table 2-3. projection of RSL near Oregon coast as suggested by NRC (2012) .............. 45

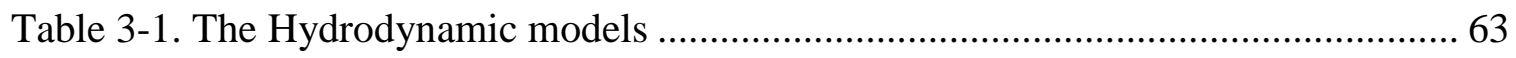

Table 3-2. Example of total flow (rive + tide) percentage at each cross-section (CR) of MB during low river discharge and spring-flood tide. SO is the South Channel, NO is the North Channel, and MI is the Middle Channel. 63

Table 3-3. Major Constituent comparison of the MM0 model in 2013 at different locations: Cape 67

Table 3-4. River discharge percentage of the modern model for different river discharges averaged over two days during high (spring) and low (neap) tides periods, were SO is South Channel, NO is the North Channel, and MI is the Middle Channel. 74 
Table 3-5. River discharge percentage of the historical model for different river discharges averaged over two days during high (spring) and low (neap) tides periods, were SO is South Channel, NO is the North Channel, and MI is the Middle Channel. 78

Table 4-1. Model Calibration Statistics: R2 is the coefficient of determination, RMSE is the mean root square error, NS is the Nash-Sutcliff coefficient, and SK is the skill coefficient (one indicates there is the perfect match between the model and the observation, while zero is no match at all) 103

Table 4-2. Maximum and minimum hourly salt intrusion in $\mathrm{km}$ from the mouth of the CRE (using 2-psu isohaline) for the three cases (MM, MH, and $\mathrm{HH}$ ), using mean flow, 25th, and 75th percentiles of flow 107

Table 4-3. The effective variables and ranges in the parameter space: $\mathrm{Q}_{\mathrm{T}}$ is the river discharge at the BAT, Qs is the freshwater in the South Channel, $\mathrm{H}$ is the water depth range, A is the cross-section area, $U_{T}$ is the tidal velocity range, and $U_{R}$ is the river velocity range in the South Channel. 120

Table 5-1. Simulation scenarios for the constant river discharge 128

Table 5-2.Hydrologic modeling for the Columbia River above The Dalles [after the Bureau of Reclamation, (2016)] 131

Table 5-3. Simulation scenarios for a variable river discharge 132

Table 5-4. Sea-level rise and earthquake-induced land subsidence effects on $\mathbf{M}_{2}$ amplitude and location of Maximum $\mathrm{M}_{2}$ inside the South Channel of the estuary. Mean water depth 
is during low flow, averaged over neap-spring, and averaged spatially along the South Channel.

Table 5-5. Tidally averaged Salinity intrusion in the South Channel during spring (SP) and neap (NE) tides and low river discharge (Q).

Table 5-6. Maximum and minimum limits of X2 for river discharge and SLR interaction (+ for percentage increase, and - for decrease)

Table 5-7. Water depth (averaged during spring-neap cycle) increment due to SLR and river discharge variation. 


\section{List of Figures}

Figure 1-1. Estuarine classifications .................................................................. 3

Figure 1-2. Estuarine classification based on water mixing after Valle-Levinson, (2010) 4

Figure 1-3. Salinity intrusion a-concept, and b- example of modeled salinity intrusion where the white curve represents the 2 psu isohaline ................................................. 5

Figure 1-4. Columbia River watershed .............................................................. 7

Figure 1-5. CR mouth before jetty construction (1839), (Hickson \& Rodolf, 1951) ........ 9

Figure 1-6. CR mouth after jetty construction (1950), (Hickson \& Rodolf, 1951) ......... 10

Figure 1-7. Monthly mean flow of Columbia River at The Dalles/Oregon..................... 12

Figure 2-1. Percentage of contribution to salinity intrusion by river flow (Q) and channel depth $(\mathrm{H})$ variations. The percentage approximates the theoretical scaling Xs $\sim \mathrm{H} 2 / \mathrm{Q}-$ $1 / 3$. The percentage represents the effect of the 2 nd power of $H$ and the cubic root of $Q$, the same percentage of doubling the two parameters (H\&Q) .................................... 26

Figure 2-2. Estuarine parameter space (Geyer \& MacCready, 2014)............................. 30

Figure 2-3. Physical mechanism layout of tidal asymmetry ....................................... 39

Figure 2-4. Sea-level curves calculated by different research groups with various methods. The curves show the sea-level relative to the satellite era (since 1992), http://www.realclimate.org/index.php/archives/2015/01/a-new-sea-level-curve/.... 43 
Figure 2-5. Estimated land subsidence from a magnitude 9 earthquake on Astoria and

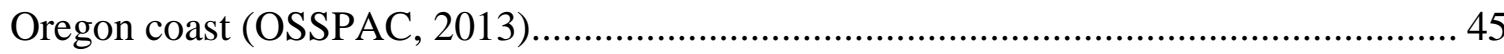

Figure 2-6. Change in the bathymetry of CRE and Oregon coast from magnitude 9-modeled earthquake after Kalmbacher and Hill (2015). Note: negative values represent the upward displacement 46

Figure 3-1. CR Bathymetrical change over the past 150-year: a) modern bathymetry (USACE, 2010); also shown are the grid boundaries, the calibration point locations (Cape Disappointment, Astoria Downtown, Tongue Point, Skamokawa, and Wauna), the North \& South Channels layout, and the cross-sections along the estuary. b-historical bathymetry (Burke, 2010). Note: coordinates are in Washington South-State Plane Coordinate System (WA-SPCS) 57

Figure 3-2. Changes in the CR discharge at The Dalles (30-day moving average). The solid black and the dashed black curves represent, respectively, the historical (1879-1929) and the modern (1967-2016) daily mean river discharge (50th percentile). The shadow curves for each period extend from the 25 th to 75 th percentiles of river discharge. 58

Figure 3-3. CR 1876-hydrograph at the Beaver Army Terminal (BAT). The FM hydrograph used in modeling is derived from the 1880 hydrograph. The green curve is the estimate of river discharge in 1876 at BAT by Talke et al. (2020). 65 Figure 3-4. Modern Bathymetrical Model (MM0) calibration at Tongue Point (TP) during low river discharge (a) and high river discharge (b). Historical Bathymetrical Model (HH0) 
at Astoria downtown (ASD) during low river discharge (c) and high discharge (d); the blue plot is the error for each case (modeled-observed). 66

Figure 3-5. Monthly averaged WL for the MM0 calibration (2013, a \& b), and HH0 (1876, c \& d) 68

Figure 3-6. Total flow percentage in the North and South Channels. The Lutz et al. (1975) data is represented in black bars to show the portion of the flow in the North Channel at each flow rate and the red bars for the South Channel percentage (dashed lines are the average percentage at each channel). The circles represent data from our analysis using the modern bathymetry model (MB). 70

Figure 3-7. $M_{2}$ Maps: a-modern bathymetry model, b-historical bathymetry model, c- $\mathrm{M}_{2}$ amplitude in the South Channel for MM (modern bathymetry/modern river flow), HH (historical bathymetry/historical river flow, and $\mathrm{MH}$ (modern bathymetry/historical river flow) models, the actual values represented by squares at Tongue Point (TP) at 2013 and Downtown Astoria (ASD) in 2015 and 1876, and d-M2 phases at South Channel. 72

Figure 3-8. Modern-model river discharge distribution for low (LO)/ high (HI) river discharge and spring/neap scenarios (two days mean around the highest water level (spring) and lowest water level (neap)). The red dots represent the percentage of river discharge along the South Channel (SO), blue represent the North Channel (NO), and green the Middle channels (MI). 73

Figure 3-9. Variation of discharge asymmetry index with river discharge 75 
Figure 3-10. Tidally averaged surface slope $(\mathrm{m} / \mathrm{m})$ of each point on each junction and point 1 (where the two channels meet). The color plots represent the spatial water level map emean water level comparison between the South and North Channels (dashed lines are the water level in the North Channel), max difference in water levels between North and South Channel between the North Channel boundaries (South-North) are a-4.7, b-1.7, c-5.3, and $\mathrm{d}-2.1 \mathrm{~cm}$. 77

Figure 3-11. Historical-model river discharge distribution. The red dots represent the percentage of river discharge in the South Channel, and the blue is the percentage in the North Channels, the green is the percentage in the Middle Channel, the magenta is the percentage in the braided channels in Cathlamet Bay area that eventually meet in one location close to about $25 \mathrm{~km}$ from the mouth (just upstream Tongue Point, Point 2 in Figure $3-12$ 79

Figure 3-12. tidally averaged slopes of the South, North and the Middle Channels in the historical model 80

Figure 3-13. Effect of Manning equation parameters on flow distribution between the Middle channel (MI) and the South Channel (SO) near Tongue Point. RQ is the ratio of river discharge of Middle to the South Channel, ( $\mathrm{Q}$ is river discharge, $\mathrm{Rh}$ is the hydraulic radius, $\mathrm{A}$ is the cross-sectional area, $\mathrm{H}$ is the mean water depth, $\mathrm{n}$ is bed friction coefficient, $\mathrm{S}$ is the surface slope, and $\mathrm{P}$ is the wetted parameter). 81 
Figure 3-14. The river flows vs. South Channel percentage in MB (a) and HB (b), (c): represents the relation between river discharge and slopes for North \& South Channels

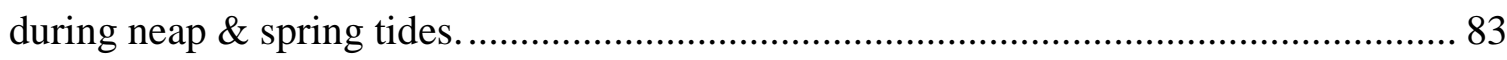

Figure 3-15. Subtidal salt fluxes percentage variation with river discharge (averaged over

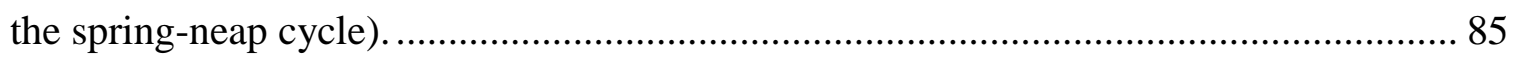

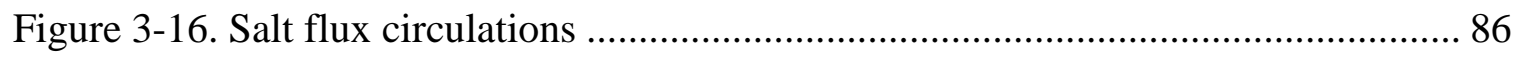

Figure 4-1. Columbia River Estuary (CRE) topographical changes: a-modern bathymetric topography (2008-2010), observation point's locations (OC2, SAT3 \& Tongue Point), North \& South channels layout, and river boundary (BAT), b-historical bathymetric topography (1870-1900), and c-South Channel bathymetric changes. The axes coordinate system referenced to Washington South State Plane Coordinate System (SPCS), E is for

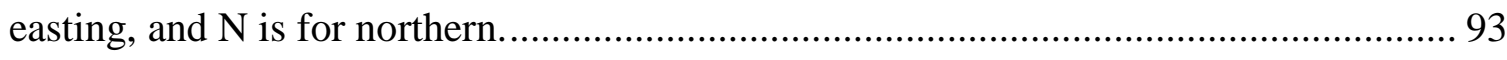

Figure 4-2. Modern vs. historical flow hydrograph (30 days moving average) at The Dalles. The solid lines are the $50^{\text {th }}$ percentile of 50 years while the shaded areas are for the $25^{\text {th }}$ and $75^{\text {th }}$ percentiles. 94

Figure 4-3. Observed vs. modeled salinity comparison, FM-models (top panels: a \& b). Karna et al. 2015 model (bottom panels: c \& d). Left panels for low flow (fall: a \& c) while right panels for high flow (spring: $b$ \& d). 103

Figure 4-4. Calibration of the CMOP stations 104 
Figure 4-5. Instantaneous (hourly) Salinity intrusion seasonal variation of the South Channel. The 2-psu isohaline is the limit between blue color and the other colors. a) MM, b) $\mathrm{MH}$, and c) $\mathrm{HH}$. The white curve is the river hydrograph. 106

Figure 4-6. Tidally averaged salt intrusion based on the mean flow, gray lines mark the neap tide 109

Figure 4-7. (a) River discharge tidally averaged intrusion relation at the South Channel, where $X=0 \mathrm{~km}$ (at the mouth) is obtained from the corps of engineers (see Figure 4-1-a). $\mathrm{Q}_{\mathrm{H}}$ refers to the historical hydrograph while $\mathrm{Q}_{\mathrm{M}}$ is the modern one. (b) river discharge power (n) sensitivity to zero $\mathrm{km}(\mathrm{X} 0)$ selection

Figure 4-8. South Channel stratification -salinity intrusion relation for the modern model (MM). The blue curve is tidally averaged salinity intrusion (X2) time series. The orange is a tidally averaged stratification index $(\varnothing)$. Region A represents a high flow period, region $\mathrm{C}$ represents a low flow, and region $\mathrm{B}$ shows the correlation between $\mathrm{X} 2 \& \varnothing$ 112

Figure 4-9. South Channel stratification. (a) MM, (b) MH and (c) HH. 114

Figure 4-10. Eulerian Approach, (1) is the RKM0 location at the mouth, (2) is the SAT3 location (11.5km from the mouth), and (3) is the Tongue point location (25Km from the mouth). The red dots are for the end of the flood, while the green ones are for the end of the ebb period. The black solid line is the mean flood time and the dashed line is the mean ebb time. Finally, the top row is for the high flow conditions and the lower panel is for the low flow period. 117 
Figure 4-11. Eulerian vs. Lagrangian approaches. The three Eulerian locations are RKM0, SAT3, and Tongue point (TP). The Lagrangian approach is from Rkm0 to the white line (2psu isohaline moving boundary)

Figure 4-12. Vertical salinity structure of the modern model (MM) for the South Channel during the high flow period. F \& E denote the spatial structure at the end of flood and ebb periods; numbers represent the number of floods/ebbs since the beginning of the month. Green rectangles enclose the situation where the total vertical mixing is likely to happen.

Figure 4-13. Parameter space for the modern and historical models, where (a) \& (b) represent the Lagrangian approach for flood and ebb of the 41 tidal cycles during June (high flow period), and (c) is the presentation of modeling results of modern and historical models 120

Figure 5-1. (a) Projected relative sea-level rise scenarios near CRE with 5 and 95\% confidence interval, RCP8.5 is a sub-model with a high greenhouse emissions scenario, $\mathrm{RCP} 4.5$ is a moderate greenhouse emissions scenario, and RCP2.6 is a low greenhouse emissions scenario. The green plot is from NRC, 2012 predictions. (b) Sea-level rise stations along the west coast (Kopp et al., 2017)

Figure 5-2. Projected subsidence scenario in the LCRE a result of a Cascadia zone subduction earthquake; the scenario is $2 \mathrm{~m}$ subsidence at the coast, zero at the upstream model boundary (Rkm 86), and 1.5m at Astoria, after Kalmbacher \& Hill (2015)....... 130 
Figure 5-3. Future hydrograph changes (Winter increases by $26 \%$ and spring freshet reduced by $17 \%$ ) 131

Figure 5-4. Changes in tides forth scenarios indicated; squares represent the location of maximum amplitude. For South Channel location, see Figure 5-2.

Figure 5-5. Salinity intrusion maps, white contours represent 31-psu \& 2-psu isohalines.

Figure 5-6. Tidally averaged bottom salinity profile along the South Channel 136

Figure 5-7. South Channel average salinity transaction (averaged over the spring-neap cycle) 138

Figure 5-8. Tidally averaged salinity intrusion (X2) along the South Channel 139

Figure 5-9. Change in water depth in shallow water habitats. Shading represents the range between low (3,000 CMS) and high river discharge (15,000 CMS). 141 


\section{Chapter 1 Overview of Dissertation}

\subsection{Introduction}

This chapter includes general information about the definition of estuaries, their importance, and their classification. In this chapter, I will review salinity intrusion, and then give a brief history of the Lower Columbia River Estuary (LCRE), and the morphological and hydrological changes since the mid-1800s. Finally, this chapter describes how these changes motivated the research questions about how hydrodynamic and salinity transport have changed.

\subsection{General}

Estuaries are typically defined as the transition region in which freshwater from river flow mixes with salt water from the ocean, producing a horizontal density gradient and (often) vertical stratification (Wilson, 1977; Hansen \& Rattray, 1966; Pritchard, 1967). Estuaries are valuable natural systems both ecologically and economically (Lenanton \& Potter, 1987). From the environmental point of view, estuaries provide habitat for fishes, plants, and birds. Estuaries can filter out sediment and pollutants coming from the river and going to the ocean. Economically, estuaries are useful for fishing, transportation, and recreation; also, they act as protective buffers against floods and help dissipate storm surge.

The morphological and hydrological conditions can control tides and circulation in estuaries. Further, estuaries are affected by river flow, tidal forcing, and wind stresses. 
These factors can control vertical/horizontal mixing, and stratification, and hence, estuarine circulation. Moreover, these factors can be altered by human interference and climate change (Miranda et. al., 2017). Estuaries can be classified based on water balance, geomorphology, vertical salinity structure, and hydrodynamic characteristics (Figure 1-1). A positive estuary means there is a net-inflow of freshwater, while an inverse estuary means that a net loss of water due to evaporation occurs. Based on geomorphology, estuaries can be Coastal Plain (formed from sea-level rise), Fjord (marked by a deep channel with a sill), bar-built (characterized by a sand bar formed between ocean \& estuary), or tectonic (formed from vertical land movement). The vertical salinity structure defines whether an estuary is classified as a salt-wedge, strongly stratified, weakly stratified, or well mixed (Figure 1-2a, b). A salt wedge is a wedge shaped boundary that separates the bottom high-density layer from the upper freshwater layer, with minimal mixing, because of large river discharge and weak tidal forcing (Figure 1-2a), A strongly stratified estuary has a large salinity difference between layers (usually associated with large river flow). Weakly stratified (partially mixed, Figure 1-2c) occurs where the river flow is weak to moderate and tidal mixing is moderate to strong, such that the tidal forcing enhances mixing of the two layers. A vertically mixed system (well mixed, Figure 1-2d) is characterized by strong mixing between the freshwater layer and ocean water layer. This mixing is a result of strong tidal forcing and weak river flow (i.e., no stratification). For these reasons, hydrodynamic classification depends on circulation (the ratio of the surface 
flow to column-averaged flow) and stratification (the ratio of salinity difference between top and bottom compared the depth-averaged salinity) (Parker, 1991).

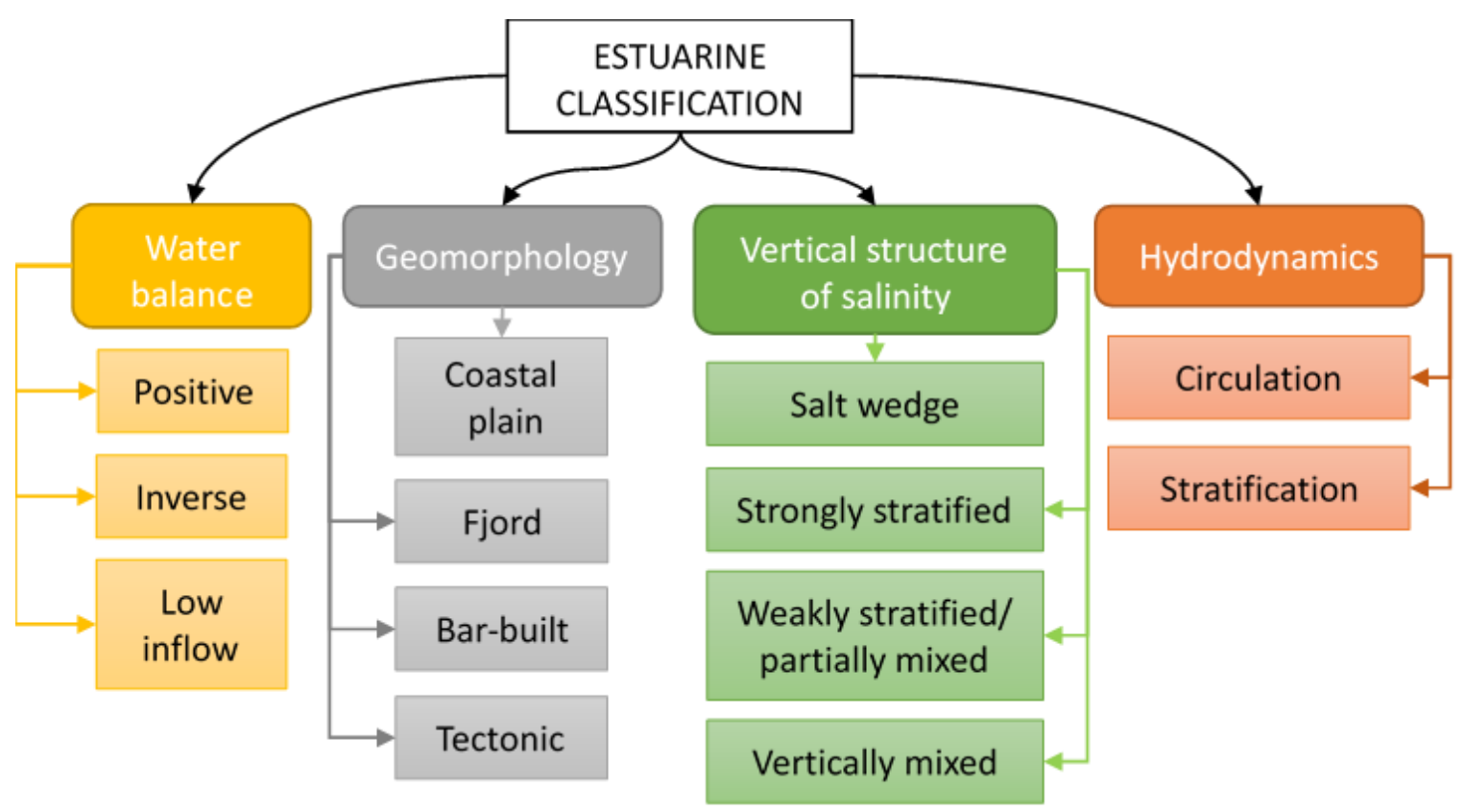

Figure 1-1. Estuarine classifications 

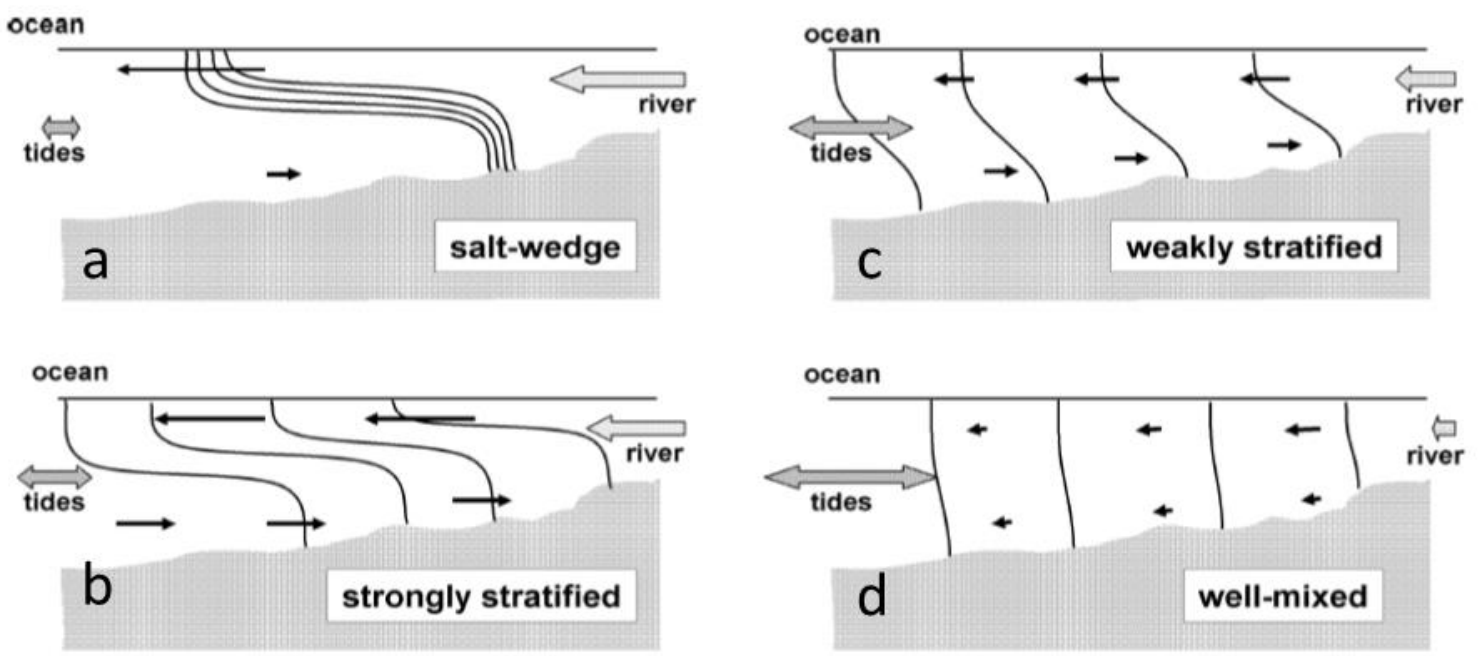

Figure 1-2. Estuarine classification based on water mixing after Valle-Levinson, (2010)

The estuarine classification shows the importance of the morphological parameters such as channel depth and the amount of freshwater provided by river discharge in changing the system from one state to another. Hence, altering the system can modify estuarine hydrodynamics and circulation. Both river flow and morphology of the Columbia River Estuary (CRE) have changed significantly over the past 150 years, which suggests a change in the hydrodynamics of the estuary.

At present, the classification of CRE varies from a salt wedge to well mixed estuary. During high river flow, the system is highly stratified and the estuary is a salt wedge for all tidal conditions. During low flow conditions the tidal forcing becomes critical to keeping the system partially mixed (Jay \& Smith, 1990). The long-term changes to the 
estuary and their effect on salinity intrusion are important since they can affect freshwater availability and can affect the type of habitats and species within estuaries.

\subsection{Salinity intrusion}

When freshwater from the river meets saline water from the ocean, the freshwater tends to dilute the mixture, while the tidal motion tends to drive the salt upstream by advection. This is because of the density difference between seawater and river discharge. The result is intrusion of ocean salt water into the estuary. Because of the temporal variation of tidal forcing and river flow, salinity intrusion can greatly vary over time (MacCready \& Geyer, 2010). The salinity intrusion length is typically defined as the point at which the bottom salinity equals 2-psu (Monismith et al., 2002; MacWilliams et al., 2015),see (Figure $1-3)$.
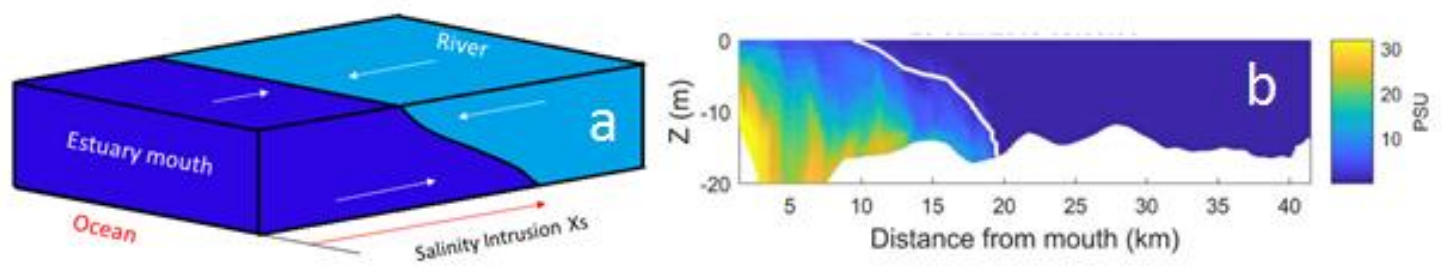

Figure 1-3. Salinity intrusion a-concept, and b-example of modeled salinity intrusion where the white curve represents the $2 p s u$ isohaline 


\subsection{Columbia River Estuary (CRE)}

The Columbia River (CR) is the fourth largest river in in North America that drains to the ocean. Its length is about $1900 \mathrm{~km}$ and its basin drainage area is about $660,480 \mathrm{~km}^{2}$ (Simenstad \& Sherwood, 1990). The CR passes through seven states inside the United States and a Canadian province (see Figure 1-4). The river provides hydropower with 14 dams on the main river and 450 dams on its tributaries (Osborn, 2012). The CR estuary has two channels (North and South); most of the river flow goes through the South Channel, while most of the tidal prism fills and empties through the North Channel (Chawla et al., 2008). Before 1850, the estuary was primarily used for fishing by natives who inhabited the area. At present, the estuary is used for industry, navigation, agricultural, fishing, and tourism purposes. 


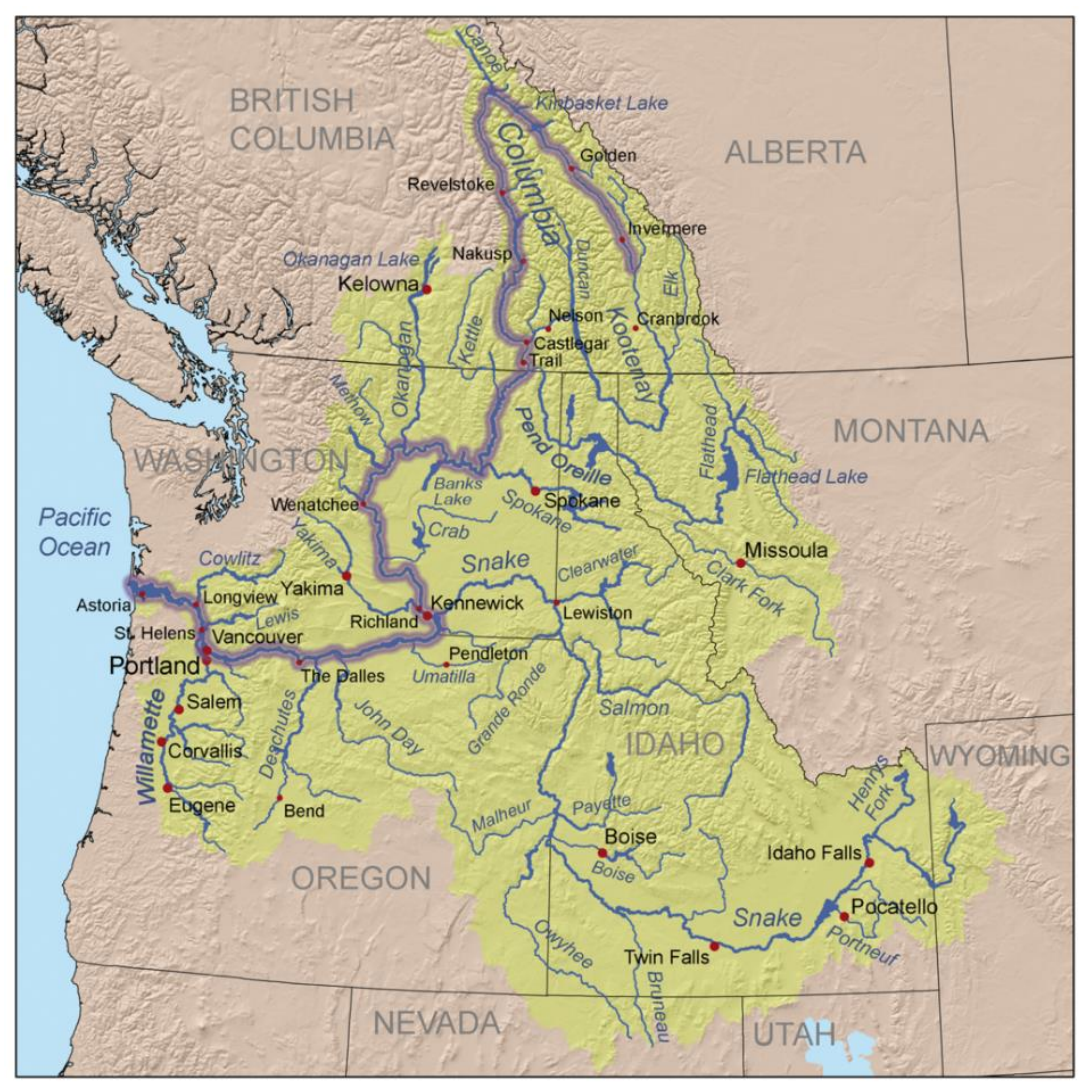

Figure 1-4. Columbia River watershed

\subsection{Bathymetry}

The major changes in the morphology of the CR are due to dredging activities and jetty construction. Before the construction of jetties, the Columbia River mouth lay between two sand spits: Point Adams, on the south, and Cape Disappointment, on the north. Cape Disappointment is about 6 miles north-northwest from Point Adams (Figure 1-5). Also, there were two areas with shoals: Peacock Spit to the south-west of Cape Disappointment, and Clatsop Spit to the north-west of Point Adams. These two spits were connected by an ocean bar across the river entrance and the navigation channel was over 
the southwest quadrant of the bar. The shoals and the bar at the entrance were continuously changing position due to waves and wind (Hickson \& Rodolf, 1951), (see Figure 1-5).

The construction of the south jetty began in 1885 , but the channel deepening did not start until 1889 , such that the channel depth changed from $17 \mathrm{ft}$ to $31 \mathrm{ft}$ by 1895 (Sherwood et al., 1990). After the completion of the north jetty (1913-1917), the depth of the entrance had increased to $37 \mathrm{ft}$. However, the depth gradually increased to reach $46-48 \mathrm{ft}$ by 1925 . By 1928, Clatsop Spit had advanced into the river, and the navigation channel was forced to the north (Figure 1-5). Furthermore, the construction of jetties had advanced the bar into the ocean by about 1 mile in 1900 and 5 miles by 1950 (Hickson \& Rodolf, 1951). Upon the completion of the jetty construction in 1939 , the entrance width between north and south jetties had narrowed from 6 to 2 miles (USGS, 1981), (see Figure 1-6).

Besides the construction of jetties, maintaining the navigation channel through dredging and destroying the habitat through filling have had a continued impact on the estuary morphology (Simenstad et al., 1990). The largest change in morphology was between 1867-1958, caused by navigational improvements such as channel dredging, jetties, and pile dikes. Diking and filling were responsible for the loss of 77\% (8100ha) of tidal swamps, 62\% (4050ha) of tidal marshes, and 7\% (1195ha) of tidal flats (Sherwood et al., 1990). Dredging activities began in 1873 (U.S. Army, 2012), but major dredging did not begin until 1909 (Sherwood et al., 1990). Some portion of the removed materials were disposed of offshore, while others were dumped in wetlands. Because of the dredging activities, the estuary bathymetry changed dramatically. The controlling depth of the South 
Channel is $13 \mathrm{~m}$ in the estuary, and $18 \mathrm{~m}$ at the mouth, while it was about $6 \mathrm{~m}$ in the 1868 1901 period. The development of the depth and width of the navigation channel and the mouth can be found in Table 1-1.

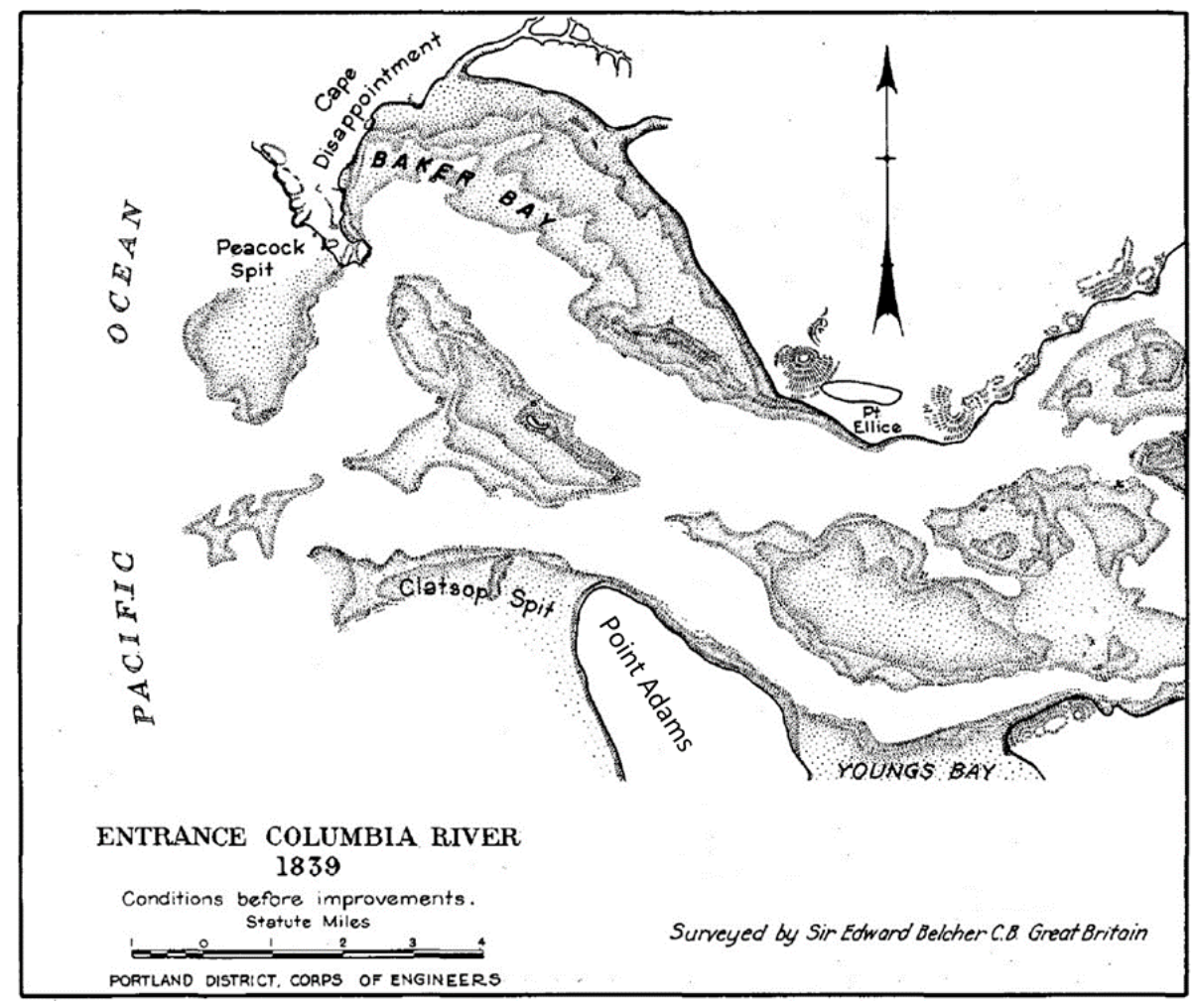

Figure 1-5. CR mouth before jetty construction (1839), (Hickson \& Rodolf, 1951) 


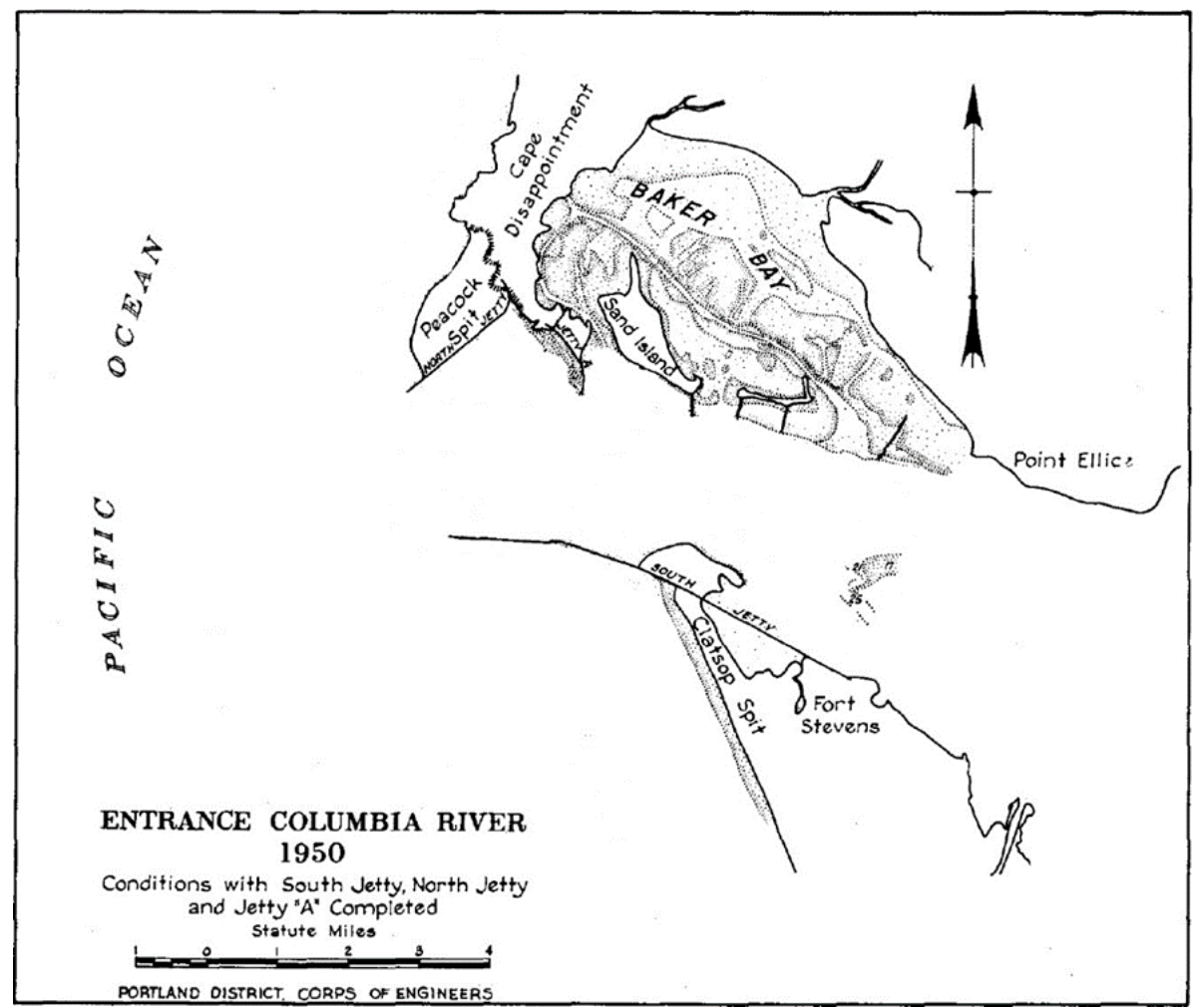

Figure 1-6. CR mouth after jetty construction (1950), (Hickson \& Rodolf, 1951)

Table 1-1. Columbia River mouth \& navigation channel development by U.S. Army Corp of Engineers (USACE)

\begin{tabular}{|c|l|c|c|}
\hline \multicolumn{2}{|l|}{ Mouth of the Columbia River } & Depth & Width \\
\hline 1882 & Public Acts of the 47 ${ }^{\text {th }}$ Congress & $30^{\prime}$ & \\
\hline 1905 & River and Harbor Act & $40^{\prime}$ & $1 / 2$ mile \\
\hline 1954 & River and Harbor Act & $48^{\prime}$ & $1 / 2$ mile \\
\hline \multicolumn{2}{|l|}{ Columbia River Channel } & \\
\hline 1878 & River and Harbor Act & $20^{\prime}$ & \\
\hline 1899 & River and Harbor Appropriation Act & $25^{\prime}$ & \\
\hline 1912 & River and Harbor Act & $30^{\prime}$ & $300^{\prime}$ \\
\hline 1930 & River and Harbor Act & $35^{\prime}$ & $500^{\prime}$ \\
\hline 1962 & River and Harbor Act & $40^{\prime}$ & $600^{\prime}$ \\
\hline 1999 & Water Resources Development Act & $43^{\prime}$ & \\
\hline
\end{tabular}




\subsection{River flow}

The Columbia River hydrograph has changed dramatically as a result of energy demand, irrigation demand, flood control, temperature, and precipitation changes (Naik \& Jay, 2011), see (Figure 1-7). At present, the maximum daily flow during spring freshet (Apr-Jun) often reaches more than $12,000 \mathrm{~m}^{3} / \mathrm{s}$, while minimum daily flow goes below $2000 \mathrm{~m}^{3} / \mathrm{s}$ during the dry season (July-Oct). Monthly average flow, however, ranges between $3,000-8,000 \mathrm{~m}^{3} / \mathrm{s}$. Historically (before 1900 ), the monthly average range was between $2,500-15,000 \mathrm{~m}^{3} / \mathrm{s}$, (Figure 1-7), while the daily range was $1000-35,000 \mathrm{~m}^{3} / \mathrm{s}$ (Chawla et al., 2008).

The biggest change in the seasonal cycle started around 1960 due to flow regulation (Sherwood et al., 1990). Winter season river flow has since increased and spring-freshet flow has decreased (Figure 1-7). Naik \& Jay, (2011) reported a 17\% reduction in the annual mean flow, a $46.5 \%$ reduction in spring freshet, and a $44 \%$ decrease in the maximum daily flow. The Spring-freshet timing has changed as well, such that, due to climate change and flow regulation, it occurs about two weeks earlier than it did before 1960.

The river hydrograph will likely continue to change in the future due to human and natural intervention (Knowles et al., 2006). For example, Cohen et al. (2000) have predicted an earlier peak and possible reduction in lower minimum flow and total annual flow. Bürger et al. (2011) have also predicted an earlier peak flow from July to June, with a decrease in summer flow and no increase in total flow. 


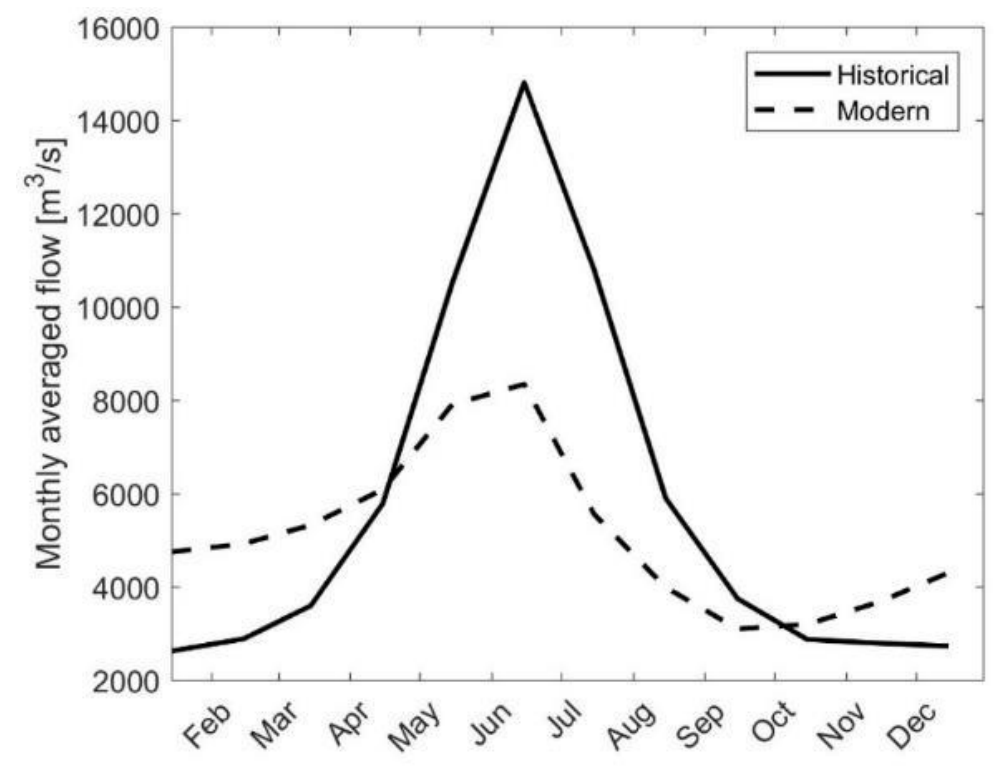

Figure 1-7. Monthly mean flow of Columbia River at The Dalles/Oregon

\subsection{Motivation and research questions}

Salinity intrusion can threaten the freshwater supply in an estuary, especially in dry seasons, although it varies, specially and temporally, depending on freshwater supply and tidal forcing (Gong \& Shen, 2011). Furthermore, salinity has a large effect on what species can exist in aquatic environments, since some species tolerate only specific ranges of salinity. Salinity has a profound effect on the distribution and abundance of aquatic organisms. It is one of the determinants of the abundance of organisms in estuarine habitats (Bell et al., 2003). Change in salinity affects organism distribution, behavior, and limits reproduction. Stratification, mixing, and exchange flow have a significant impact on 
salinity intrusion, and both affect the suspended sediment and dissolved substances in estuaries (Geyer \& MacCready, 2014; Dijkstra et al., 2017).

Changes to the tidal forcing and river discharge have a direct impact on salinity in estuaries and can change the vertical structure and intrusion length. For example, partiallymixed estuaries have a maximum salinity intrusion during neap tides (Monismith et al., 2002; MacCready, 2007; Ralston et al., 2008) while a well-mixed and salt-wedge estuaries expect a higher intrusion during spring tides (Ralston et al., 2010). Further, salinity intrusion length has a power relation with river discharge (inversely correlated). The power exponent varies in different estuaries (Monismith et al., 2002; Bowen and Geyer, 2003).

Most investigations of salinity intrusion focus on estuaries with one primary channel such that the whole river discharge and tidal forcing pass through that channel (Monismith et al., 2002; Ralston et al., 2008). This approach cannot be used on estuaries with more than one channel, since the tidally averaged flows are distributed between the channels as a variable function of river discharge and tidal forcing (Buschman et al., 2010; Sassi et al., 2011; Zhang et al., 2017). Hence, the salinity intrusion and river flow relation can change (different power exponent). Overall, river flow bifurcation along with the tidal asymmetry in flood-ebb for the multiple channels (Robinson, 1960) will produce different salinity intrusion behavior than a single channel estuary.

The Lower Columbia River Estuary (LCRE) is a multi-channel estuary with two primary channels (North \& South). The majority of tidal exchange occurs at the North Channel (Lutz et al., 1975; Chawla et al., 2008; Jay \& Smith, 1990) while the majority of 
river flow has been diverted into the South Channel through dredging and the construction of islands and other flow training structures. The Columbia River has been significantly altered in terms of geometry and river hydrograph during the last 150 years (Naik \& Jay, 2005). The major change has been the deepening of the navigation channel, which has increased the tidal range and reduced the river slope in the CRE (Helaire et al., 2019) such that the tidal range near Astoria has increased by 5.6\% ( 0.11m) since 1855 (Talke et al., 2020a). The river forcing alteration and the tidal change could have altered the freshwater distribution in the estuary. Accordingly, the transport of sediment and salt could have changed as well.

The long-term change to river hydrograph and the morphological change in the estuary (bathymetry, the construction of jetties) have changed the estuarine geometry and likely the freshwater distribution in the estuary (the South and North Channels). These changes have motivated my first research questions: How is the river flow distributed between the North and South Channels? How do the river flow and bathymetric changes affect the river flow bifurcation in the Lower Columbia River Estuary? These questions are addressed in Chapter 3.

Changes in river discharge, bathymetry, and possibly flow bifurcation raise the possibility that salinity intrusion has changed since the 1800 s. This observation leads to the following question: How have long-term modifications to the bathymetry and fluvial boundary conditions of the system altered the hydrodynamics and transport processes within the estuary? This question is addressed in Chapter 4. 
Finally, changes in bathymetry and river discharge may continue in the future, due to sea-level rise and possibly a Cascadia subduction zone earthquake. These observations have motivated the third research question: What is the potential impact of future sealevel rise, altered river discharge, and land subsidence due to an earthquake on system tides and salinity intrusion? This question is addressed in Chapter 5. 


\section{Chapter 2 Theory and Literature Review}

\subsection{Introduction}

In this chapter, I will review the importance of channel depth and river discharge on estuarine circulation, vertical salinity profile, and salinity intrusion based on available scientific literature. Further, I will review how salinity intrusion varies with river discharge in different estuaries. I will reivew the possible future effects of climate change on the hydrological cycle and sea-level rise. Finally, I also provide an overview of tidal asymmetry, exchange flow, flow partitioning, and estuarine classification.

\subsection{Theory}

\subsubsection{Effect of channel depth on estuarine circulation and salinity profile}

Hansen \& Rattray (1965) proposed a model to describe circulation and salt flux processes in estuaries. The model equations describing circulation and salinity distribution are the equations of motion, mass conservation, salt conservation, and the equation of state. The model assumes lateral homogeneity, i.e., the model is reduced to longitudinal \& vertical dimensions, where the $\mathrm{x}$-axis and $\mathrm{z}$-axis are positive, seaward and downward, respectively). Further, the estuary has a constant width and depth. The analysis neglects Coriolis forces, the viscous frictional terms, and applies the approximation of Boussinesq (i.e., it neglects density variation in all but buoyancy terms). It also assumes that the pressure variations are applied to water only (atmospheric pressure is assumed constant). 
The momentum equation (before time averaging) in the longitudinal direction can then be written as

$$
\underbrace{\frac{\partial u}{\partial t}}_{\begin{array}{c}
\text { Local } \\
\text { acceleration }
\end{array}}+\underbrace{\frac{\partial(u u)}{\partial x}+\frac{\partial(w u)}{\partial z}}_{\begin{array}{c}
\text { convective } \\
\text { flux }
\end{array}}=-\underbrace{\frac{1}{\rho} \frac{\partial p}{\partial}}_{\begin{array}{c}
\text { pressure } \\
\text { force }
\end{array}} .
$$

The momentum equation in z-direction assuming the hydrostatic conditions (inertial and convective acceleration are neglected) is

$$
0=-\frac{1}{\rho} \frac{\partial p}{\partial z}+g /
$$

The conservation of salt, neglecting molecular diffusion is

$$
\frac{\partial s}{\partial t}+\frac{\partial(u s)}{\partial x}+\frac{\partial(w s)}{\partial z}=0
$$

and the two-dimensional mass conservation equation (incompressible flow) is

$$
\frac{\partial(u)}{\partial x}+\frac{\partial(w)}{\partial z}=0
$$

where $t$ is time, $x \& z$ are rectangular space coordinates with origins in the mean sea surface (positive seaward and downward), $u \& w$ are horizontal and vertical velocity components; $p$ is pressure, $\rho \& \rho_{0}$ are densities of estuarine water and freshwater, $g$ is gravitational acceleration, and $s$ is salinity.

The analysis next applies Reynolds averaging (i.e., splitting $u, w \& s$ into depth-averaged and depth varying parts) 


$$
u=\bar{u}(x)+u^{\prime}(x, z), s=\bar{s}(x)+s^{\prime}(x, z), w=\bar{w}(x)+w^{\prime}(x, z),
$$

and introduces mean eddy coefficients

$$
-\frac{\partial \overline{\left(u^{\prime} w^{\prime}\right\rangle}}{\partial z}=\frac{\partial}{\partial z}\left(K_{m} \frac{\partial u}{\partial z}\right),-\frac{\partial\left\langle\overline{u^{\prime} s^{\prime}}\right\rangle}{\partial x}=\frac{\partial}{\partial x}\left(K_{h} \frac{\partial S}{\partial x}\right), \text { and }-\frac{\partial\left\langle\overline{\left.w^{\prime} s^{\prime}\right\rangle}\right.}{\partial z}=\frac{\partial}{\partial z}\left(K_{v} \frac{\partial s}{\partial z}\right),
$$

where $K_{m}$ is tidally averaged vertical eddy viscosity, $K_{h} \& K_{v}$ are horizontal and vertical eddy diffusivities. ' $\longrightarrow$ is turbulent average, \langle\rangle is average over the tidal period, $u^{\prime}, w^{\prime}$, and $s^{\prime}$ are the turbulent components, and $u \& s$ are averages over a tidal period of horizontal velocity and salinity. With the additional assumption of vertically uniform $K_{m}$, the horizontal momentum equation becomes:

$$
\frac{\partial u}{\partial t}+u \frac{\partial(u)}{\partial x}+w \frac{\partial(u)}{\partial z}=-\frac{1}{\rho} \frac{\partial p}{\partial x}+K_{m} \frac{\partial^{2} u}{\partial z^{2}}
$$

In the analysis of the James River data, Pritchard $(1954,1956)$ argues that the dominant terms in the longitudinal equation of motion are the pressure gradient and the vertical eddy flux of momentum; all other terms are of second order. The set of the model equation becomes

$$
\begin{gathered}
0=-\frac{1}{\rho} \frac{\partial p}{\partial x}+K_{m} \frac{\partial^{2} u}{\partial z^{2}} \\
0=-\frac{1}{\rho} \frac{\partial p}{\partial z}+g \\
\frac{\partial s}{\partial t}+\frac{1}{A} \frac{\partial(u s A)}{\partial x}+\frac{\partial(w s)}{\partial z}=\frac{1}{A} \frac{\partial}{\partial x}\left(A K_{h} \frac{\partial s}{\partial x}\right)+\frac{\partial}{\partial z}\left(K_{v} \frac{\partial s}{\partial z}\right), \\
\frac{\partial(u)}{\partial x}+\frac{\partial(w)}{\partial z}=0
\end{gathered}
$$


From equation (2.9), $\frac{\partial p}{\partial z}=g \rho \rightarrow p(z)=\int_{z}^{\eta} \rho g d z=\rho g(\eta-z)$,

and the pressure gradient becomes (assuming vertically uniform $\frac{\partial \rho}{\partial x}$ ):

$$
\frac{\partial p}{\partial x}=\rho g \frac{\partial \eta}{\partial x}+(\eta-z) g \frac{\partial \rho}{\partial x}=\rho g \frac{\partial \eta}{\partial x}-g \frac{\partial \rho}{\partial x} z,
$$

where $\eta$ is neglected using the rigid lid assumption (i.e., $\eta$ is insignificant compared to $z$ ).

The relationship between salinity and density is given by the approximate equation of state $\rho=\rho_{0}(1+\beta s-\alpha T)$, where the temperature (T) effect can be disregarded. Hence

$$
\rho=\rho_{0}(1+\beta s)
$$

where $\beta$ is the coefficient of saline contraction $=7.7 \times 10^{-4}\left[\mathrm{psu}^{-1}\right]$.

Hence, $\frac{\partial \rho}{\partial x}=\frac{\partial \rho_{0}}{\partial x}+\rho_{0} \beta \frac{\partial s}{\partial x}=\rho_{0} \beta \frac{\partial s}{\partial x}$, since $\frac{\partial \rho_{0}}{\partial x}=0$.

Thus, equation (2.12) becomes $\frac{\partial p}{\partial x}=\rho g \frac{\partial \eta}{\partial x}-g \rho_{0} \beta \frac{\partial s}{\partial x} z$, and the $\mathrm{x}$-axis momentum equation becomes

$$
0=-g \frac{\partial \eta}{\partial x}+g \beta \frac{\partial s}{\partial x} z+K_{m} \frac{\partial^{2} u}{\partial z^{2}}
$$

Taking $\frac{\partial}{\partial z}$ of eq (2.14) results in

$$
\frac{\partial^{3} u}{\partial z^{3}}=-\frac{g \beta}{K_{m}} \frac{\partial s}{\partial x}
$$

Equation (2.15) is integrated with the following boundary conditions: 


$$
\begin{aligned}
& \mathrm{u}(\mathrm{z}=-\mathrm{H})=0, \\
& \frac{\partial u}{\partial z}(z=0)=0, \text { and } \\
& \frac{1}{H} \int_{-H}^{0} u d z=\bar{u}=\frac{Q_{r}}{A},
\end{aligned}
$$

where $Q_{r}$ is the river flow, and A is the cross-sectional area. After integration and applying boundary conditions, the solution reads:

$u^{\prime}=\bar{u}\left(\frac{1}{2}-\frac{3}{2} \zeta^{2}\right)+u_{E}\left(1-9 \zeta^{2}-8 \zeta^{3}\right)$,

where $\zeta=z / H$. The scale of the exchange flow is given by

$$
u_{E}=\frac{g}{48} \frac{H^{3} \beta}{K_{m}} \frac{\partial s}{\partial x}
$$

and indicates the dependency of the exchange flow on the salinity gradient $\left(\frac{\partial s}{\partial x}\right)$.

Internal tidal asymmetry (Jay \& Musiak, 1994) is another important cause of estuarine circulation. Internal tidal asymmetry is caused by tidally variable vertical and horizontal density gradients, which cause a difference in stratification between flood and ebb tides. Stratification suppresses the mixing in an estuary, producing an asymmetry in flood mixing compared to ebb mixing. This produces an asymmetry in the vertical shear in the along channel momentum that produces the estuarine circulation $\left(u_{E}\right)$. Jay and Musiak (1996) suggest that about half of the two-layer estuarine circulation in the Columbia River under moderate to high flow conditions is caused by internal asymmetry, with the other half being caused by gravitational circulation. 
The dependency of the salinity profile on depth is explored by taking the depth average for the salt conservation equation (2.10), with $\mathrm{w}=0, K_{v} \frac{\partial s}{\partial z}=0$ at top and bottom, resulting in

$$
\frac{\partial \bar{s}}{\partial t}+\frac{1}{A} \frac{\partial(\overline{u s} A)}{\partial x}+\frac{1}{A} \frac{\partial\left(\overline{u^{\prime} s^{\prime}} A\right)}{\partial x}=\frac{1}{A} \frac{\partial}{\partial x}\left(A K_{h} \frac{\partial \bar{s}}{\partial x}\right)
$$

Subtracting eq (2.19) from (2.10), yields:

$$
\frac{\partial s^{\prime}}{\partial t}+\frac{1}{A} \frac{\partial\left[\left(u s-\overline{u s}-\overline{u^{\prime} s^{\prime}}\right) A\right]}{\partial x}+\frac{\partial(w s)}{\partial z}=\frac{\partial}{\partial z}\left(K_{v} \frac{\partial s^{\prime}}{\partial z}\right),
$$

where $\frac{\partial s^{\prime}}{\partial x}$ is assumed to be much less than $\frac{\partial \bar{s}}{\partial x}$, allowing cancelation of the $K_{h}$ term. For partially mixed and well-mixed systems, the dominant steady balance for s' is between the creation of stratification by vertical shear and its destruction by vertical mixing (Pritchard 1954). Taking $K_{v}$ as a constant in the $\mathrm{z}$ direction (MacCready, 2004) yields.

$$
u^{\prime} \frac{\partial \bar{s}}{\partial x} \cong K_{v} \frac{\partial^{2} s^{\prime}}{\partial z^{2}}
$$

where $u^{\prime} \frac{\partial \bar{s}}{\partial t}$ arises from $\frac{\partial u s}{\partial x}$ in eq (2.20), (MacCready, 2004)

This may be integrated directly as:

$$
s^{\prime}=\frac{H^{2}}{K_{v}} \frac{\partial \bar{s}}{\partial x}\left[\bar{u}\left(-\frac{7}{120}+\frac{1}{4} \zeta^{2}-\frac{1}{8} \zeta^{4}\right)+u_{E}\left(-\frac{1}{12}+\frac{1}{2} \zeta^{2}-\frac{3}{4} \zeta^{4}-\frac{2}{5} \zeta^{5}\right)\right] .
$$

Equation 2.16 suggests a strong dependence of estuarine circulation on depth $\left(u_{E} \alpha H^{3}\right)$. Furthermore, changing depth could also modify the longitudinal salinity gradient and eddy diffusivity (Chant et al., 2018). In addition, the salt content and the associated salinity 
gradient are vary with river discharge, exchange flow, and tidally induced salt transport processes, as suggested by equation 2.20. Chant et al. (2018) reported that an increase of $15 \%$ depth in Newark Bay, New Jersey depth resulted in doubling the exchange flow, a slight increase in salinity and longitudinal salinity gradient, a decrease in tidal current amplitude, and a spatially variable change in the tidal range.

\subsubsection{Tidal changes}

Tides can be described by the Reynolds averaged shallow water equations in one dimension that assume a nonrotating flow, and uniform density. The continuity equation (mass conservation) can be written as

$\underbrace{\frac{d h}{d t}}_{\begin{array}{l}\text { local change of } \\ \text { surface height }\end{array}}+\underbrace{u \frac{d h}{d x}}_{\begin{array}{c}\text { advectionof } \\ \text { height }\end{array}}+\underbrace{h \frac{d u}{d x}}_{\begin{array}{c}\text { volume } \\ \text { convergence }\end{array}}=0$

This shows that the rate of local change in the water surface is controlled by the advection of height and the volume convergence, where $(h)$ is the local water depth, $(u)$ is the longitudinal velocity (x-direction), and $(t)$ is the time (Jay, 1991; Friedrichs \& Aubrey, 1994).

Similarly, using the balance of momentum with the hydrostatic pressure assumption yields the equation of motion. This states that the rate of local change of velocity is controlled by the advection of momentum, the pressure gradient, and bottom stress. 
$\underbrace{\frac{\partial u}{\partial t}}_{\begin{array}{c}\text { local change } \\ \text { of velocity }\end{array}}+\underbrace{u \frac{\partial u}{\partial x}}_{\begin{array}{c}\text { advectionof } \\ \text { momentume }\end{array}}+\underbrace{g \frac{\partial h}{\partial x}}_{\begin{array}{c}\text { pressure } \\ \text { gradient }\end{array}}+\underbrace{\frac{\tau_{b}}{\rho h}}_{\begin{array}{c}\text { bottom } \\ \text { stress }\end{array}}=0$

where $\tau_{b}$ is bottom stress, and $\rho$ is water density (Jay, 1991; Friedrichs \& Aubrey, 1994) . Both equations of continuity and momentum show that tidal amplitude and velocity can be affected by the increase of the local water surface height $(h)$ in response to sea-level rise.

\subsubsection{Effect of river flow and bathymetry on salinity intrusion}

The river flow has a direct effect on salinity intrusion; high flow is associated with reduced salinity intrusion, and vice versa (Hansen \& Rattray, 1965; 1966; MacCready, 1999; MacCready, 2007; Monismith et al., 2002; Geyer \& MacCready, 2014). A theoretical analysis of salinity intrusion, presented by Monismith et al. (2002) based on the tidally averaged salt conservation equation and the work of Hansen \& Rattray (1965) follows. The analysis starts with the salt conservation equation that is averaged tidally and cross-sectionally:

$$
A(x) \frac{\partial S}{\partial t}+\frac{\partial}{\partial x}(Q S)=\frac{\partial}{\partial x}\left[K_{x}(x) A(x) \frac{\partial S}{\partial x}\right]
$$

where: A=local cross-section area, $\mathrm{x}=$ the distance landward from the mouth of the estuary, $\mathrm{S}=$ the salinity, $\mathrm{Q}=$ the river flow, and $\mathrm{K}_{\mathrm{x}}=$ the longitudinal dispersion coefficient. The vertical shear of the flow is given by: 


$$
U_{g} \sim \frac{\beta g\left(\frac{d S}{d x}\right) H^{3}}{v_{t}} \quad \text { (Hansen \& Rattray, 1965) }
$$

also, $\quad K_{x} \sim \frac{(\beta g)^{2}\left(\frac{d S}{d x}\right) H^{8}}{v_{t} t^{3}} \quad$ (Hansen \& Rattray, 1965)

at steady state, the net flux is zero, so that

$$
\frac{-Q}{A} S=K_{x} \frac{d S}{d x}=\frac{\alpha(\beta g)^{2} H^{8}}{v_{t}{ }^{3}}\left(\frac{d S}{d x}\right)^{3},
$$

where $\alpha=5.4 \times 10^{-5}$ (Monismith et al., 2002).

$$
\text { Re-arranging: } \quad\left(\frac{d S}{d x}\right)^{3}=\frac{-Q v_{t}{ }^{3}}{W \alpha(\beta g)^{2} H^{9}} S,
$$

which in terms of salinity intrusion $X_{\mathrm{s}}$ gives

$$
\frac{S_{O}}{X_{S}} \sim \frac{Q^{1 / 3} v_{t} S_{0}^{1 / 3}}{(W \alpha)^{1 / 3}(\beta g)^{2 / 3} H^{3}} \quad \text { or } \quad X_{S}=\frac{(W \alpha)^{1 / 3}\left(\beta g S_{o}\right)^{2 / 3} H^{3}}{Q^{1 / 3} v_{t}}
$$

where $X_{S}$ is the salinity intrusion length from the mouth of the estuary toward the upstream (where the bottom salinity is 2-psu (Monismith et al., 2002) and (MacWilliams et al., $2015)$ ). Here, $W$ is the width, $\alpha$ is the constant of proportionality $(5.4 \times 10 \mathrm{E}-5), \quad \beta$ is the saline expansivity $\left(7.7 \times 10 \mathrm{E}-4 \mathrm{psu}^{-1}\right), S_{o}$ is ocean salinity, $H$ is the local depth, $Q$ is the river flow, and $v_{t}$ is the eddy diffusion coefficient $\left(v_{t}\right.$ can be scaled to $u_{t} H$, and $u_{t}$ is the tidal velocity).

Salt is transported landward due to tidal dispersion, while seaward transportation is driven by river discharge (eq. 2.30). The river flow freshens the estuary, which decreases 
the salinity intrusion. On the other hand, increasing channel depth leads to an increase in stratification, reduces mixing, and eventually increases salinity intrusion landward at the bottom (eq. 2.30).

From the foregoing analysis, it appears that salinity intrusion varies with the second power of channel depth $\left(X_{S} \sim H^{2}\right)$ and inversely with the cubic root of the river discharge $\left(X_{S} \sim Q^{-1 / 3}\right)$. This means that, theoretically, the salinity intrusion is much more sensitive to changes in bathymetry than to river discharge (see Figure 2-1). The percentages in Figure 2-1 represent the effect of doubling the two parameters $H$ and $Q$ in Equation 2.30. As shown, the second power of $\mathrm{H}$ produces a much larger effect on salinity intrusion than the cubic root of Q. The processes controlling salinity intrusion is more complex than shown in Figure 2-1, because of tidal asymmetry, bottom drag nonlinearity, and other non-linear interactions that are functions of $H$ and $Q$. Due to the complex 3D bathymetry and the presence of two estuary channels in the Columbia River Estuary a numerical model is needed to explore the response of the estuary to changed bathymetry and river discharge. 


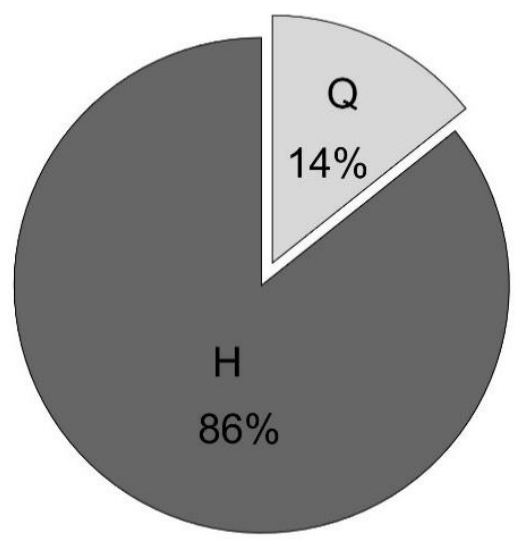

Figure 2-1. Percentage of contribution to salinity intrusion by river flow $(Q)$ and channel depth $(H)$ variations. The percentage approximates the theoretical scaling $X_{S} \sim H^{2} / Q^{-1 / 3}$. The percentage represents the effect of the 2 nd power of $H$ and the cubic root of $Q$, the same percentage of doubling the two parameters $(H \& Q)$.

\subsubsection{Bifurcation theory}

According to Buschman et al. (2010), the subtidal discharge division at a bifurcation can be quantified as

$$
\Psi=\frac{\left\langle Q_{1}\right\rangle-\left\langle Q_{2}\right\rangle}{\left\langle Q_{1}\right\rangle+\left\langle Q_{2}\right\rangle},
$$

where $<>$ indicates tidally average, $\mathrm{Q}_{1}$ is the first channel discharge, $\mathrm{Q}_{2}$ is the second channel discharge, and $\Psi$ is the discharge asymmetry index. When the index is zero, both channels have an equal share of flow. If the index is positive, then the first channel discharge is larger than the second channel. If it is one, all the flow goes through channel one. The subtidal flow due to river discharge and tides can be decomposed into

$$
\langle Q\rangle=Q_{r}+\left\langle Q_{t}\right\rangle+\left\langle Q_{r t}\right\rangle
$$


where $Q_{r}$ is river flow, $Q_{t}$ is the tidal flow, and $Q_{r t}$ is the tide-river interaction flow. Similarly, the asymmetry index can be decomposed into three components

$$
\Psi=\Psi_{r}+\Psi_{t}+\Psi_{r t},
$$

where $\Psi_{r}$ the asymmetry in freshwater flow, $\Psi_{t}$ is the tidal flow asymmetry, and $\Psi_{r t}$ is the river-tide flow interaction asymmetry (Sassi et al., 2011).

However, the vertically integrated tidal flow can be decomposed into

$$
\left\langle Q_{t}\right\rangle=\underbrace{W\left\langle U^{\prime} \eta^{\prime}\right\rangle}_{Q_{s}(\text { stokes transport })}+\underbrace{W h\langle U\rangle}_{\left.Q_{R} \text { (return discharge }\right)}+\underbrace{W\langle U\rangle\langle\eta\rangle}_{\text {residual }},
$$

where $\mathrm{U}$ is the cross-section average velocity and equal to $\langle U\rangle+U^{\prime}$ (prime denotes the tidal variation), $\mathrm{W}$ is the channel width, $\mathrm{h}$ is the water depth, and $\eta$ is water level (total water depth, $\mathrm{d}=\mathrm{h}+\eta)$. The residual term is negligible since it is small when $\langle\eta\rangle$ is near zero. For a single channel with a constant width, Qs (landward) and $\mathrm{Q}_{\mathrm{R}}$ (seaward), the water storage balance $\left(\mathrm{Qs}_{\mathrm{s}} \mathrm{Q}_{\mathrm{R}}\right)$. Hence, $\mathrm{Q}_{\mathrm{t}}$ is small or zero. In network channels, they (Stokes and return flows) do not necessarily balance, and $\mathrm{Q}_{\mathrm{t}}$ has a non-zero value (Buschman et al., 2010).

\subsubsection{Estuarine classification theory (parameter-space)}

Geyer \& MacCready, (2014) used two parameters to classify estuaries: the freshwater Froude number that represents river flow effects, 


$$
F r_{f}=U_{R} /\left(\beta g s_{\text {ocean }} H\right)^{1 / 2},
$$

and a mixing number that represents the tidal forcing,

$$
M^{2}=\frac{C_{D} U_{T}^{2}}{\omega N_{0} H^{2}} .
$$

Here, $U_{R}$ is the river flow velocity, $\beta$ is the saline expansivity, $s_{\text {ocean }}$ is the ocean salinity, $H$ is the channel depth, $C_{D}$ is the drag coefficient, $U_{T}$ is the tidal velocity, $\omega$ is the tidal frequency and $N_{0}$ is buoyancy frequency $=\left(\beta g s_{\text {ocean }} H\right)^{1 / 2}$. The freshwater Froude number, $F r_{f}$, represents the ratio of the river flow net velocity to frontal propagation speed, while $M^{2}$ represents the ratio of the tidal timescale to the vertical mixing timescale, or equivalently the effectiveness of tidal mixing and tidal straining. Note that a critical mixing condition occurs when the tidal boundary layer penetrates the entire column and reaches the surface. This occurs when

$$
\left(\frac{s_{\text {ocean }}}{\delta S_{i}}\right)^{1 / 2} M^{2} \approx 1,
$$

where $\delta S_{i}$ is the vertical salinity difference. The equation of stratification from (MacCready, 1999) is:

$$
\frac{\delta s}{s_{\text {ocean }}}=\alpha F r_{f}^{2 / 3} \text {, }
$$

where $\alpha=3.4$ based on (Geyer, 2010). Substituting Eq. 2.38 into Eq. 2.37 yields the following condition for vertical mixing,

$$
\alpha^{-1 / 2} F r_{f}^{-1 / 3} M^{2} \approx 1 .
$$


The parameter-space plot in Figure 2-2 depends on two parameters: the freshwater Froude number $\left(F r_{f}\right)$ and the mixing parameter $\left(M^{2}\right)$. The freshwater Froude number is the river velocity scaled by the maximum possible frontal propagation speed, while the mixing number is the ratio of the tidal timescale to the vertical mixing timescale.

The red solid diagonal line in Figure 2-2 divides the estuaries that should always remain stratified (to the left of the red diagonal line) from those in which boundary generated mixing reaches the surface within a tidal cycle (to the right of the red diagonal line). Each estuary occupies an area inside the diagram, because of the tidal velocity springneap variation (x-axis) and seasonal river flow variation (y-axis). Furthermore, the parameter-space classified estuaries into six categories; salt-wedge, strongly stratified, SIPS, partially mixed, well mixed, and time-dependent salt-wedge. An estuary is a saltwedge when seawater advances into the estuary as a wedge-shaped bottom layer, which slightly mixes with the freshwater upper layer because of weak tidal motion and high river flow. When the tidal mixing is significant enough to erase the salt-wedge, then the estuary is partially mixed. It is well mixed if a shallow estuary has a strong tidal mixing and low river flow. SIPS or Strain-Induced periodic Stratification is the switching between mixing and stratified states over a single tidal cycle (Simpson et al., 1990); the mixing of the water column is due to tidal straining, while the interaction of a horizontal density gradient with a vertical shear produces a periodic stratification.

From the previous definitions - the mixing parameter $\left(M^{2}\right)$, and freshwater Froude number equations $\left(F r_{f}\right)$ - it can be concluded that the classification in Figure 2-2 strongly 
depends on the river flow, tidal velocity, and estuarine depth. The three parameters have likely changed in the Columbia River Estuary over the last 150 years because of both bathymetric and hydrological changes.

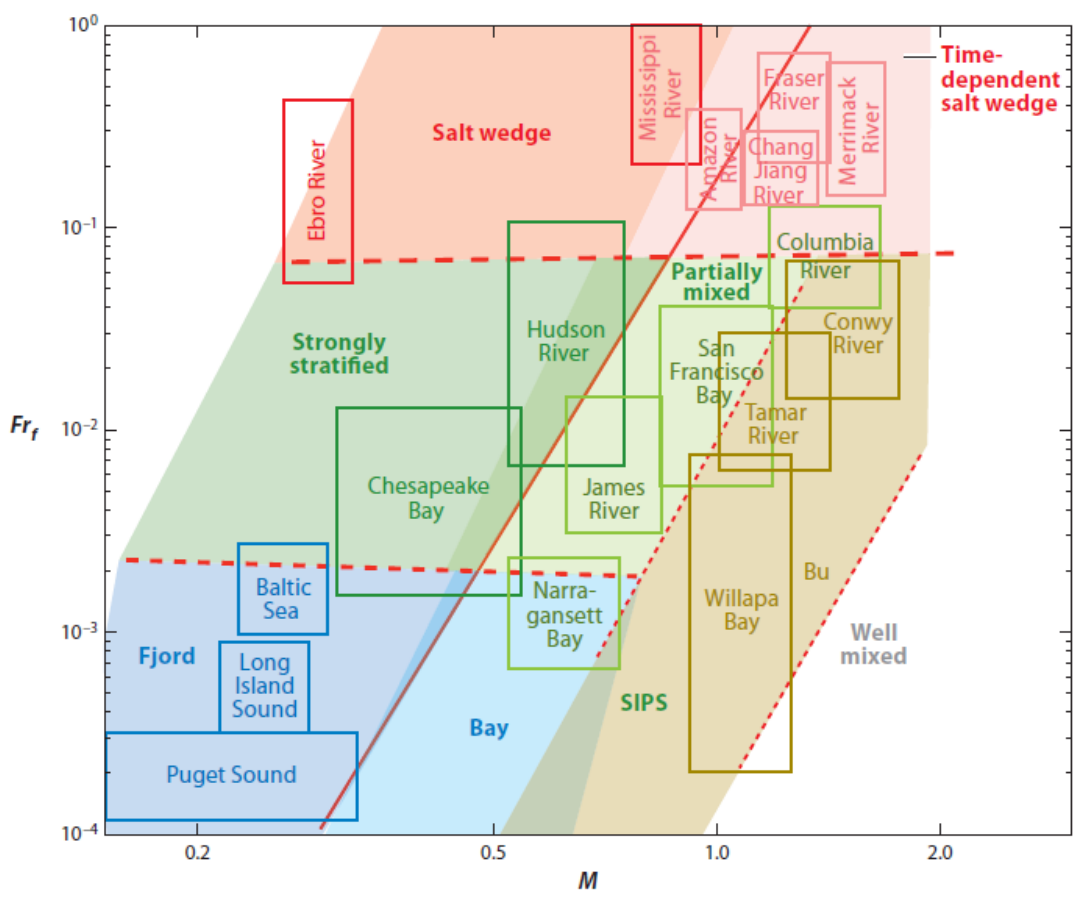

Figure 2-2. Estuarine parameter space (Geyer \& MacCready, 2014).

\subsection{Literature review}

\subsubsection{Literature on modeling hydrodynamic and transport processes in estuaries}

The hydrodynamics of estuaries are described by the shallow water equations (mass momentum conservation, and the equation of state). In order to solve these equations analytically, many assumptions and simplifications are considered. Since the estuarine 
transport and circulation are usually turbulent, time-dependent, and 3-dimensional (Sheng \& Wang, 1988), and because the flow features complexity and a strong density gradient (Kärnä et al., 2015), 3d-hydrodynamic modeling is often necessary to better understand the spatial and temporal structure of the flow (Aristizábal \& Chant, 2013; MacWilliams et al., 2015).

Numerical modeling has been used for several decades as a useful tool in estuarine investigations (Ganju et al., 2016). In order to validate results, a calibration to real data is necessary. Model accuracy depends on many factors such as; grid resolution, length of simulations, diffusion coefficients, boundary conditions, and bottom roughness. The sensitivity to grid resolution, eddy viscosity, and eddy diffusivity were presented, for example, by Ralston (2010). He used a 3D hydrodynamic model to simulate the Merrimack estuary and compared it to observed data. The comparison included water level, salinity, and velocity. The skill assessment showed that the model well represented the salinity spatial structure as well as the along and cross estuary salt flux. Similarly, Warner et al. (2005) addressed the importance of bottom friction and grid resolution by using a 3D numerical model for the Hudson River. The model compared water level, velocity, salinity (vertical and horizontal), and salt flux. The model was able to capture the stratification during spring-neap tides. Although the top-bottom salinity difference was captured well, the vertical salinity structure was not well represented. The model was found to be sensitive to the bottom drag coefficient and salinity at the open boundaries, such that decreases in the bottom roughness led to higher velocities near the bottom. This prevented the migration 
of the bottom boundary layer into the upper column and reduced mixing, and consequently increased the salinity intrusion length.

For the Columbia River Estuary, Kärnä et al. (2015) constructed a numerical model based on the finite element and finite volume principle. It was tested under variable conditions that covered the spring-neap tide period as well as the conditions of high and low flow. The model was able to simulate the CRE circulation. It used a skill assessment and found that bed friction variation is the key to get a better simulation. The model successfully predicted the salinity intrusion during low and high flow conditions but it underestimated the gravitational circulations especially during spring and neap conditions. Kärnä et al. (2015) also found that the density field is smoother in the model than in measurements, due to numerical mixing. Baptista et al. (2005) recommend that model validation should extend for a long period of time (months-years) to eliminate local bias. They used an Eulerian-Lagrangian three-dimensional model of the Columbia River estuary, plume, and shelf. This model, an earlier version of the Kärnä et al. (2015) model, simulated water levels well but could not well simulate the plume dynamics and the salinity intrusion.

Using modeling techniques is an effective way to address estuarine salinity intrusion and the factors that can contribute to its variability. Tidal advection and diffusion are among the most important factors, especially during low to moderate river flow (Wei et al., 2016). The geometry of the estuary is another important factor in salinity intrusion, as found by MacWilliams et al. (2015). In their model, they tried to simulate the 
hydrodynamics of the San Francisco Estuary for a 3-year period that covered a variety of flow and tidal conditions. By comparing the model to actual data and evaluating the model using multiple metric assessment skills, they found that the model was appropriate to use to predict salinity and circulation. By applying the model, they found out that the location, area, volume, and average depth of the low salinity zone (0.5-6-psu) is proportional to salinity intrusion length (2-psu daily averaged bottom salinity) and depends on the estuary geometry. MacCready (2007) applied a tidally and width-averaged numerical model to explore the subtidal salinity adaptation to tidal mixing and river flow variation. An analytical expression $\left[T_{A D J}=(1 / 6) L / \bar{u}\right]$ was developed for the time that it takes the salinity fields to adjust to a step-change in river flow. He found that the adjustment time $\left(T_{A D J}\right)$ is directly proportional to the salinity intrusion length $(L)$ and inversely proportional to width-averaged river velocity $(\bar{u})$. He also pointed out the importance of adjustment time compared to a forcing time scale. For example, the adjustment time for the Hudson River is much faster than the seasonal river flow variation timescale, while it is nearly equivalent to the tidal variation period for spring-neap mixing ( 7days).

\subsubsection{Flow partitioning literature}

Investigating flow division at river junctions is important to understand the transport and pathways of sediments, contaminants, and nutrients. A larger share of river flow may result from a larger water surface slope of one-channel compared to the other. The slope difference can be caused by an asymmetry upstream of the junction. Asymmetries can include different channel directions with respect to the feeding river 
channel and bends or curves in channels upstream of the junction. The channels' geometry and their hydraulic roughness can also control the water division. In addition, the flow division gets more complicated by enhanced friction from non-linear interaction between river flow and tides (Buschman et al., 2010).

Swart (2015) suggested that salinity intrusion and tidal propagation in a multichannel estuary are significantly different from a single channel estuary. He used an idealized model of a two-channel estuary with different length channels that meet at a tidal junction upstream. He found that the tidal energy could transfer from the shorter channel to the longer channel at the junction. This happens because of the tidal velocity phase difference between the two channels, where the phase difference increases linearly with the channel length, so the tidal wave in the shorter channel will round the corner faster. This can affect the water level amplitudes and gradients, which increases the freshwater percentage in the shorter channel. The result of this freshwater partitioning difference could lead to more salinity intrusion in the longer channel. This finding agrees with Buschman et al. (2010), who showed that tidal motion makes the freshwater division more unequal at a tidal junction, with smaller tidal amplitude and larger subtidal water level gradient in the shorter channel.

For the CRE, Lutz et al. (1975) reported that for mean daily river flow of less than $4670 \mathrm{~m}^{3} / \mathrm{s}$ or greater than $5380 \mathrm{~m}^{3} / \mathrm{s}$, the South Channel at Astoria Reach conveys more flow during ebb than during flood, while the reverse occurs in the North Channel and shallow mid-estuary (Middle Channel). This produces a net clockwise circulation between the two 
channels. For river discharge in between these values, the net circulation was counterclockwise. The percentage of tidal flow in the North Channel near Astoria Reach is about $76 \%$ of flood flow, and $69 \%$ of the ebb flow. Furthermore, their observation near Astoria indicates that the maximum surface velocities for ebb and flood were 2.4 and 1.8 $\mathrm{m} / \mathrm{s}$, respectively, while the lateral and time-averaged velocities were 0.9 and $0.6 \mathrm{~m} / \mathrm{s}$, respectively. They also pointed out that the direction of flow in the channels (North \& South) runs parallel to the riverbank, but diagonally in the Middle Channel. Although the South Channel has been deepened since the 1970s (see Table 1-1), a similar pattern may still exist today. This question will be investigated using modeling.

\subsubsection{Salinity intrusion literature}

As discussed above, idealized scaling of salinity intrusion (Equations 2.25 thru 2.30; Hansen \& Rattray, 1965), suggest that salinity intrusion is inversely proportional to the river flow to the power of one third (assuming steady-state conditions and zero net salt flux; see e.g., (Monismith et al., 2002; MacCready, 1999). Following this theoretical work, many empirical studies have interpreted salinity intrusion using a power-law relation $\left(X \sim Q^{-n}\right)$. Abood (1974), found $n=1$ in the Hudson River estuary for low flow and found $\mathrm{n}=1 / 3$ for high flow conditions. For the same estuary, $n$ was found to be $1 / 5$ by Oey (1984). When including the boundary layer as an effective mixing length scale, Ralston et al. (2008) found a value of $n$ equal to 0.35 . When the full water depth was used, $n=0.4$ was found. Within San Francisco Bay, Monismith et al. (2002) found a value of $n=1 / 7$ and determined an adjustment time of about 2 weeks. The adjustment time is the time needed 
for density and estuarine circulation to adapt to the change in river flow and tidal mixing (MacCready, 1999). Finally, n was found to be 0.1 for the Delaware Bay by Aristizábal \& Chant (2013).

For the Columbia River Estuary (CRE), Chawla et al. (2008) used CTD (an instrument that can measure conductivity, temperature, and depth/pressure of a water column) cast data to measure the salinity intrusion along the South Channel. They recorded the salinity intrusion during two spring freshet periods. Their measurements suggested that the salt intrusion from the estuary entrance doubles when the river flow decreases by a factor of about four; i.e., that $n \approx 1 / 2$. Putra et al. (2015) used a multi-station calibration of a 3D flexible mesh model of the Columbia River Estuary and found that during spring tide salinity intrusion can reach $40 \mathrm{~km}$ upstream of the mouth of the CRE during low river flow condition. See comparisons of $n$ in Table 2-1 for different estuaries.

Table 2-1. Salinity intrusion length $\left(X_{S}\right)$, river discharge $(Q)$ relation for different estuaries. Where Kmo is a mixing coefficient that uses the whole water column depth as an effective mixing length scale, while KmBL uses the bottom boundary layer height.

\begin{tabular}{|l|l|l|}
\hline \multicolumn{1}{|c|}{ Estuary } & \multicolumn{1}{c|}{ Discharge power } & \multicolumn{1}{c|}{ Researchers } \\
\hline Delaware Bay & $X_{S} \sim Q^{-0.1}$ & (Aristizábal \& Chant, 2013) \\
\hline Columbia River Estuary & $X_{S} \sim Q^{-1 / 2}$ & (Chawla et al., 2008a) \\
\hline Hudson & $X_{S} \sim Q^{-0.4} \rightarrow \mathrm{K}_{\mathrm{mo}}$ \\
& $X_{S} \sim Q^{-0.35} \rightarrow \mathrm{K}_{\mathrm{mBL}}$ & (Ralston et al., 2008) \\
\hline San Francisco Bay & $X_{S} \sim Q^{-0.20} \rightarrow \mathrm{K}_{\mathrm{mo}}$ \\
& $X_{S} \sim Q^{-0.17} \rightarrow \mathrm{K}_{\mathrm{mBL}}$ & (Ralston et al., 2008) \\
\hline Theoretical & $X_{S} \sim Q^{-1 / 3}$ & (Monismith et al., 2002) \\
\hline San Francisco Bay & $X_{S} \sim Q^{-1 / 7}$ & (Monismith et al., 2002) \\
\hline Hudson & $X_{S} \sim Q^{-1 / 5}$ & (Oey, 1984) \\
\hline Hudson & $X_{S} \sim Q^{-1 / 3} \rightarrow$ low flow \\
& $X_{S} \sim Q^{-1} \rightarrow$ high flow & (Abood, 1974) \\
\hline
\end{tabular}




\subsubsection{Tidal asymmetry and exchange flow literature}

Tidal asymmetry is the difference in duration and current magnitudes of the flood and ebb tides. It can be either ebb or flood dominant. Whether an estuary location is ebb or flood dominant depends on the phase difference between the tidal components, while the degree of distortion depends on the ratio of constituent amplitudes (Jay \& Musiak, 1996).

A main source of asymmetry is the interaction of principal lunar semidiurnal tides $\left(M_{2}\right)$ with its overtides (e.g., $\left.M_{4}\right)$, the harmonic frequencies that are integer multiples of a principal constituent). Another source of asymmetry is the nonlinear interaction of semidiurnal tides (e.g., $\mathrm{M}_{2}, \mathrm{~N}_{2}$, and $\mathrm{S}_{2}$ ) and diurnal tides $\left(\mathrm{K}_{1}\right.$ and $\left.\mathrm{O}_{1}\right)$, which produces harmonics generated from sum or differences of two frequencies (examples include $\mathrm{MS}_{4}$ and $\mathrm{MK}_{3}$ ). Both overtides and compound tides are generated from the distortion of the astronomical tides in shallow water (Nidzieko, 2010). The tidal asymmetry can be called "barotropic asymmetry" because it distorts the free surface and influences flood/ebb dominance. Meanwhile, river flow can reinforce the tidal asymmetry by increasing friction, which is the main cause of tidal distortion (Kukulka \& Jay, 2003b).

The physical mechanism of the tidal asymmetry is the non-linear, shallow water processes that transfers energy from the tide to higher and lower frequencies. The nonlinearities in the equations of motions arise from the time-varying depth and width in the continuity equation, the time-varying depth and velocity in the quadratic friction in the momentum equation, and the nonlinear advection acceleration in the momentum equation 
(Parker, 1991). See Figure 2-3 for an illustration of the mechanisms involved in barotropic tidal asymmetry.

Another type of tidal asymmetry known as "internal tidal asymmetry" can cause estuarine circulation related to correlations in tidally varying stratification and mixing (Jay \& Musiak, 1994, 1996). Internal tidal asymmetry leads to density field distortion associated with energy transfer from the surface tide to higher and lower frequencies (Jay \& Musiak, 1996). That is, internal asymmetry leads to differences in stratification between ebb and flood, which causes tidal differences in vertical mixing. This can lead to asymmetric vertical shear of the along-channel momentum, which ultimately causes two-layer residual estuarine circulation (Becherer et al., 2015). Estuarine circulation, or exchange flow, is simply the water entering the estuary near the bottom which is compensated by the outflow near the surface (tidally averaged circulation). It is caused by both gravitational circulation and internal asymmetry. The exchange flow is important to estuarine dynamics since it affects the transport of salt, nutrients and suspended sediments (Becherer et al., 2015; Wang et al., 2017). 


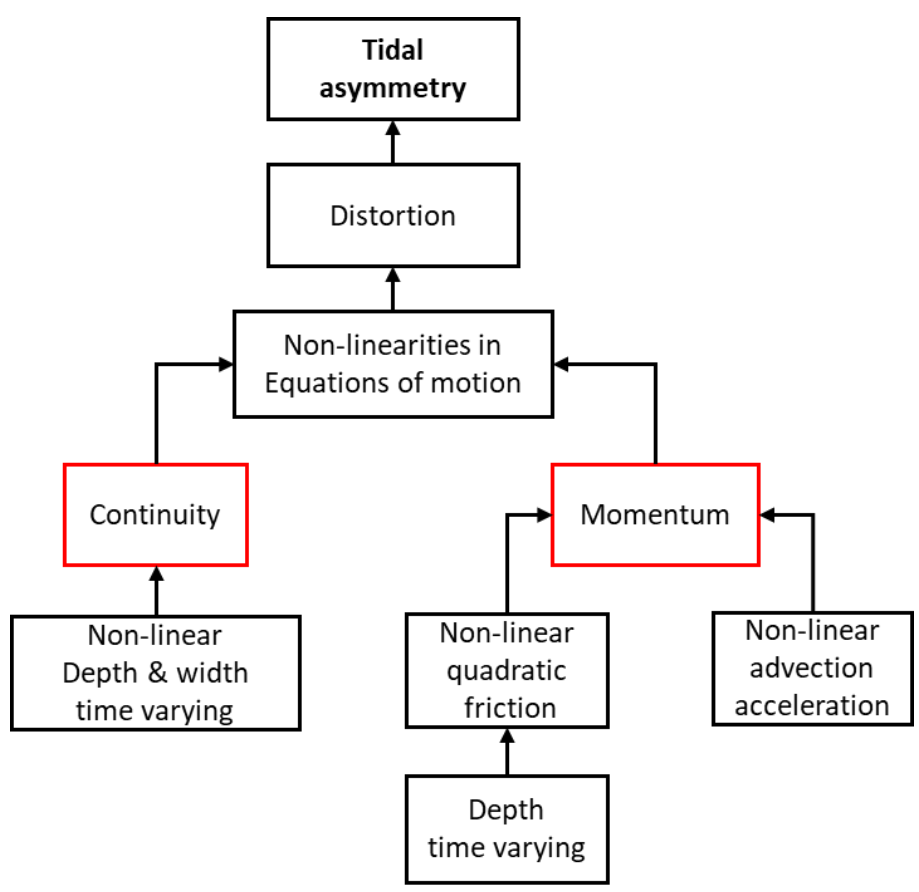

Figure 2-3. Physical mechanism layout of tidal asymmetry

The estuarine circulation helps define the salinity structure. It can be quantified using total exchange flow (TEF). TEF is tidally averaged salt flux through an estuarine cross section, using salinity instead of spatial position in the calculation of the exchange flow. MacCready (2011) applied the TEF method to a numerical simulation of the Columbia River estuary for the period from April to September of 2005. He found that the tidal salt flux $\left(\mathrm{F}_{\mathrm{T}}\right)$ dominated over exchange flux $\left(\mathrm{F}_{\mathrm{E}}\right)$ in the outer part of the estuary because this region is within one tidal excursion of the mouth. By using the volume flux through the mouth section, he found that the average water inflow occurs over a narrow salinity range near oceanic values, while seaward transport of water occurs over a much larger salinity range (0-30psu). This occurs because of mixing within the estuary. Wang et 
al. (2017) utilized the TEF concept and linked it to mixing in the Hudson estuary using a numerical model. They found that the total exchange flow reaches its maximum near minimum neap tide, but vertical (entrainment) salt transport reaches its maximum during the maximum spring tide.

\subsubsection{Climate change literature}

\subsubsection{River hydrograph}

The Columbia River discharge has changed and it continues to evolve because of climate change and flow control. Hamlet et al. (2013) studied the climate change impact on the Columbia Basin and predicted changes in spring snowpack and fundamental shifts from snow and mixed-rain-and-snow to rain-dominant behavior across most of the domain. They also anticipated decreases in summer precipitation, increases in extreme low flows in intensity for most of the river sites, and increases in flooding in mixed-rain-and-snow basins in mid-winter. Warner et al. (2015) investigated the changes in winter atmospheric rivers along the U.S. North West coast and forecasted increases in winter mean precipitation by $11 \%-18 \%$ by the end of this century. Lee et al. (2016) assessed the combined effects of changing natural flow due to climate change and dam operations that determine impacts to regulated flow for the Skagit River, a river north of Seattle. The results show that climate change is likely to cause substantial seasonal changes in both natural and regulated flow, with more flow in the winter and spring, and less in summer. The regulated 100 -year flood is projected to increase by $23 \%$ by the 2040 s and $49 \%$ by the 2080s (Lee et al., 2016). 
The USBR (2016) reported potential hydrologic impacts of climate change on the Columbia River Basin. They stated that average mean-annual air temperature has increased by approximately $2^{\circ} \mathrm{F}$ since the late 1800 s. Also, the Columbia River Basin has experienced a general decline in spring snowpack since the mid-20th century due to more precipitation occurring as rain (rather than snow) and earlier snowmelt runoff. Projected scenarios from USBR (2016) of future Columbia River flow above the Dalles are presented in Table 2-2. The data shows the simulated percent change from the 1990s (1980 to 2009) to the 2040s (2030 to 2059) and 2080s (2070 to 2099)for mean annual runoff, winter runoff (DecemberMarch), and spring runoff (April through July). Overall, a large increase in winter runoff is projected, while spring flows may either increase or decrease.

Table 2-2. Hydrologic modeling for the Columbia River above The Dalles [after Bureau of Reclamation, (2016)]

\begin{tabular}{|c|c|c|}
\hline Change from 1990s period & 2040s & 2080s \\
\hline Mean Annual Runoff (\%) & -5 to +10 & -4 to +15 \\
\hline Mean Dec-Mar Runoff $(\%)$ & +13 to +44 & +26 to +91 \\
\hline Mean Apr-Jul Runoff $(\%)$ & -8 to +8 & -17 to +10 \\
\hline
\end{tabular}

\subsubsection{Sea-level rise}

Sea-levels are rising globally as a result of climate change. As air and water temperature increase, the Greenland and Antarctic ice sheets melt and cause more rapid rise in sea-level. Warmer water temperatures also causes thermal expansion and a rise in mean water levels. Sea-level rise can have a significant impact on salinity intrusion (Xiao et al., 2014). Rice et al. (2012) investigated the salinity intrusion change of Chesapeake Bay because of sea-level rise using a three-dimensional model. Their results showed that 
the James River's mean salinity increases (2-4 ppt) when the sea-level rises $(0.5-1 \mathrm{~m})$, and the effect is more severe during dry years. Furthermore, the isohalines move upstream as the sea-level rises.

Regarding global mean sea-level rise (GMSL), Church \& White (2011) estimated historical global sea-level rise from coastal and island sea-level measurements and satellite data. This study concluded that the global sea-level has risen about $210 \mathrm{~mm}$ between 1880 and 2009, with a linear trend of $1.7 \mp 0.2 \mathrm{~mm} /$ year. For the satellite data era since 1991, the trend was $3.2 \mp 0.4 \mathrm{~mm} /$ year. Hay et al. (2015) combined tide gauge records with modeling of the various contributing signals and indicated that GMSL rose at a rate of 1.2 $\mp 0.2 \mathrm{~mm} /$ year between 1901 and 1990. Dangendorf et al. (2017) used an area-weighting technique for averaging tide gauge records and estimated a sea-level rise of $1.1 \mp 0.3$ mm/year before 1990 and $3.1 \mp 1.4 \mathrm{~mm} /$ year from 1993 to 2012. The methods and calculations of various researchers are shown in Figure 2-4. 


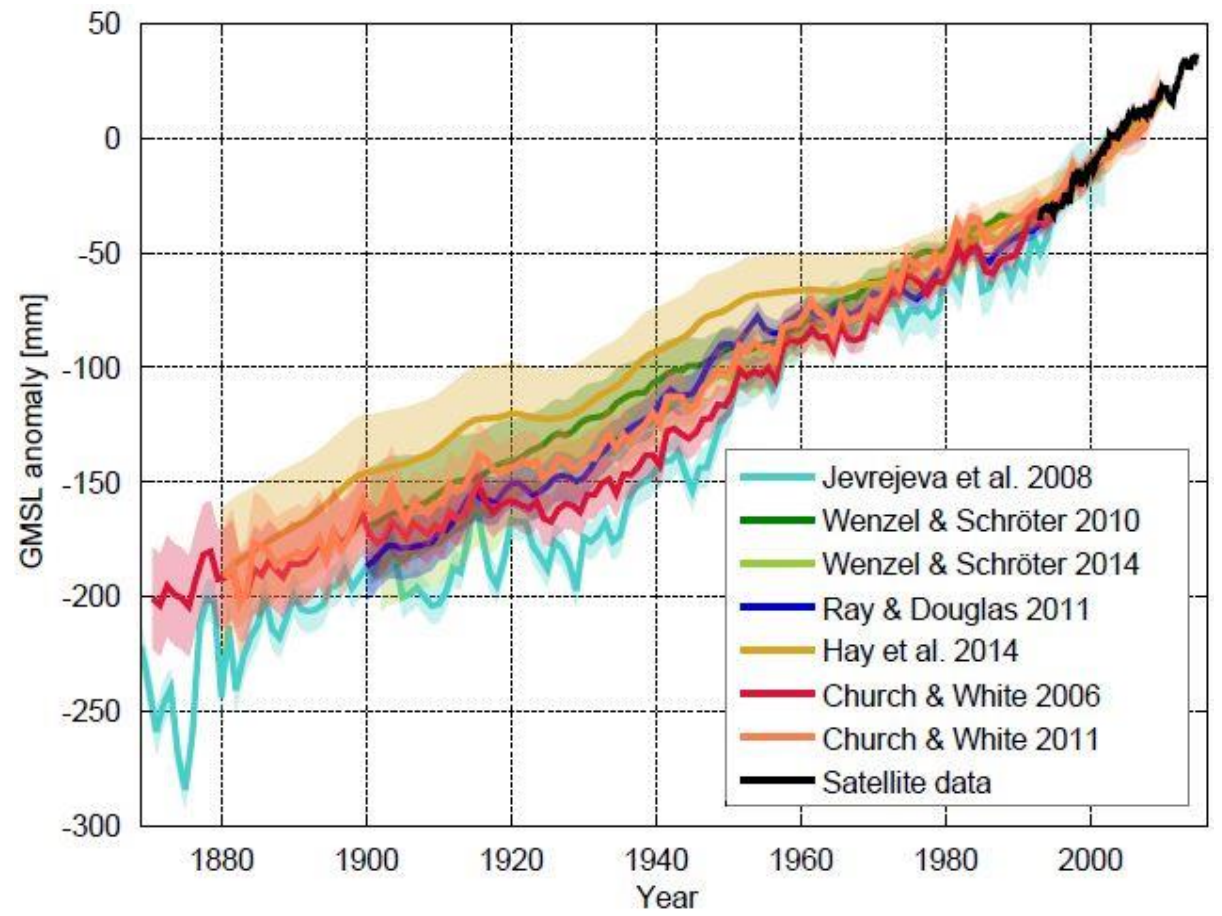

Figure 2-4. Sea-level curves calculated by different research groups with various methods. The curves show the sea-level relative to the satellite era (since 1992),

http://www.realclimate.org/index.php/archives/2015/01/a-new-sea-level-curve/.

Relative sea-level rise (RSL) is the sea-level rise relative to a local reference land level. RSL rise is more important than global MSL rise for most management purposes. In addition to MSL, it can be affected by many factors including changes in the gravitational attraction of ice, ocean-atmosphere interaction (El-Nino Southern Oscillation, or ENSO), and Pacific Decadal Oscillation (PDO) patterns which affect wind and temperature, terrestrial water storage, groundwater withdrawal, glacial isostatic adjustment, density changes, ocean circulation, and uplift and subsidence (NRC, 2012). RSL can be affected by the gravitational pull of the large mass of glacier ice sheets. When they melt, the gravitational pull decreases and produces a spatial pattern of regional sea-level. Regarding 
Oregon, the RSL increases during the warm phase (El-Nino, up to $10-30 \mathrm{~cm}$ for several months) and can drop during the cold phase (La-Nina) by a similar amount. Melting from Alaska and Greenland causes a fall in RSL, while melting from Antarctica causes a rise in RSL near Oregon. Additionally, the land is sinking at about $0.37 \mathrm{~mm} /$ year in Astoria and $1.3 \mathrm{~mm} /$ year in Fort Stevens (according to glacial isostatic adjustment models, GIA), which causes an increase in sea-level in the region (Burgette et al., 2009; Talke et al., 2020). Hence, because of the subduction zone effect on the area, the land at the coast is pushed upward. Recently, sea-level rise rates in the Eastern Pacific were suppressed by a change in wind stress pattern caused by the Pacific decadal oscillation (PDO), which led to the suppression of relative sea-level rise (Merrifield et al., 2012). Once this pattern changes again, the relative sea-level rise could match the global projections of sea-level or even surpass them (Bromirski et al., 2011).

The projection of sea-level rise in Oregon (including global and local effects) suggested by NRC (2012) suggests that the RSL could increase by $1.43 \mathrm{~m}$ by 2100 ; see Table 2-3. Additionally, a potential earthquake $>=9$ in magnitude could rise the regional sea-level (RSL) an additional 1-2m over the projected values, by causing subsidence of $2 \mathrm{~m}$ at the coast, zero at the upstream boundary, and 1.5m at Astoria (Kalmbacher \& Hill, 2015), see Figure 2-5 \& Figure 2-6. NRC (2012), Pfeffer et al. (2008), and Vermeer \& Rahmstorf (2009) predicted that the global sea-level will rise about $1-2 \mathrm{~m}$ along the Oregon shore, which will increase flooding and may affect salinity intrusion. 
Table 2-3. projection of RSL near Oregon coast as suggested by NRC (2012)

\begin{tabular}{|c|c|c|c|}
\hline Projection (yrs) & $\mathbf{2 0 3 0}$ & $\mathbf{2 0 5 0}$ & $\mathbf{2 1 0 0}$ \\
\hline RSL (cm) & -4 to +23 & -3 to 48 & 10 to 143 \\
\hline
\end{tabular}

\section{9_subsidence in feet}
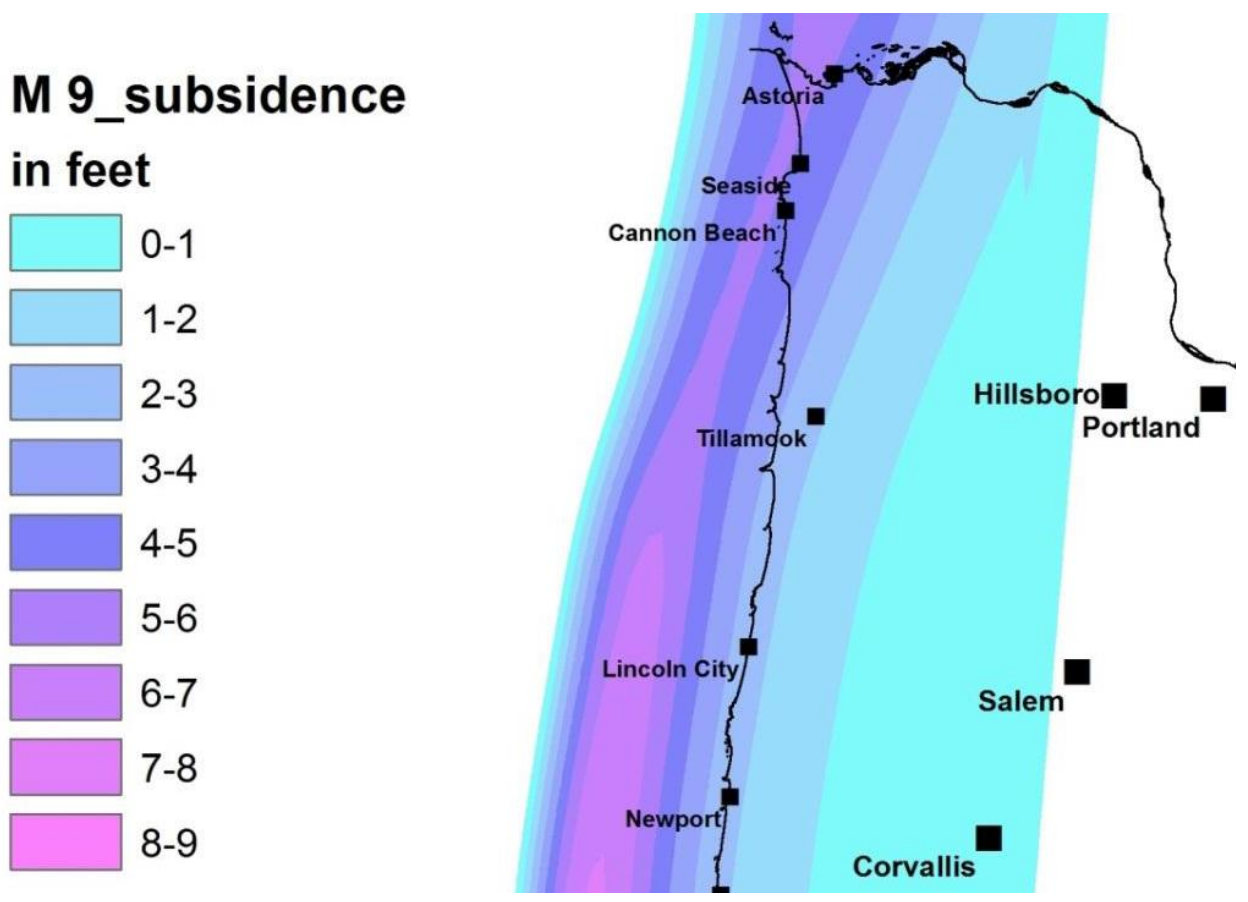

Figure 2-5. Estimated land subsidence from a magnitude 9 earthquake on Astoria and Oregon coast (OSSPAC, 2013). 


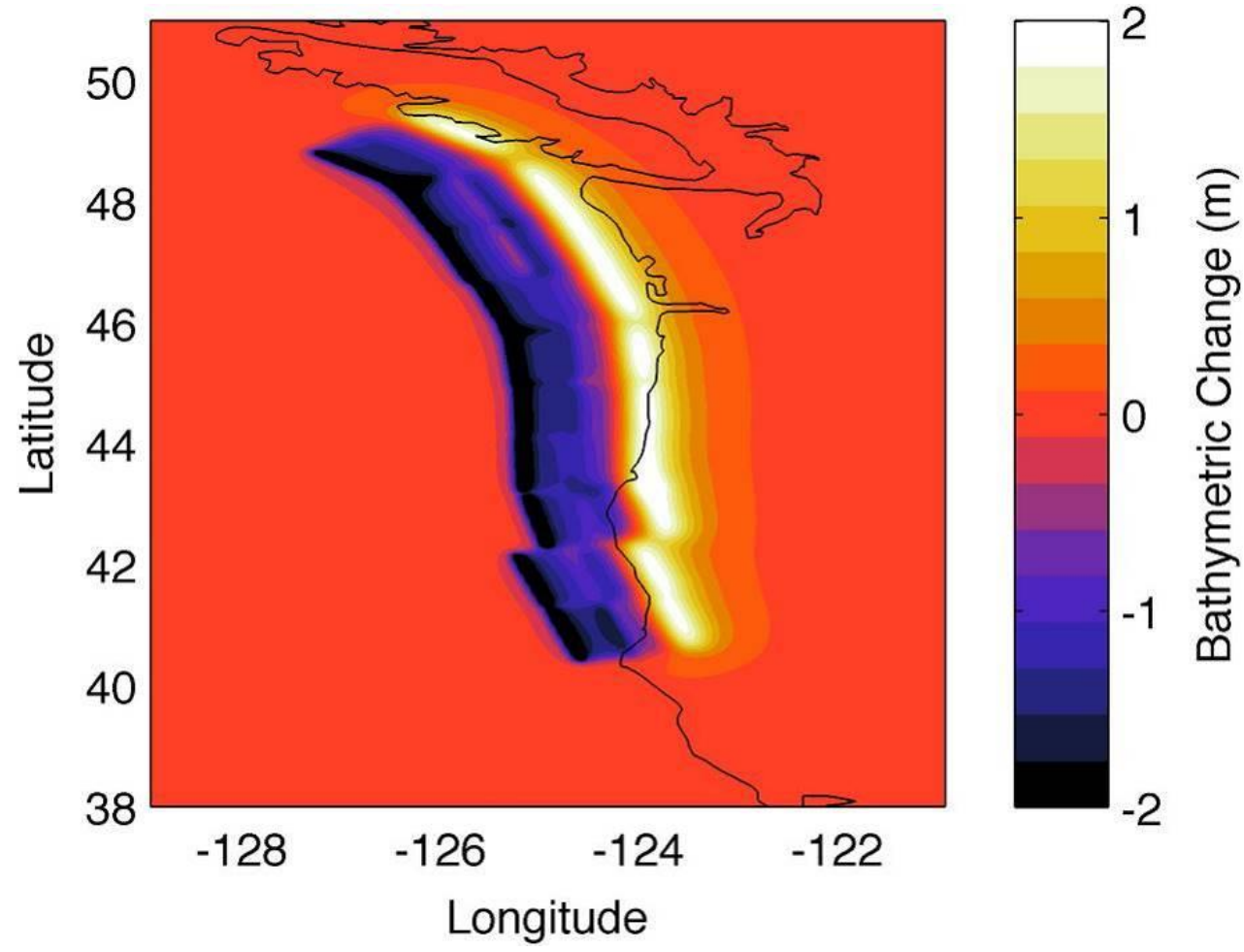

Figure 2-6. Change in the bathymetry of CRE and Oregon coast from magnitude 9-modeled earthquake after Kalmbacher and Hill (2015). Note: negative values represent the upward displacement 


\section{Chapter 3 Flow Bifurcation in the Lower Columbia River Estuary}

\subsection{Introduction}

River discharge and tides exert a dominant influence on barotropic estuarine processes and affect stratification, mixing, circulation, and hence salinity intrusion and other transport processes (Hansen \& Rattray, 1965; Hansen \& Rattray, 1966; Jay \& Musiak, 1996; MacCready, 1999; Monismith et al., 2002; MacCready \& Geyer, 2010). Because many estuaries have only one primary channel, theory has traditionally evaluated estuarine dynamics within a single channel, assuming that river discharge enters far upstream of estuarine circulation (Monismith et al., 2002; Ralston et al., 2008). Although this approach has yielded many insights into tidal dynamics (e.g., Godin, 1985, 1999; Jay, 1991), a simple theory is inadequate when multiple channels are found in an estuary, as is frequently the case. Examples that received early attention include a) the Thames Estuary in the Southeast of Great Britain with flood-ebb asymmetric tides on each channel (Robinson, 1960); b) the Humber Estuary on the east coast of Northern England, where channel width determines whether channels are flood or ebb dominant (Robinson, 1960); and c) the Wadden Sea in the Netherlands where scalars are dispersed chaotically (Zimmerman, 1986). More recently, it has become clear that the amount of tidal flow and river flow in the channels of multi-channel systems is not simply a function of channel cross-section. Thus, the distribution of tidally-averaged flow may vary, for example, as a function of depth, channel curvature, river discharge and/or tidal forcing (Buschman et al., 2010; Sassi et al., 2011; and Zhang et al., 2017). 
Here, I use the multi-channel Lower Columbia River Estuary (LCRE) to examine numerically how river flow is distributed between channels, how this division has been altered by navigational development, and finally, how LCRE tidal processes, in general, have been altered by navigational development.

The Lower Columbia River Estuary (LCRE) is a multi-channel estuary with two primary channels and multiple smaller ones. It is characterized by strong tidal currents as high as 2-4 m/s (Gonzales, 1984; Jay \& Smith, 1990) and large river discharge that varies seasonally from 2000 to $17,000 \mathrm{~m}^{3} / \mathrm{s}$ (Naik \& Jay, 2011) The seasonal variation in the tidal range and river discharge along with the non-uniformity of the estuary geometry can lead to laterally variable water levels (Hudson et al., 2017), which can then lead to lateral variations in the along channel water surface slope and an uneven distribution of flow among channels.

The Columbia River has been strongly altered in terms of geometry and river hydrograph over the last 150 years (Sherwood et al., 1990; Simenstad et al., 1992; Naik \& Jay, 2005, 2011). Deepening the navigation channel has increased the tidal range and reduced the river slope in the CRE (Helaire et al., 2019) such that the tidal range has increased by 5.6\% ( 0.11m) near Astoria since 1855 (Talke et al., 2020). Changes in river flow and tidal range have likely altered the distribution of freshwater fluxes in the estuary along with the transport of sediment and salt. The changes in salt transport are investigated in chapter 4 . Previous analyses have suggested that until the beginning of the 20th century, the North Channel was the primary conduit for river inflow and tidal transport of water 
(Hamilton, 1990). Over the past century, however, the majority of river flow has been diverted into the South Channel, through dredging and the construction of islands and other flow training structures (Sherwood et al., 1990), although the majority of tidal exchange still occurs at the North Channel (Lutz et al., 1975; Chawla et al., 2008; Jay \& Smith, 1990).

In this chapter, I analyze via numerical modeling how the river discharge distribution between the North and South Channels of LCRE has changed over time, and I explore the factors that have affected the distribution. Also, I compare the modern hydrodynamics of the estuary to the historical one (150 years ago) to quantify the tidal change inside the estuary due to human alteration of the system (channel deepening and river discharge management).

\subsection{Theory and methods}

According to Manning's equation (Manning, 1891), steady, uniform flow (Q) in open channels depends on bed friction (n), channel cross-sectional area (A), hydraulic radius $\left(R_{h}\right)$, and channel slope $(S)$, where the bed slope is the same as water surface slope under the uniform condition assumption. This leads to:

$$
Q=\frac{1}{n} A R_{h}^{2 / 3} S^{1 / 2} \quad[S I], \quad \text { (Manning, 1891) }
$$

Using Manning's arguments, the ratio of river flow entering two channels at a bifurcation is a function of the ratios of Manning's equation in the two channels (Ramamurthy et al., 1990): 


$$
\frac{Q_{1}}{Q_{2}}=\frac{\frac{1}{n_{1}} A_{1} R_{h 1}^{2 / 3} S_{1}^{1 / 2}}{\frac{1}{n_{2}} A_{2} R_{h 2}^{2 / 3} S_{2}^{1 / 2}}
$$

If I define the following terms,

$$
R_{Q}=\frac{Q_{1}}{Q_{2}}, R_{n}=\frac{n_{2}}{n_{1}}, R_{A}=\frac{A_{1}}{A_{2}}, R_{R_{h}}=\frac{R_{h 1}^{2 / 3}}{R_{h 2}^{2 / 3}}, \text { and } R_{S}=\frac{S_{1}^{1 / 2}}{S_{2}^{1 / 2}}
$$

Then,

$$
R_{Q}=R_{n} \cdot R_{A} \cdot R_{R_{h}} \cdot R_{S}
$$

Thus, the ratio of flow of two channels braided from a channel is a function of the ratio of their cross-sectional areas $\left(R_{A}\right)$, relative roughness $\left(R_{n}\right)$, hydraulic radii $\left(R_{R_{h}}\right)$, and slopes $\left(R_{S}\right)$. From this simple scaling, it is possible to explore which factors dominate the bifurcation of flows, and how changes from the historical to modern bathymetry alter the balance. However, as shown in Buschman et al. (2010), tidal currents affect the tidallyaveraged friction, thereby influencing bifurcation and making it a function of the springneap cycle. Moreover, the above analysis assumes barotropic conditions and would require modification if salinity stratification were present. The possible effects of tidal forcing and stratification are investigated later using model results.

The residual flow in the estuary contains brackish water. To distinguish the freshwater percentage, I used the fraction of freshwater $(F)$ equation (Neal,1966):

$$
F=\frac{S_{o}-S_{x}}{S_{o}}
$$


where $S_{o}$ is the ocean salinity, and $S_{x}$ is the salinity inside the estuary. A fraction equal to one indicates $100 \%$ freshwater, while $\mathrm{F}=$ zero means there is no fresh water at all. The fraction is calculated during spring and neap tides (tidally averaged) and a range of river discharges to explore the tide and river flow effect on freshwater bifurcation.

\subsubsection{Salt fluxes}

In a steady-state condition, the tidally averaged salt transport from river flow is balanced by the estuarine circulation. The salt transported seaward by the river discharge is equal to the input of salt due to estuarine circulation, or:

$$
U_{r} S_{0}=a_{0} U_{e} \Delta S
$$

where $U_{r}$ is the river velocity and is defined by the river discharge over a cross-sectional area $\left(Q_{r} / A\right), S_{0}$ is tidally averaged salinity, $a_{0}$ is a constant $\sim 0.5, U_{e}$ is the estuarine circulation, and $\Delta S$ is the stratification (the difference between the top and bottom salinities). The scaling of estuarine circulation $\left(U_{e}\right)$ and stratification $(\Delta S)$ gives:

$$
\begin{aligned}
& U_{e}=a_{1} \frac{\beta g \frac{\partial s}{\partial x} h^{2}}{C_{d} U_{t}}, \\
& \Delta S=a_{1} a_{2} \frac{\beta g\left(\frac{\partial s}{\partial x}\right)^{2} h^{3}}{\left(C_{d} U_{t}\right)^{2}},
\end{aligned}
$$

where $a_{1} \& a_{2}$ are constant and depends on the shape of the salinity and velocity profile ( $\sim 0.3$ and $\sim 50$, respectively, for the Hudson River), $\beta$ is saline expansion, $g$ is gravitational acceleration, $\frac{\partial s}{\partial x}$ is the salinity gradient, $h$ is the depth, $C_{d}$ is the drag coefficient, and $U_{t}$ is 
the tidal velocity). The combination of the above three equation (salt balance, estuarine circulation, and stratification gives:

$$
\frac{\partial s}{\partial x}=\frac{C_{d}}{a} \frac{U_{t} U_{r}^{1 / 3} s_{0}^{1 / 3}}{(\beta g)^{2 / 3} h^{5 / 3}}, \text { and } a=\left(a_{0}^{2} a_{1} a_{2}\right)^{1 / 3}
$$

This steady-state equation indicates that salt flux is sensitive to the $1 / 3$ power of river flow, the first power of tidal velocity, and 5/3 power of depth. However, the salt flux is less sensitive when vertical mixing is included (Geyer, 2010). The possible change in river flow bifurcation and bathymetric changes are likely impacted the salt flux distribution in the LCRE. For the purpose of this research, the salt flux was calculated as follows:

$$
\begin{gathered}
q_{s}=u_{(x, z, t)} s_{(x, z, t)}, \\
q_{s}=(\bar{u}+\dot{u})\left(\bar{s}+s^{\prime}\right), \\
q_{s}=\bar{u} \bar{s}+\bar{u} s^{\prime} \\
Q_{s}=\iiint q_{s} d z d y d t,
\end{gathered}
$$

where $q_{s}$ is the salt flux in each cell, $u \& s$ are the instantaneous velocity and salt such that they are variable in time $(t)$, and space (longitudinal $(x)$, and vertical $(z)$ coordinates). $\bar{u} \& \bar{s}$ are depth average velocity and salinity while $u \& \&$ are depth varying. $Q_{s}$ is the total tidally averaged salt flux through a cross-section. 


\subsubsection{Hydrodynamics models}

I have built two 3D hydrodynamic models using Delft3D Flexible Mesh (D-flow FM) Suite 2017 HMWQ software by Deltares, a model that allows the use of unstructured grids (Roelvink and Van Banning, 1995). The modern and historical models represent, respectively, modern bathymetry (MB, Figure 3-1-a, b) and pre-1900 historical bathymetry (HB). The D-flow FM is a three-dimensional (3D) hydrodynamic simulation program that can solve the shallow water equations (continuity, momentum, and transport). The model grids cover the LCRE from the Beaver Army Terminal (Rkm 86, where hourly river discharge is available by USGS) to about $30 \mathrm{~km}$ offshore (E-W) and cover about $60 \mathrm{~km}$ of the coastal area (N-S), as shown in Figure 3-1-c. Each model contains over 58,000 cells (ranging from $100 \mathrm{~m}$ inside the estuary to $1000 \mathrm{~m}$ in the farthest point in the ocean, while the vertical resolution is 36 sigma layers (the vertical spacing and the height of a layer adjusts to the local water column height). This high resolution in the vertical is needed to simulate vertical density variation. Bottom friction is represented using the Chezy formulation, such that the Chezy coefficient (C) for the MB is 65 for the area between the ocean boundary and Skamokawa station (Rkm55), then decreases gradually to 40 near Wauna (Rkm66); it is constant thereafter (Figure 3-1a). The HB Chezy coefficient is depthdependent ( 65 for deep channels and 25 for shallow areas) because the historical floodplain had more vegetation (and was much larger) than it is at present (Helaire et al., 2019).

The horizontal coordinate system is referenced to NAD83/Washington South, while the vertical datum is referenced to NAVD88. The modern digital elevation map 
(DEM) is based on data collected between 2008-2010 as multi-beam surveys (in water) and LiDAR surveys (subaerial, USACE, 2010). The historical model bathymetry was collected between 1868-1901 by the US Coastal Survey and the US Geodetic Survey. They were digitized and geo-rectified by Burke (2010).

\subsubsection{Study area}

The Columbia River (CR) is one of the biggest rivers in the US. Its length is about $1900 \mathrm{~km}$, and it has a drainage area of $660,480 \mathrm{~km}^{2}$ (Simenstad \& Sherwood, 1990). The CR passes through seven states inside the United States and a Canadian province. It provides hydropower and has 14 dams on the main river and 450 dams on its tributaries (Osborn, 2012). Reservoir management has reduced peak spring flows by about $45 \%$ and enhanced low flow during fall and winter. Irrigation diversion and climate change have reduced peak flows by about $15-17 \%$. The present mean annual river discharge to the ocean is about 7,300 $\mathrm{m}^{3} / \mathrm{s}$ (Naik and Jay, 2005, 2010; Jay and Naik, 2011; Talke et al., 2020).

The Lower Columbia River Estuary (LCRE) is characterized by mixed diurnal and semidiurnal tides with a tidal range at Astoria Tongue Point of 1.7-3.7 m (Kukulka \& Jay, 2003 and Jay et al., 2016). As discussed above, the estuary has two primary channels: South and North, and several braided channels that connect between them (Figure 3-1a). I refer to these collectively as the "Middle Channel."

The area of study covers the estuary from the mouth to the Beaver Army Terminal (BAT), which is about $87 \mathrm{~km}$ upstream of the mouth to the Pacific Ocean boundary (see 
Figure 3-1a). The modern and historical models represent the four estuarine zones of eight LCRE zones, as defined by Jay et al. (2016). The four zones modeled are: The Entrance, and the Lower, Middle, and Upper Estuary Zones. Salinity intrusion is usually absent from the Upper Estuary. The zones not represented make up the tidal river part of the system, using the tidal definition of the boundary between the estuary and tidal river suggested by Hoitink \& Jay (2016). More specifically, BAT is the most seaward point in the system where the lowest low waters occur on neap tides, not spring tides. Low waters are lower in a tidal river on the neaps, because the neap-spring difference in river stage is larger than the neap-spring difference in tidal range.

The estuary has seen dramatic changes in morphology over the past 150 years (Sherwood et al., 1990, Simenstad et al., 1994). Historical uses like fishing and log transport and storage have largely been replaced by a variety of industrial, agricultural, fishing, and tourism purposes. Navigational use has been ongoing since the pre-historical period, and the system has been heavily modified for navigation since the 1870s (Helaire et al., 2019). Major changes include jetty construction, channel deepening, and straightening. Blockage of side channels and installation of pile dikes have been used to concentrate flow in the navigation channel. Extensive wetland loss has occurred due to wetland reclamation for industry and agriculture (Simenstad et al., 1990). Marcoe \& Pilson (2017) reported a loss of $68-70 \%$ of the tidal wetlands over the past 140 years. Dredging activities began in 1873 (U.S. Army, 2012), but major dredging began about 1909 (Sherwood et al., 1990). Some portion of the removed materials were moved offshore, 
while $30-40 \%$ were likely placed in wetlands (Templeton \& Jay, 2013). Especially relevant, the maintained controlling depth of the South (navigation) Channel is $13 \mathrm{~m}$ today (and 14.6m at the entrance), while the natural controlling depth was about $6 \mathrm{~m}$ before 1900 (Figure 3-1a \& b). These depths are relative to mean lower low water (MLLW). Also, dredging and jetty construction at the mouth have created a narrower entrance (3.2 instead of $9.7 \mathrm{~km}$ wide) (Helaire et al., 2019).

Extensive hydrological change is primarily due to energy and irrigation demand, flood control, and temperature and precipitation changes (Naik \& Jay, 2011). The biggest changes in the seasonal flow cycle started around 1960 due to water management (Sherwood et al., 1990), such that the flow in winter is now higher than 150 years ago by about 50\% and lower by $\sim 45-50 \%$ during Spring (Naik \& Jay, 2011), see Figure 3-2. Higher flows are needed in winter for electric power generation, while flood control and irrigation withdrawal have reduced spring freshet flows and augmented low fall flows. 

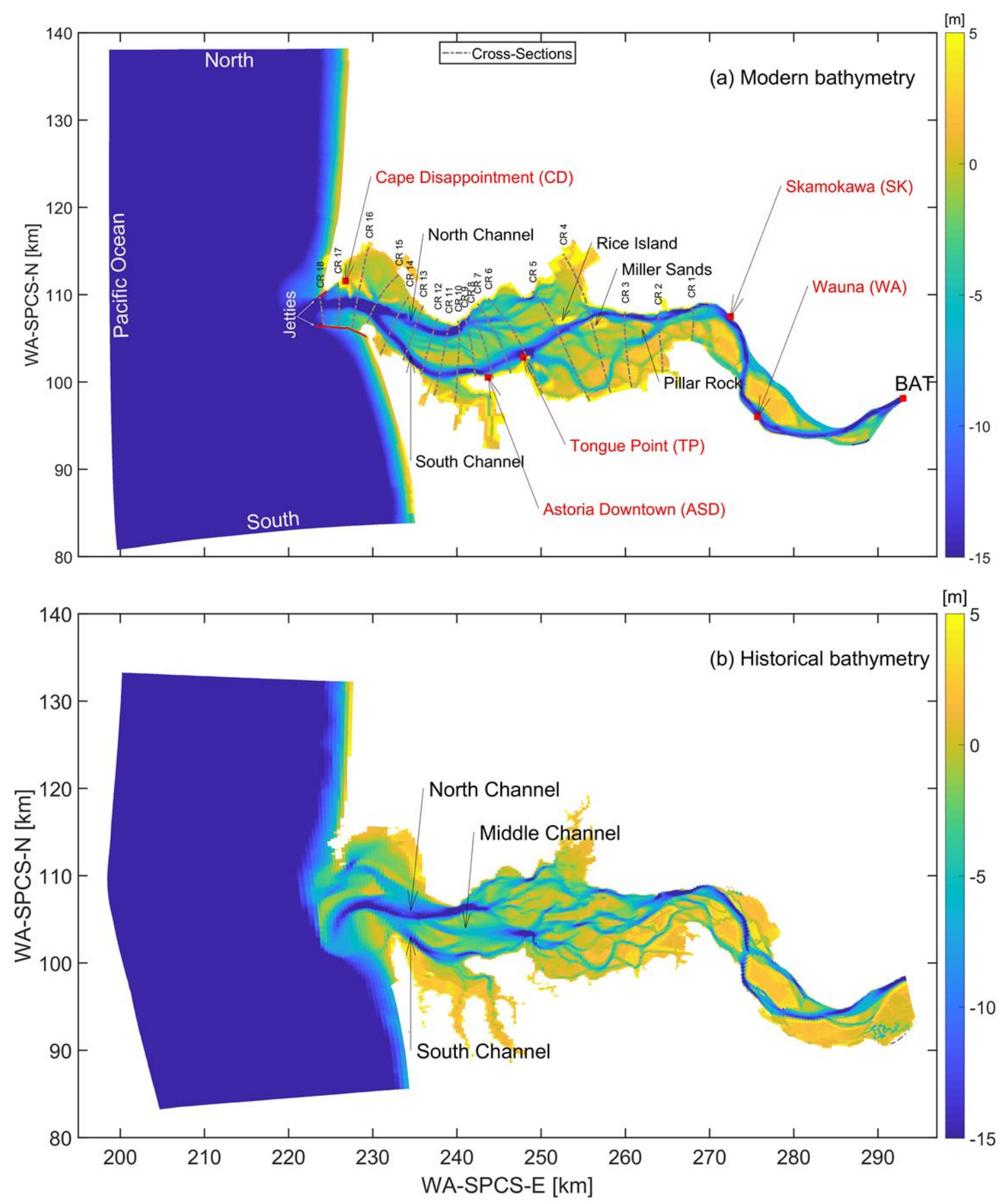

Figure 3-1. CR Bathymetrical change over the past 150-year: a) modern bathymetry (USACE, 2010); also shown are the grid boundaries, the calibration point locations (Cape Disappointment, Astoria Downtown, Tongue Point, Skamokawa, and Wauna), the North \& South Channels layout, and the cross-sections along the estuary. b-historical bathymetry (Burke, 2010). Note: coordinates are in Washington South-State Plane Coordinate System (WA-SPCS). 


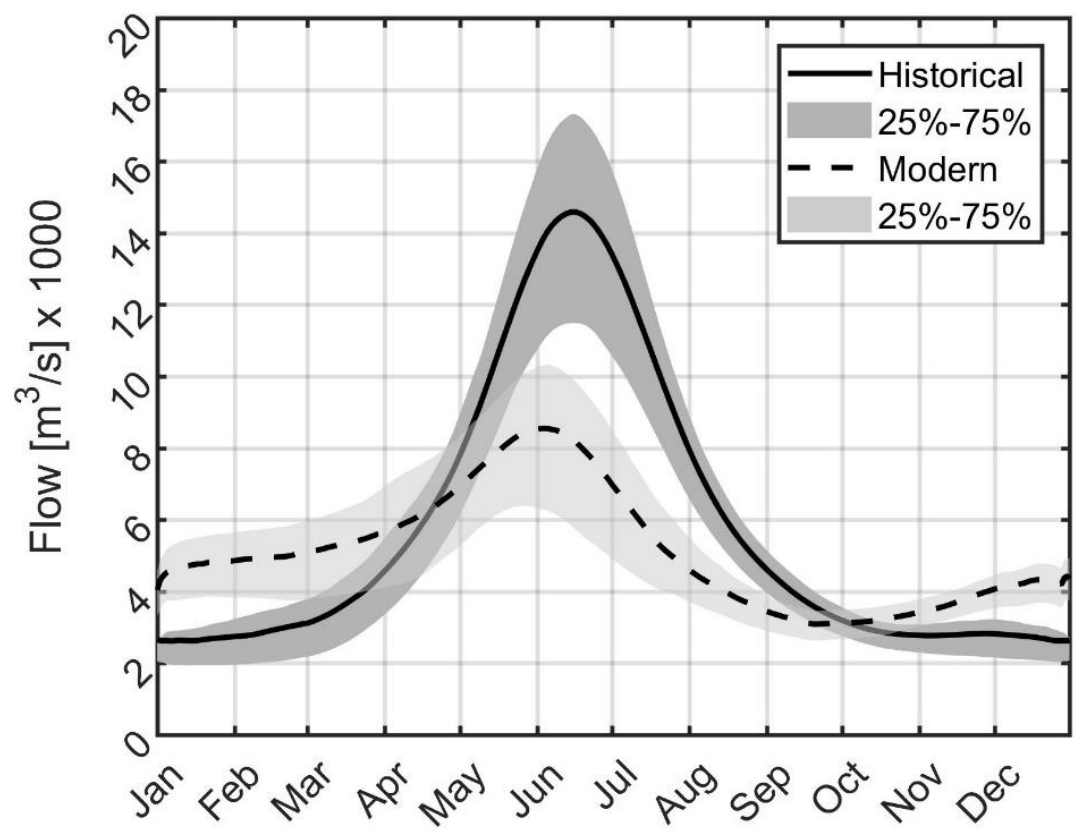

Figure 3-2. Changes in the CR discharge at The Dalles (30-day moving average). The solid black and the dashed black curves represent, respectively, the historical (1879-1929) and the modern (1967-2016) daily mean river discharge (50th percentile). The shadow curves for each period extend from the 25th to 75 th percentiles of river discharge.

\subsubsection{The boundary conditions}

I apply river discharge, tidal forcing, and meteorological forcing at the model boundaries because these are the major external forces that affect the circulation in the CRE (Baptista et al., 2004). 


\subsubsection{Meteorological forcing}

Wind is the most significant factor among the meteorological factors, and it varies spatially and temporally. Over the coastal ocean, a median wind speed of $6 \mathrm{~m} / \mathrm{s}$ with a range of 0.1-24m/s was measured 1984-2016 at the National Data Buoy Center (NDBC) station 46029 at the Columbia River bar. Wind conditions can be categorized into three periods, according to Chawla et al. (2008a): winter, spring, and summer-fall period. The winter period occurs from October to March and is characterized by a strong but variable wind that comes from the south and south-west, which leads to downwelling near the coast. The spring freshet season occurs from April to June and is considered a transition period from downwelling to upwelling wind. The last period is from July to November (summer-fall), where wind from the Northwest is dominant and leads to upwelling conditions. For the modern bathymetry model (MB), a climatological average of wind speed and direction from NDBC station 46029 were applied to the offshore area of the model, while data from the National Oceanic and Atmospheric Administration (NOAA) at Astoria, OR-station 9439040 was used inside the estuary. The same wind forcing was used for the historical bathymetry model (HB) because there are no accurate historical records and so the models could be compared under the same conditions.

\subsubsection{River boundary}

Hourly river flow records were used to force the riverside boundary. The modern hourly flow records (50 percentile of the 1967-2016 river flow) were obtained from USGS 14246900 site on the Columbia River at Port Westward near Quincy, OR, at the Beaver 
Army Terminal (BAT). The flow at BAT includes the Columbia River and its major tributaries, such as the Willamette, Lewis, Cowlitz, and Clatskanie rivers (USGS, 2016). This part of the river is also tidal so that the hourly data reflect tidal variability. The historical flow (1879-1929) is available as a daily record for the Columbia River (CR) at The Dalles (Naik \& Jay, 2005), and the Willamette River (WR) at Albany (Naik \& Jay, 2011). These daily records were used as rivers boundary conditions in a 2D hydrodynamic model (from Helaire et al., 2019). The Helaire et al. (2019) model extended from Bonneville Dam at CR and Oregon City at WR to $30 \mathrm{~km}$ offshore. I used the modeled hourly discharge from Helaire et al. (2019) at BAT as a boundary condition for my historical model. See Section 3.2.4 below for details of the historical simulations.

\subsubsection{Ocean boundary}

Eight major constituents $\left(\mathrm{Q}_{1}, \mathrm{P}_{1}, \mathrm{O}_{1}, \mathrm{~K}_{1}, \mathrm{~N}_{2}, \mathrm{M}_{2}, \mathrm{~S}_{2}\right.$, and $\left.\mathrm{K}_{2}\right)$ were used to force the astronomical water level from the ocean side for both bathymetry models. The amplitude and phase for each constituent were found using a tidal prediction software called the Tide Model Driver (TMD) (Egbert \& Erofeeva, 2002). At the north and south side boundaries, I used Neumann boundary conditions (water level gradient). The assumed mean sea-level is $+1.15 \mathrm{~m}$ (NAVD88, https://vdatum.noaa.gov/) and is kept constant for all simulations. The salinity and temperature boundary conditions for the model are described in section 4.2.4. 


\subsubsection{Model simulations:}

Two hydrodynamic model grids were used to represent the LCRE modern and historical bathymetric models (MB and HB). For calibration, the 2013 river discharge hydrograph was used with the MB; this run is known as MM0. HB was calibrated using the 1876 river hydrograph $(\mathrm{HH} 0)$. The daily river flow during the simulation period was not available, so an estimation from a similar hydrological year (1880) for high flow period and a 10-year hydrological average (1880-1890) for low flow periods were used. Three other model runs were used to investigate the long-term changes in tidal forcing; these were run with the $50^{\text {th }}$ percentile river shown in Figure 2 (modern $\&$ historical). The first run uses $\mathrm{MB}$ with a modern hydrograph (MM). The second run uses the $\mathrm{HB}$ and historical river hydrograph $(\mathrm{HH})$. A hypothetical case was also run using $\mathrm{MB}$ and the historical river discharge $(\mathrm{MH})$; this run was used to distinguish the effects of changes in river discharge variation vs. bathymetric changes. Each run covered a one-year period with tidally variable river discharge applied at BAT.

Furthermore, to investigate the effect of river discharge on channel bifurcations, 13 additional simulations were needed, denoted MB1-6 and HB1-7, adapted for constant river discharge. Six simulations were used to represent a range of constant river discharge (3000$15000 \mathrm{~m}^{3} / \mathrm{s}$ in increments of $2000 \mathrm{~m}^{3} / \mathrm{s}$,) for $\mathrm{MB}$ and modern river discharge. Seven simulations were used to cover the larger historical river flow range $\left(2000-18000 \mathrm{~m}^{3} / \mathrm{s}\right.$ in increments of $2000 \mathrm{~m}^{3} / \mathrm{s}$ ) with $\mathrm{HB}$. The bifurcation simulations were run for 1.5 months for each river discharge, see Table 3-1. The range of river discharge was selected to represent 
the area between the $25^{\text {th }}$ and $75^{\text {th }}$ percentiles of the modern and historical river discharge for each model.

Finally, eighteen cross-sections $(2.5 \mathrm{~km}$ apart $)$ were defined along the estuary transection (Figure 3-1-a) for the bifurcation investigation. These many cross-sections were selected to check the spatial variability of freshwater distribution among the channels. At each cross-section, the boundaries of the channels were then selected according to the cross-section bed topography, with three channels defined at each location, South Channel (SO), North Channel (NO), and Middle Channel (MI). The SO and NO channels are connected through the MI and many other braided channels, which allows water exchange between them. Therefore, an estimate of flow at a specific cross-section is unreasonable. To overcome this problem, a spatially averaged percentage was used for the area that covers both channels (cross-sections 10-14, see Figure 3-1a). The flow percentage was found through each channel at each cross-section, after which the mean of all cross-sections was considered (Table 3-2). A Godin filter (Godin, 1972) was used to estimate the mean flow from hourly simulation data at each cross-section. The Godin filter is a low-pass filter that applies a moving average over 24,24 , and 25 hours to remove the tidal signal. 
Table 3-1. The Hydrodynamic models

\begin{tabular}{cllll}
\hline Model & Bathymetry & $\begin{array}{l}\text { River discharge, } \\
\text { Q [m3/s] }\end{array}$ & Simulation Period & Purpose \\
\hline MM0 & Modern & Modern (2013 hydrograph) & 1 year & Calibration \\
HHO & Historical & Historical (1876 hydrograph) & 10 months & \\
\hline MM & Modern & Modern (50th percentile) & 1 year & Tidal \\
HH & Historical & Historical (50th percentile) & 1 year & change \\
MH & Modern & Historical (50th percentile) & 1 year & investigation \\
\hline MB & Modern & $3000,5000,7000,9000,12000$, & 1.5 months for each & $\begin{array}{l}\text { Flow bifurcation } \\
\text { investigation }\end{array}$ \\
& & and 15000 & Q & \\
HB & Historical & $2000,3000,5000,7000,9000$, & 1.5 month for each & \\
& & 12000,15000, and 18000 & Q & \\
\hline
\end{tabular}

Table 3-2. Example of total flow (rive + tide) percentage at each cross-section $(C R)$ of $M B$ during low river discharge and spring-flood tide. SO is the South Channel, NO is the North Channel, and MI is the Middle Channel.

\begin{tabular}{|c|c|c|c|}
\hline Cross-section & SO\% & MI\% & NO\% \\
\hline CR10 & 31 & 15 & 54 \\
\hline CR11 & 34 & 4 & 62 \\
\hline CR12 & 34 & 6 & 61 \\
\hline CR13 & 37 & 7 & 56 \\
\hline CR14 & 36 & 13 & 51 \\
\hline Mean & 34 & 9 & 57 \\
\hline
\end{tabular}

\subsection{Model calibration}

The modern model (MM0) was calibrated to water level measurements at Cape Disappointment (CD, NOAA station ID: 9440581), Astoria Downtown (ASD, a radar gauge with data spanning from October 2015 to the present (Talke et al., 2020)), Tongue Point (TP, NOAA station ID: 9439040), Skamokawa (SK, NOAA Station ID: 9440569), and Wauna (WA, Station ID: 9439099); see Figure 3-1a for locations. An example of the water level time series at TP showed a good agreement between the actual water levels and the modeled water levels during low river discharge (Figure 3-4a), with mean root square error (RMSE) of $0.11 \mathrm{~m}$ and 0.98 of the variance accounted for adjusted $\mathrm{R}^{2}$. On the other 
hand, the high river discharge simulation (Figure 3-4b) produced 0.15m RMSE and 0.97 adjusted $\mathrm{R}^{2}$. Additionally, the major tidal constituents $\left(\mathrm{M}_{2}, \mathrm{~S}_{2}, \mathrm{~K}_{1}\right.$, and $\left.\mathrm{O}_{1}\right)$ of the $\mathrm{MM}$ were calibrated at variable stations along the estuary. The percentage difference shows that the major constituent $\mathrm{M}_{2}$ has the best calibration values (0.5-3\%) among the other tidal components, while the worst are $\mathrm{O}_{1}$ and $\mathrm{K}_{1}$ with max percentage differences ( 34 \& 25\%, respectively) at Wauna (Table 3-3).

The historical model (HH0) was calibrated (for 1876) using historical water level data that are available from Astoria (ASD) from 1853-1876 (Talke et al., 2020). Due to the unavailability of discharge measurements for 1876, I approximated the 1876 hydrograph by using measured 1880 discharge. The 1880 hydrograph is known to be quite similar to the 1876 hydrograph, with a peak that was only $0.9 \mathrm{~m}$ lower in Portland and occurred $\sim 1$ week later. More recently, Talke et al. (2020) have produced discharge estimates for 1876, which I compare to our boundary condition in Figure 3-3. Because the method used by Talke et al. (2020) is effectively a 30d average, the peak is likely somewhat attenuated and seems to occur somewhat earlier than the measured peak in water level. Still, the estimated flow for 1876 from July-September is close to the 1880 hydrograph. Therefore, for our model calibration, I compared statistics from this time period. 


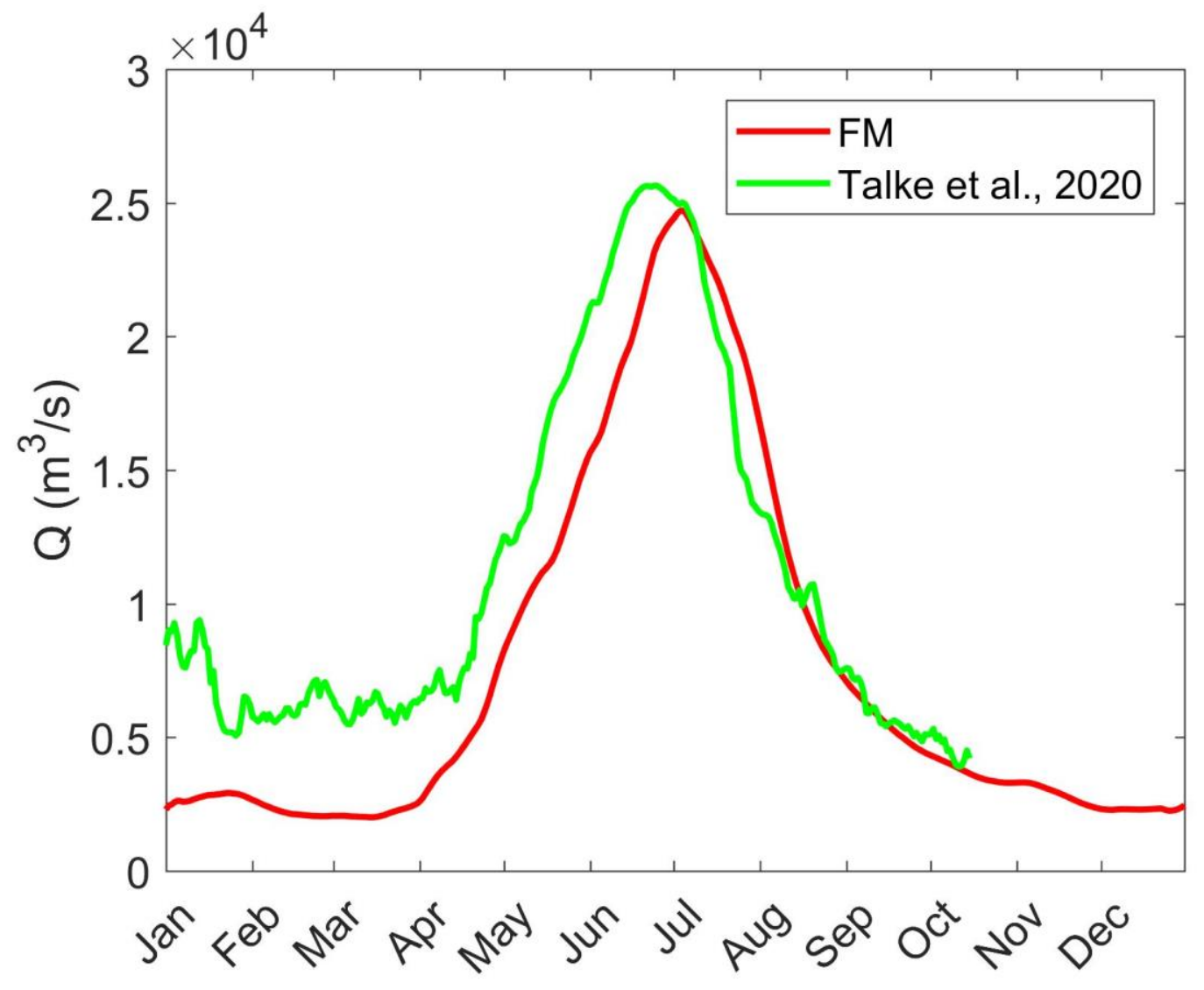

Figure 3-3. CR 1876-hydrograph at the Beaver Army Terminal (BAT). The FM hydrograph used in modeling is derived from the 1880 hydrograph. The green curve is the estimate of river discharge in 1876 at BAT by Talke et al. (2020).

The calibration at Astoria downtown $(\mathrm{R} k m 20)$ produced $0.13 \mathrm{~m}$ of RMSE and $\mathrm{R}^{2}$ $=0.97$ during low flow conditions (Figure 3-4c) and 0.15m RMSE and $\mathrm{R}^{2}=0.96$ during high river discharge (Figure 3-4d). Additionally, the model was calibrated at Cathlamet (RKM59) using records from the fall of 1877 , a low flow period $\left(0.13 \mathrm{~m}, \mathrm{RMSE}\right.$, and $\mathrm{R}^{2}=$ 0.97\%). These records are described in Helaire et al. (2019). 
All simulations in both models were tested using a skill assessment (SK) that measures agreement between models and observed data (Willmott, 1981), and the NashSutcliffe (NS) number, an indicator of how well the modeled vs simulated data fits a 1:1 line (Nash \& Sutcliffe, 1970). The minimum values of SK and NS were found to be 0.97 and 0.99 for the modern model and 0.94 and 0.98 for the historical model, respectively. Note that a value of one for these coefficients means a perfect agreement between the model and the actual data, while zero indicates no agreement at all.
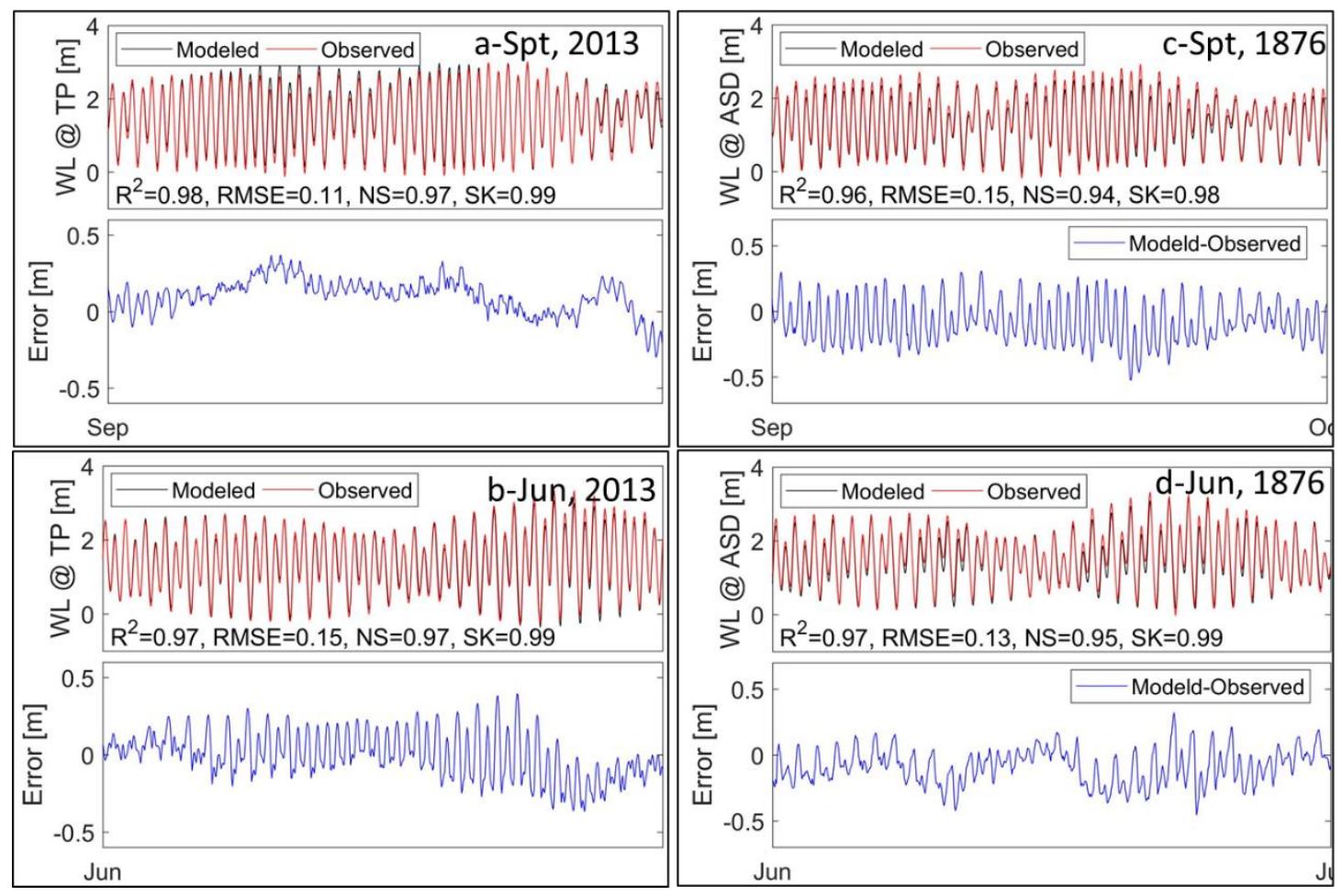

Figure 3-4. Modern Bathymetrical Model (MMO) calibration at Tongue Point (TP) during low river discharge (a) and high river discharge (b). Historical Bathymetrical Model (HHO) at Astoria downtown $(A S D)$ during low river discharge (c) and high discharge (d); the blue plot is the error for each case (modeled-observed). 
Table 3-3. Major Constituent comparison of the MMO model in 2013 at different locations: Cape Disappointment (CD), Astoria Downtown (ASD), Tongue Point (TP), and Wauna (W).

\begin{tabular}{|c|l|c|c|c|c|}
\hline Location & \multicolumn{1}{|c|}{ Constituents } & $\mathbf{O}_{\mathbf{1}}$ & $\mathbf{K}_{\mathbf{1}}$ & $\mathbf{S}_{\mathbf{2}}$ & $\mathbf{M}_{\mathbf{2}}$ \\
\hline \multirow{4}{*}{ CD } & Simulated $[\mathrm{m}]$ & 0.260 & 0.465 & 0.243 & 0.865 \\
\cline { 2 - 6 } & Actual $[\mathrm{m}]$ & 0.263 & 0.413 & 0.238 & 0.859 \\
\cline { 2 - 6 } & \% difference & $\mathbf{1}$ & $\mathbf{1 2}$ & $\mathbf{2}$ & $\mathbf{0 . 7}$ \\
\hline \multirow{4}{*}{ ASD } & Simulated $[\mathrm{m}]$ & 0.262 & 0.456 & 0.248 & 0.918 \\
\cline { 2 - 6 } & Actual $[\mathrm{m}]$ & 0.243 & 0.394 & 0.237 & 0.942 \\
\cline { 2 - 6 } & \% difference & $\mathbf{7}$ & $\mathbf{1 5}$ & $\mathbf{4}$ & $\mathbf{2 . 5}$ \\
\hline \multirow{3}{*}{ TP } & Simulated $[\mathrm{m}]$ & 0.264 & 0.458 & 0.253 & 0.939 \\
\cline { 2 - 6 } & Actual $[\mathrm{m}]$ & 0.244 & 0.400 & 0.240 & 0.970 \\
\cline { 2 - 6 } & \% difference & $\mathbf{8}$ & $\mathbf{1 4}$ & $\mathbf{5}$ & $\mathbf{3}$ \\
\hline \multirow{3}{*}{ SK } & Simulated $[\mathrm{m}]$ & 0.237 & 0.399 & 0.206 & 0.834 \\
\cline { 2 - 6 } & Actual $[\mathrm{m}]$ & 0.183 & 0.321 & 0.200 & 0.838 \\
\cline { 2 - 6 } & \% difference & $\mathbf{2 5}$ & $\mathbf{2 2}$ & $\mathbf{3}$ & $\mathbf{0 . 5}$ \\
\hline \multirow{3}{*}{ WA } & Simulated $[\mathrm{m}]$ & 0.229 & 0.381 & 0.196 & 0.793 \\
\cline { 2 - 6 } & Actual $[\mathrm{m}]$ & 0.163 & 0.294 & 0.182 & 0.800 \\
\cline { 2 - 6 } & \% difference & $\mathbf{3 4}$ & $\mathbf{2 6}$ & $\mathbf{7}$ & $\mathbf{0 . 9}$ \\
\hline
\end{tabular}

The source of errors in Figure 3-4 for both models probably include: a) using a uniform wind distribution over the estuary and the coastal area, b) not including seasonal variations in elevation in the ocean boundary condition, and c) using an approximate flow for the historical model. To understand the importance of these factors, I compared the monthly averaged water level for both models (Figure 3-5). The modern model monthly averaged water level at Tongue Point (Figure 3-5a) shows a good agreement between the simulated and the observed water level with an RMSE of $0.04 \mathrm{~m}$. The comparison of the simulated water level to in-situ data (green dashed line in Figure 3-5a) show that the MM model captured the coastal upwelling/downwelling well in all months except in September. The mismatch in September produced the most significant error in the monthly averaged data, about $0.12 \mathrm{~m}$ error between modeled and observed (Figure 3-5b). These errors could 
be the result of using uniform wind speed and direction over the entire model area, or because of neglect of offshore wind effects on the ocean boundary condition.

The monthly averaged water level in the historical model produced a 0.08 m RMSE compared to ASD measurements and showed a good agreement during high river flow (Figure 3-5c). The largest percentage of error occurred during low flow conditions. This likely occurs because: a) the flow data are from a different year than the tidal data, b) the wind forcing used in the historical model did not represent the upwelling/downwelling accurately enough, c) the effects of El Nino-Southern Oscillations conditions are not accounted for in the ocean boundary, and/or d) ocean tides may have changed over the last century (Jay, 2009).
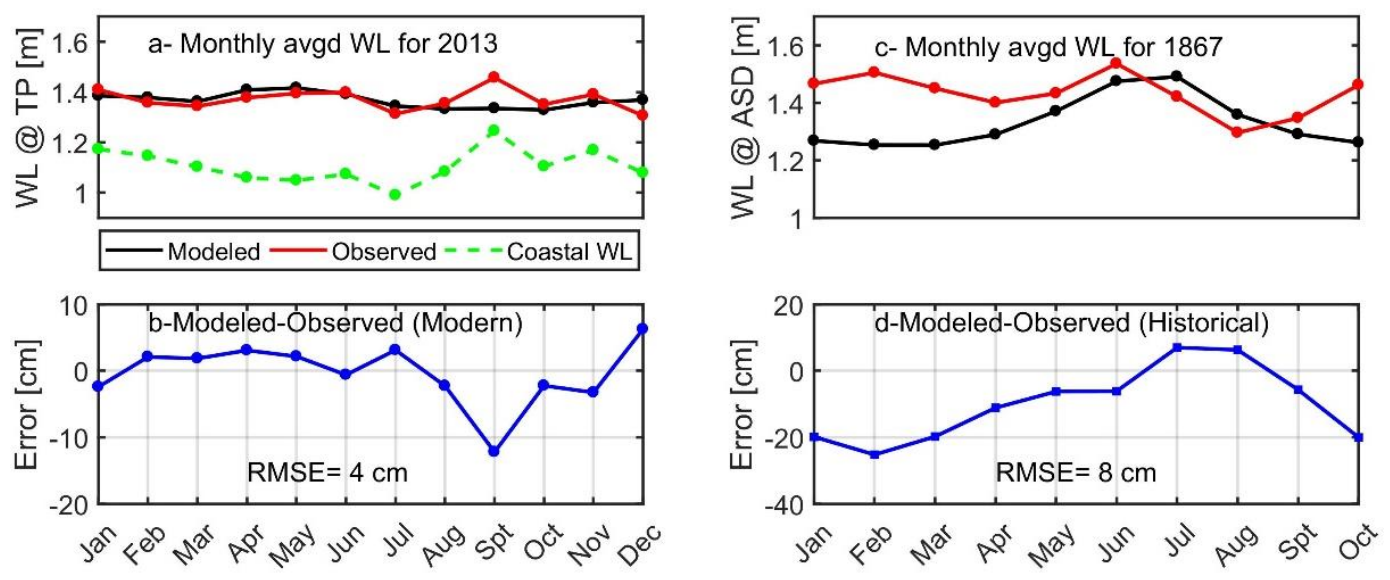

Figure 3-5. Monthly averaged WL for the MMO calibration (2013, $a \& b)$, and HHO (1876, $c \& d)$ 


\subsection{Results}

Measurements in 1968 found that $76 \%$ and $69 \%$ of the total flow passes through the North Channel during flood and ebb, respectively (black dashed lines in Figure 3-6, Lutz et al., 1975). Our results suggest that the bifurcation of river discharge and tidal flow between the North and South Channels has since remained relatively stable, despite the deepening of the estuary entrance ca 1984 (from 14.6m in 1956 to $16.8 \mathrm{~m}$ in 1984, according to Corps of Engineers, 1989); no more recent measurements are available. Specifically, my analyses show that $66 \%$ of total flow goes into the North Channel during flood-spring and $71 \%$ during flood-neap tides (filled black dots, Figure 3-6); the corresponding values are $64 \%$ during ebb-spring and 70\% during ebb-neap (hollow black dots, Figure 3-6). The dashed lines in Figure 3-6 represent the average percentage of total flow passing through the North Channel (dashed-black) and the South Channel (dashed-red). The bars in Figure 3-6 are the percentage of the total flow in the channels at different river discharges from Lutz et al., 1975. The solid and hollow black circles represent the percentage of flow in the North Channel during spring and neap tides, respectively, while the red ones are for the South Channel.

The small differences between the 1975 result and mine could be due to several reasons, such as morphological and hydrological changes in the last 45 years, changes in the tides over the previous 50 years, or differences in the calculation methodology and experimental error. Also, I am using a constant river discharge, which does not happen in practice. Considering these differences, the agreement is quite good. 


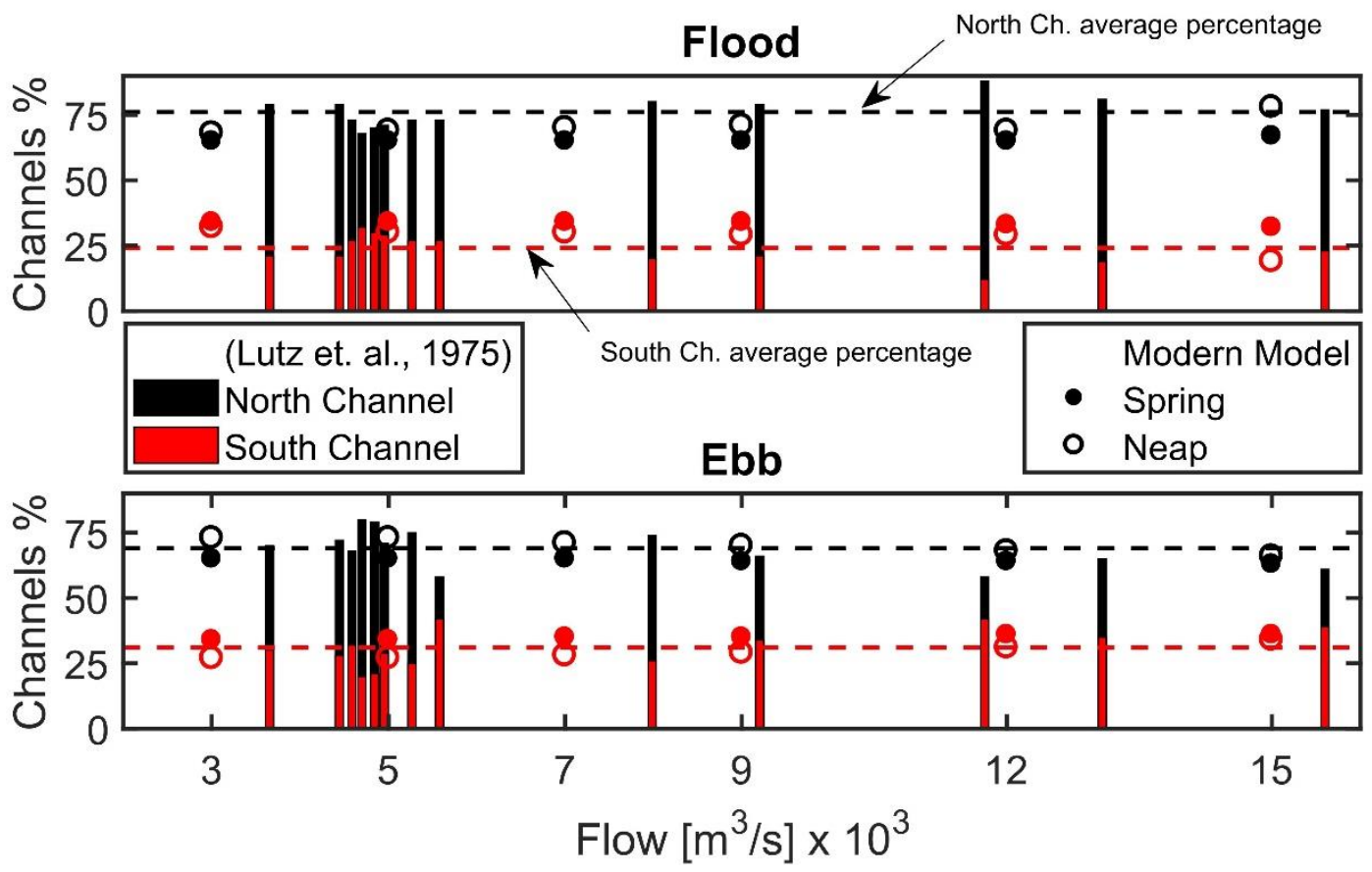

Figure 3-6. Total flow percentage in the North and South Channels. The Lutz et al. (1975) data is represented in black bars to show the portion of the flow in the North Channel at each flow rate and the red bars for the South Channel percentage (dashed lines are the average percentage at each channel). The circles represent data from our analysis using the modern bathymetry model (MB).

\subsubsection{Tide changes}

Tidal constituents have changed in magnitude and phase due to system alterations such as channel deepening, mouth narrowing, and river discharge modification (Figure 3-7a \& b). The modern model (MM) is compared to the historical model (HH). Simulation MM includes modern bathymetry (2008-2010) and the mean of modern river discharge (1967-2016). The HH simulation uses historical bathymetry (1868-1901) and the mean of historical river discharge (1879-1929). 
Results show an increase in the $\mathrm{M}_{2}$ tidal constituent of $\sim 12.5 \%$ at Astoria Downtown (ASD). Thus, the historical (HH) $\mathrm{M}_{2}$ amplitude is modeled to be $0.88 \mathrm{~m}$ while the modern $(\mathrm{MM})$ one is $\sim 0.99 \mathrm{~m}$, an increase of $0.11 \mathrm{~m}$ of $\mathrm{M}_{2}$ at ASD (Figure 3-7c). This increase of tidal amplitude is a result of both bathymetric and river discharge changes in the past 150 years. Note that the difference is less in the actual data. Talke et al. (2020) show that the change is from $0.88 \mathrm{~m}$ to $0.95 \mathrm{~m}$; hence, the modern model appears to be overpredicted. The reason could be using an average of river discharge for the period of 19672016, which is lower than the actual flow during the calibration year (2013).

When historical river flow is applied to modern bathymetry (case $\mathrm{MH}$, the $\mathrm{M}_{2}$ change is reduced to $0.1 \mathrm{~m}$. Hence, approximately $0.01 \mathrm{~m}$ of the modeled change in $\mathrm{M}_{2}$ is due to altered river flow, or roughly $10 \%$. Using empirical data and tidally-based estimates of river flow, Talke et al. (2020) also estimated that approximately $10 \%$ of the changed constituent values were due to river discharge. The effect of channel deepening is also observed in the phase speed of the tide, which arrives earlier at Tongue Point and upstream locations today, compared to historical conditions (Figure 3-7d). Another difference is a shift in the location of maximum $\mathrm{M}_{2}$ inside the estuary. In the $\mathrm{HH}$ model, the maximum $\mathrm{M}_{2}$ was near Rkm 20, while in the MM simulation, it is $8 \mathrm{~km}$ landward, near Rkm 28. 

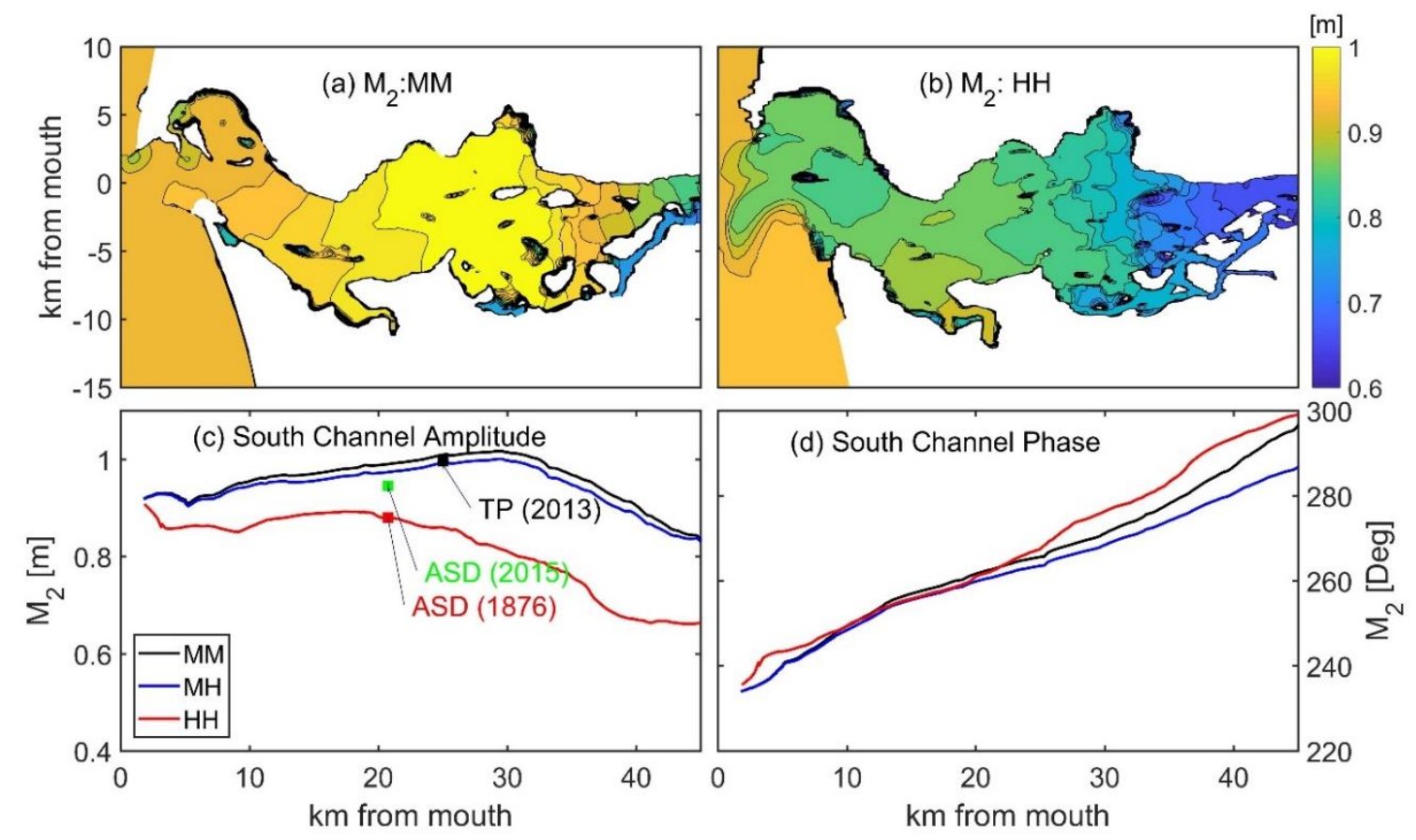

Figure 3-7. $M_{2}$ Maps: a-modern bathymetry model, b-historical bathymetry model, $c$ - $M_{2}$ amplitude in the South Channel for MM (modern bathymetry/modern river flow), HH (historical bathymetry/historical river flow, and MH (modern bathymetry/historical river flow) models, the actual values represented by squares at Tongue Point (TP) at 2013 and Downtown Astoria (ASD) in 2015 and 1876, and d-M2 phases at South Channel.

\subsubsection{Modern model bifurcation}

The bifurcation analyses show that the flow percentage going through the North and South Channels in the modern model (MM) is spatially variable along the longitudinal axis of the estuary. This occurs due to exchange between the North and South Channels via the small braided channels that connect them. The tidally averaged river discharge percentages (Figure 3-8) were carried out for low (LO: $3,000 \mathrm{~m}^{3} / \mathrm{s}$ ) and high (HI: $15,000 \mathrm{~m}^{3} / \mathrm{s}$ ) river discharge. The river discharge at each case was constant during a 1.5 - 
month simulation period. The percentage was then averaged at each channel location for two tidal days (for stability) using a Godin filter around the highest water level (spring) and lowest water level (neap) during a month of simulation.

The river discharge percentage is represented in dotted colors in Figure 3-8. The red dots represent the percentage of river discharge in the South Channel, the blue dots show the percentage in the North Channels, magenta coloring shows the percentage of river discharge circulated around tidal marshes, and green dots depict the water circulated between the South and North Channel. The dot size represents the percentage of river discharge at each location relative to the total discharge leaving the mouth (100\%).
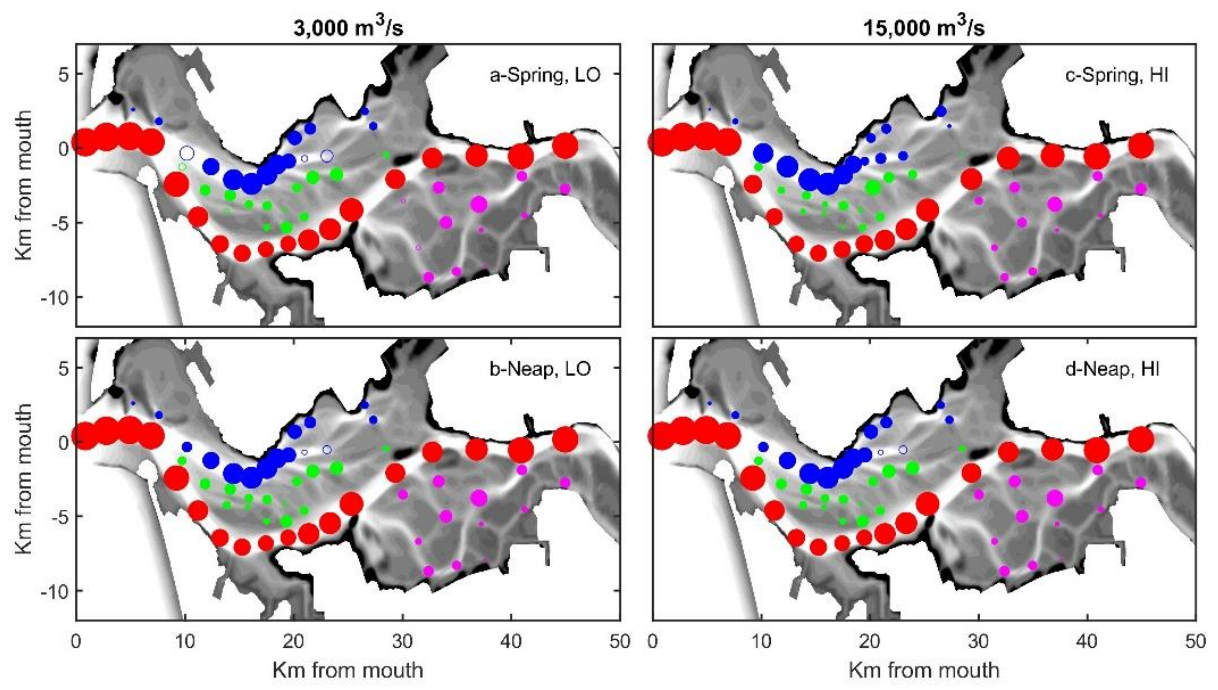

Figure 3-8. Modern-model river discharge distribution for low (LO)/ high (HI) river discharge and spring/neap scenarios (two days mean around the highest water level (spring) and lowest water level (neap)). The red dots represent the percentage of river discharge along the South Channel (SO), blue represent the North Channel (NO), and green the Middle channels (MI). 
In order to quantify the tidally averaged river discharge in each channel, a spatially averaged percentage that covers the area between cross-sections 10-15 is used. These crosssections cover the domain of the three channels, SO, MI, \& NO, between the junction near the mouth and the upstream boundary of the North Channel (Figure 3-1a). This analysis shows that during spring tides the South Channel takes a larger percentage of the river discharge than the North Channel, except when river discharge is greater than $12,000 \mathrm{~m}^{3} / \mathrm{s}$ (Table 3-4).

The dependence of partition with the spring-neap cycle likely occurs because most of the tidal exchange occurs in the North Channel ( $\sim 56 \%$, NO vs. $\sim 34 \%$ SO, and the rest in the MI). Therefore, high tidal energy in spring tides might hinder the river flow in the North Channel and push it toward the South Channel. Increasing the tidal energy during spring tides results in a larger effective friction. A similar result was found in Buschman et al. (2010) on a river delta in Indonesia. During the neap tides, the North Channel takes a larger percentage of the river discharge (Table 3-4).

Table 3-4. River discharge percentage of the modern model for different river discharges averaged over two days during high (spring) and low (neap) tides periods, were SO is South Channel, NO is the North Channel, and MI is the Middle Channel.

\begin{tabular}{|c|c|c|c|c|c|c|c|c|c|c|}
\hline $\mathrm{Q}\left[\mathrm{m}^{3} / \mathrm{s}\right]$ & \multirow{7}{*}{ 品 } & $\begin{array}{l}\text { SO } \\
{[\%]}\end{array}$ & $\begin{array}{l}\text { NO } \\
{[\%]}\end{array}$ & $\begin{array}{l}\text { MI } \\
{[\%]}\end{array}$ & $\Psi$ & \multirow{7}{*}{ そิ } & $\begin{array}{c}\text { SO } \\
{[\%]}\end{array}$ & $\begin{array}{l}\text { NO } \\
{[\%]}\end{array}$ & $\begin{array}{c}\text { MI } \\
{[\%]}\end{array}$ & $\Psi$ \\
\hline 3,000 & & 80 & 21 & -1 & 0.58 & & 44 & 48 & 9 & -0.03 \\
\hline 5,000 & & 62 & 36 & 3 & 0.26 & & 40 & 54 & 7 & -0.14 \\
\hline 7,000 & & 56 & 40 & 4 & 0.17 & & 38 & 56 & 6 & -0.18 \\
\hline 9,000 & & 53 & 42 & 5 & 0.11 & & 38 & 57 & 6 & -0.20 \\
\hline 12,000 & & 49 & 46 & 5 & 0.03 & & 36 & 59 & 6 & -0.24 \\
\hline 15,000 & & 46 & 49 & 6 & -0.03 & & 36 & 59 & 5 & -0.23 \\
\hline
\end{tabular}

The river discharge percentage in each channel varies nonlinearly with river discharge.

The percentage in the South Channel decreases as river flow increases, with more going 
to the North Channel (Table 3-4). I found the same pattern when using the asymmetry index ( $\Psi$, Equation 2.31) proposed by Buschman et al. (2010), see Figure 3-9. This figure shows that the larger percentage of river discharge is being routed through the South Channel during spring tides (positive $\Psi$ ). In contrast, during the neap tide, the large percentage is passing through the North Channel (negative $\Psi$ ).

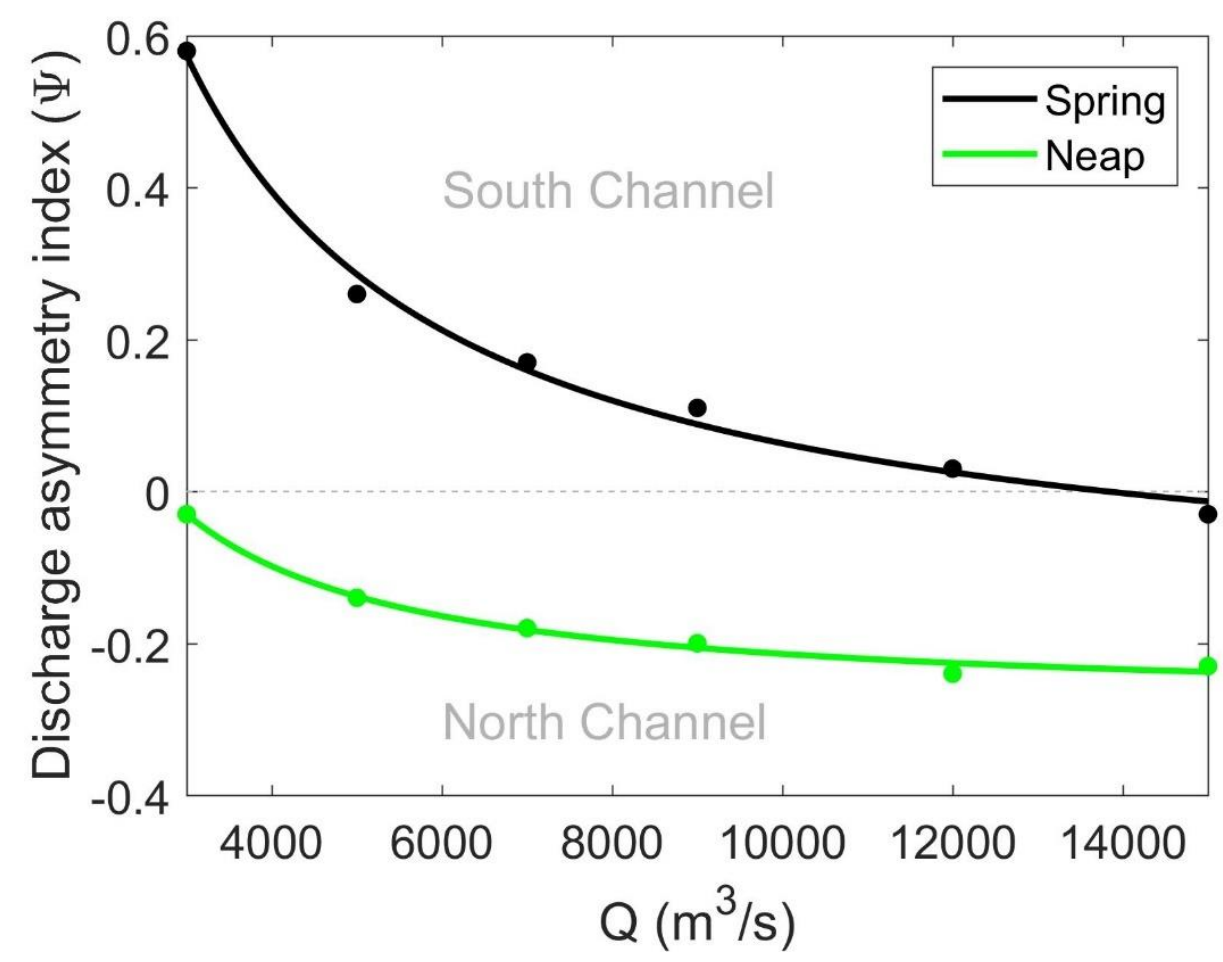

Figure 3-9. Variation of discharge asymmetry index with river discharge

The pattern of river discharge under modern bathymetric conditions can be explained in terms of water surface slope in the channels (Figure 3-10). Because water levels in the Tongue-Point to Millar Sands Reach are a function of river flow, the slope 
between North and South Channel increases as discharge increases from 3000 to $15000 \mathrm{~m}^{3} / \mathrm{s}$ (Figure 3-10). The water surface slope of the North Channel through the Middle Channels $\left(4.1 \times 10^{-6}\right.$ to $\left.1.5 \times 10^{-5} \mathrm{~m} / \mathrm{m}\right)$ is larger than the slope in the South Channel $\left(3.3 \times 10^{-6}\right.$ to $\left.1.1 \times 10^{-5} \mathrm{~m} / \mathrm{m}\right)$. This large slope produces tidally-averaged flow towards the North Channel. Therefore, a significant amount of river discharge is diverted towards the North Channel, despite the shallower and more frictional mid-channel geometry.

The mismatch between North and South Channel water levels is driven by several factors. First, the distance between point 1 and points $2-5$ is much longer $(\sim 750 \mathrm{~m}, 1950 \mathrm{~m}$, 3250m, and 3250m, respectively) along the South Channel than the North Channel. Since the total water level drop between the point where they split (point 1) and the point that they meet up again (point 5) is the same, this leads to an inherent asymmetry in slopes. Secondly, the lower flow within the North Channel between point 1 and point 5, compared to the South Channel, requires a relatively small slope to drive flow downstream. Since this slope is small, the slope between points $2-5$ must be large. The overall result is that a larger percentage of river flow is routed through the Middle Channel during periods of high discharge vs. low flow conditions (Table 3-4). 

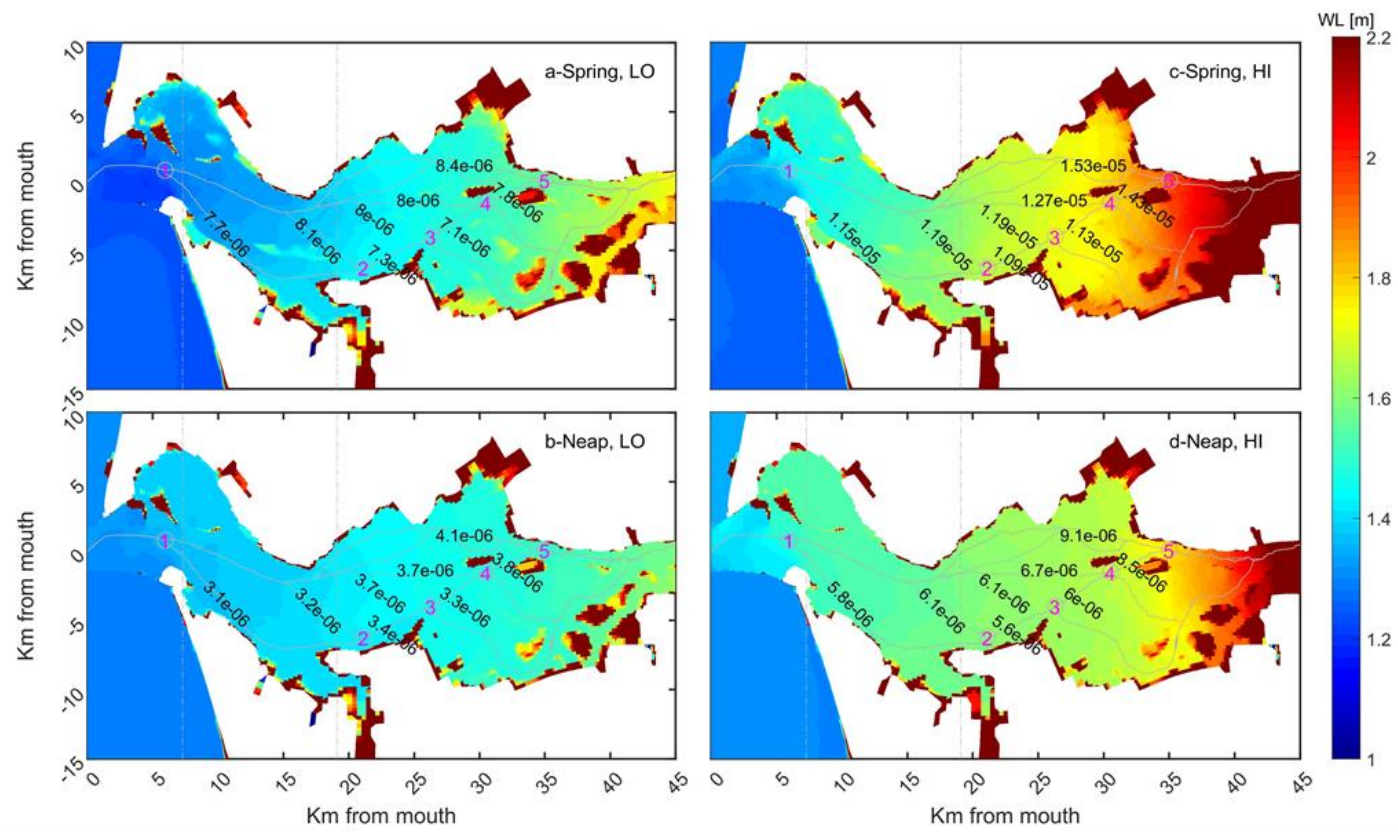

Figure 3-10. Tidally averaged surface slope $(\mathrm{m} / \mathrm{m})$ of each point on each junction and point 1 (where the two channels meet). The color plots represent the spatial water level map e- mean water level comparison between the South and North Channels (dashed lines are the water level in the North Channel), max difference in water levels between North and South Channel between the North Channel boundaries (SouthNorth) are a-4.7, b-1.7, $c-5.3$, and $d-2.1 \mathrm{~cm}$.

\subsubsection{Historical bifurcation}

Results from the HH Model show that the river discharge partition was reversed compared to the modern situation. The spatially averaged percentage for the cross-sections that cover the three channels (South, North, and Middle) show that the North Channel always takes a larger percentage of river discharge than the South Channel (Table 3-5). One reason for this result is that the Middle Channels in the historical model conveys more discharge toward the north than in the modern configuration, due to their larger crosssectional area. Also, the South Channel is deeper in the modern model (MM) due to continuous dredging. Another reason is the use of pile dikes and construction of dredged 
material islands such as Rice Island and Miller Sands (Rkm40, Figure 3-1-a), which help to direct more river discharge to the South Channel.

Table 3-5. River discharge percentage of the historical model for different river discharges averaged over two days during high (spring) and low (neap) tides periods, were SO is South Channel, NO is the North Channel, and MI is the Middle Channel.

\begin{tabular}{|c|c|c|c|c|c|c|c|c|}
\hline $\mathbf{Q}\left[\mathrm{m}^{3} / \mathrm{s}\right]$ & \multirow{8}{*}{ 哭 } & $\begin{array}{c}\text { SO } \\
{[\%]}\end{array}$ & $\begin{array}{l}\text { NO } \\
{[\%]}\end{array}$ & $\begin{array}{c}\text { MI } \\
{[\%]}\end{array}$ & \multirow{8}{*}{$\underset{\mathbb{Z}}{\stackrel{\mathscr{Z}}{Z}}$} & $\begin{array}{c}\text { SO } \\
{[\%]}\end{array}$ & $\begin{array}{l}\text { NO } \\
{[\%]}\end{array}$ & $\begin{array}{c}\text { MI } \\
{[\%]}\end{array}$ \\
\hline 2,000 & & 22 & 55 & 22 & & 17 & 55 & 28 \\
\hline 3,000 & & 24 & 58 & 28 & & 20 & 58 & 22 \\
\hline 6,000 & & 25 & 61 & 14 & & 24 & 60 & 16 \\
\hline 9,000 & & 25 & 62 & 13 & & 25 & 60 & 15 \\
\hline 12,000 & & 25 & 61 & 13 & & 25 & 61 & 14 \\
\hline 15,000 & & 25 & 62 & 13 & & 24 & 62 & 14 \\
\hline 18,000 & & 25 & 62 & 14 & & 24 & 62 & 14 \\
\hline
\end{tabular}

The river discharge distribution is illustrated in Figure 3-11 for the historical model. Upstream of Tongue Point, the South Channel feature is not a straight, dredged channel, as at present; instead, there are several braided channels. Downstream of Tongue Point, there are two main channels: The South and the Middle Channel. The Middle Channel conveys more water than the South Channel, probably because it has a larger cross-section area than the South Channel (Figure 3-11). 

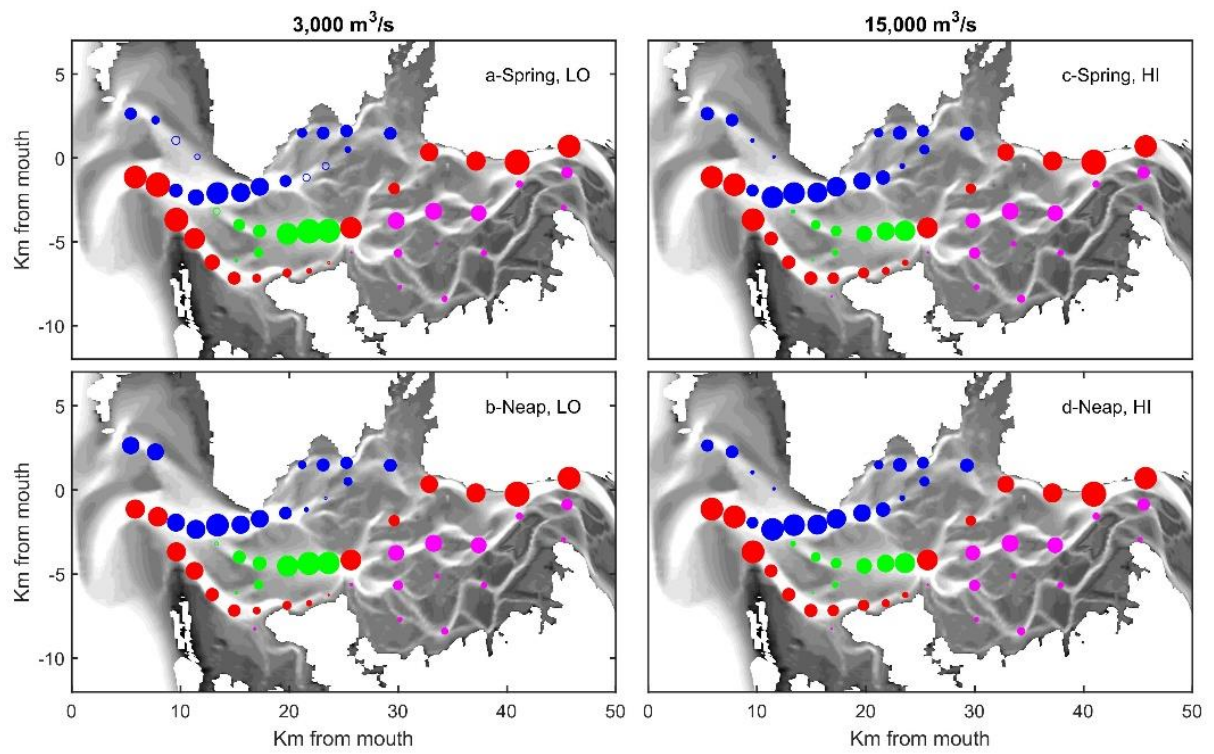

Figure 3-11. Historical-model river discharge distribution. The red dots represent the percentage of river discharge in the South Channel, and the blue is the percentage in the North Channels, the green is the percentage in the Middle Channel, the magenta is the percentage in the braided channels in Cathlamet Bay area that eventually meet in one location close to about $25 \mathrm{~km}$ from the mouth (just upstream Tongue Point, Point2 in Figure 3-12

I investigated why the Middle channel takes a larger percentage of river discharge than the South Channel by estimating the ratios of the river flow in the two channels and the other parameters of Manning's equation (friction, water surface slope, hydraulic radius, and cross-section area). The surface slope was found to be almost the same for all channels between point 2 at Tongue Point and point 1, where the South and North Channels meet near the mouth. This is because the distance between these two points along the channels between them is the same (Figure 3-12). Since the slopes are equal, there must be other factors that drive the higher percentage of flow through the Middle channel compared to the South Channel downstream of Tongue Point. Therefore, using the simulation data, I 
compared the ratio of river discharge of the two main channels $\left(R_{Q}\right)$ to the ratio of the other parameters' ratios in Manning's equation (cf. (3.1) to (3.4) above). I found that $\mathrm{n}, \mathrm{S}$, and $\mathrm{P}$ have little or no effect on river discharge distribution between the South and Middle Channels (their ratios are equal to $\sim 1$, Figure 3-13e, f, and g, respectively). On the other hand, $\mathrm{R}_{\mathrm{h}}, \mathrm{A}$, and $\mathrm{H}$ have the most effect on freshwater distribution such that the hydraulic radius and the cross-sectional area of the Middle channel are both about five times bigger than the South Channel (Figure 3-13b \& c). In contrast, the Middle Channel water depth is double than the South Channel water depth (Figure 3-13d). Therefore, the Middle Channel conveys more water than the South Channel due to its larger cross-section.
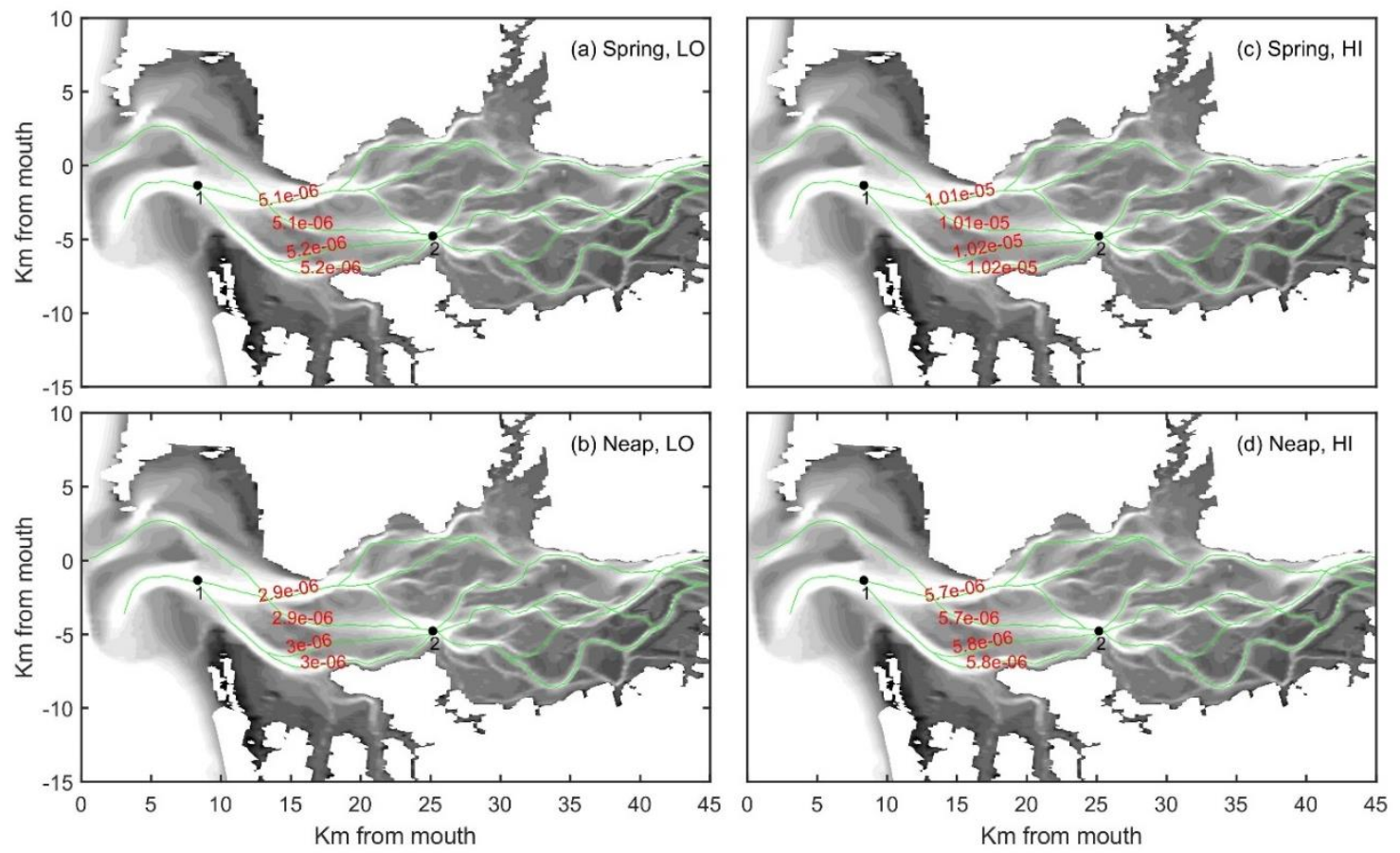

Figure 3-12. tidally averaged slopes of the South, North and the Middle Channels in the historical model 

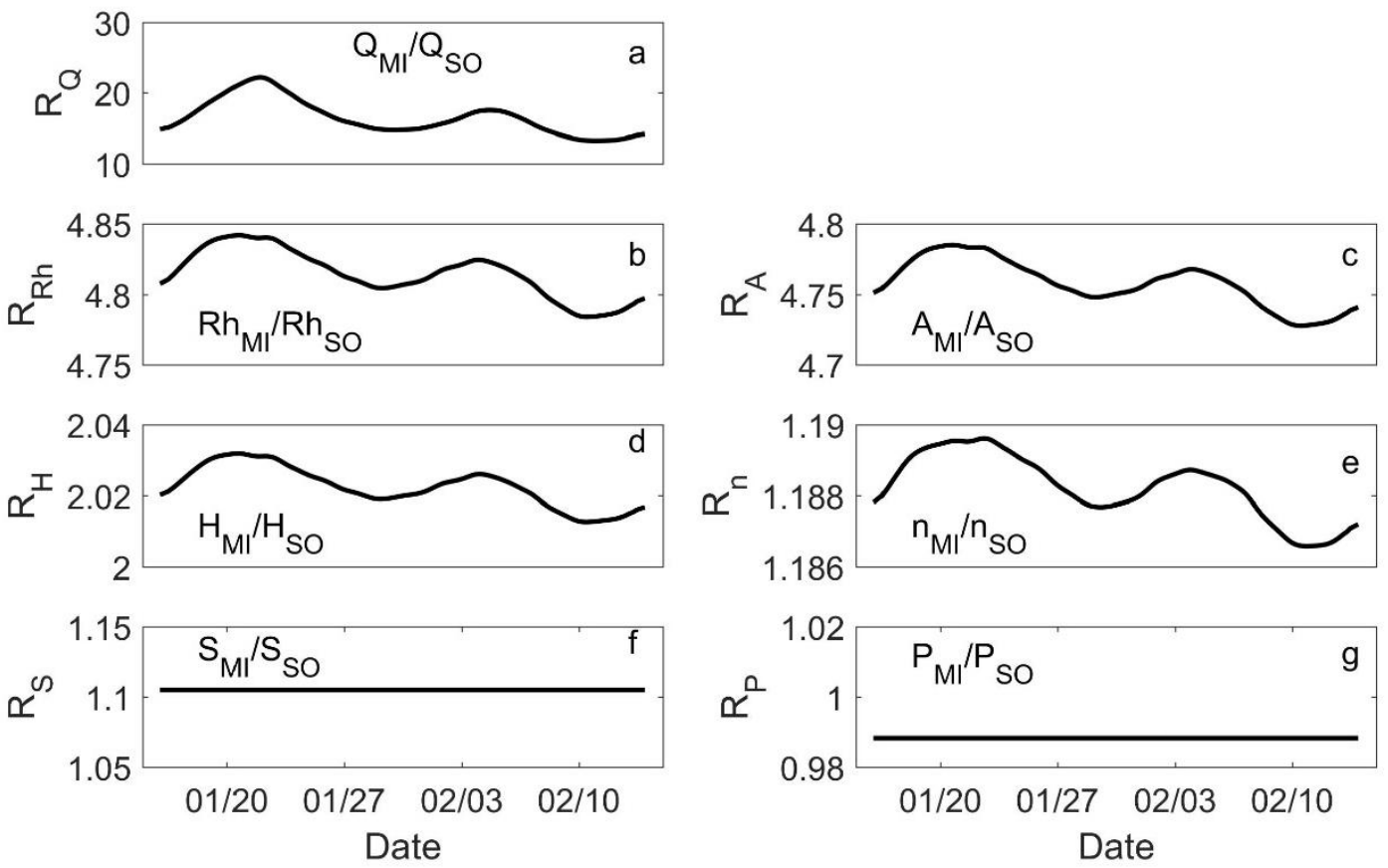

Figure 3-13. Effect of Manning equation parameters on flow distribution between the Middle channel (MI) and the South Channel (SO) near Tongue Point. RQ is the ratio of river discharge of Middle to the South Channel, $(Q$ is river discharge, $R$ h is the hydraulic radius, $A$ is the cross-sectional area, $H$ is the mean water depth, $n$ is bed friction coefficient, $S$ is the surface slope, and $P$ is the wetted parameter).

The flow bifurcation analyses show that the river discharge-tidal forcing interaction and the morphological differences between the modern and historical cases alter the flow distribution. In the modern model (MB), the percentage of freshwater discharge is found to have a negative relation to the river discharge. Hence, the percentage of freshwater flow in the South Channel decreases as the river discharge increases (Figure 3-14a). This occurs because the slope in the MB is a function of river discharge (positively correlated) and the slope in the North Channel is higher than the South Channel, see Figure 3-14c (i.e., the percentage of the South Channel decreases with higher river discharge, Table 3-4). 
However, the neap tide can reduce the availability of freshwater to the South Channel, especially in low river discharge (Figure 1-a), because the water surface slope is lower in neap than in spring tide (Figure 3-14c). In the historical model (HB), since the slope of the south, middle, and North Channel are nearly equal, the most effective parameter in the discharge distribution between the channels is the cross-sectional area. Therefore, the percentage of freshwater in the South Channel is positively correlated to river discharge (Figure 3-14b) with the tendency of neap tides to reduce the South Channel share--the same as in the MB. 


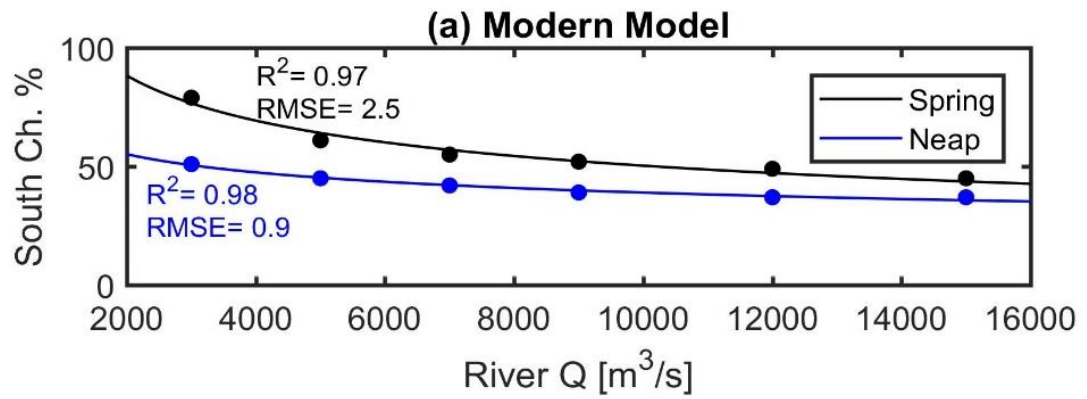

(b) Historical Model
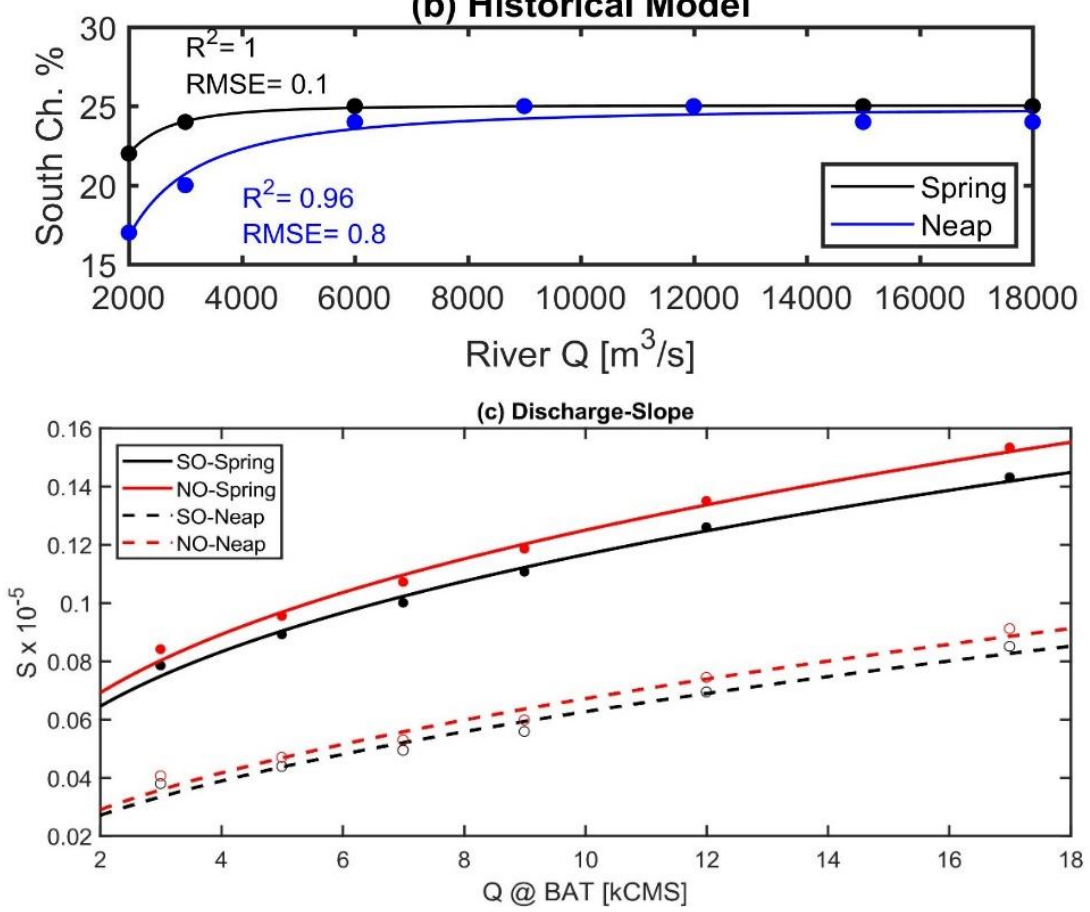

Figure 3-14. The river flows vs. South Channel percentage in $M B(a)$ and $H B(b),(c)$ : represents the relation between river discharge and slopes for North \& South Channels during neap \& spring tides.

\subsubsection{Salt fluxes}

Salt flux analysis (Figure 3-15) shows that most of the salt transport is confined within the South and North Channels (Hamilton, 1990 concluded the same result). In the MM model, about $44 \%$ of mean salt is transported through the North Channel, 51\% in the South Channel, and 5\% in the Middle Channel. However, $75 \%$ of fluxes pass through the 
South Channel during low flow $\left(2,000 \mathrm{~m}^{3} / \mathrm{s}\right)$ vs. $40 \%$ during high river discharge $(15,000$ $\left.\mathrm{m}^{3} / \mathrm{s}\right)$. During low river flow, the South Channel is highly stratified due to the high percentage of freshwater passing through the Channel (Figure 3-14a), which enables more salt flux to be exchanged through the South Channel (i.e., salt transport increases during high stratification). The North Channel salt exchange trend is opposite that of the South Channel transport (Figure 3-15a).

In the historical model, the percentage of freshwater in the North Channel is always higher than the South Channel percentage (Figure 3-14b). Consequently, about 60\% of salt exchange happens through the North Channel, $24 \%$ in the South Channel, and $16 \%$ in the Middle Channel. This percentage is averaged over the spring-neap tidal cycle and then averaged along the river flow range (Figure 3-14b). 

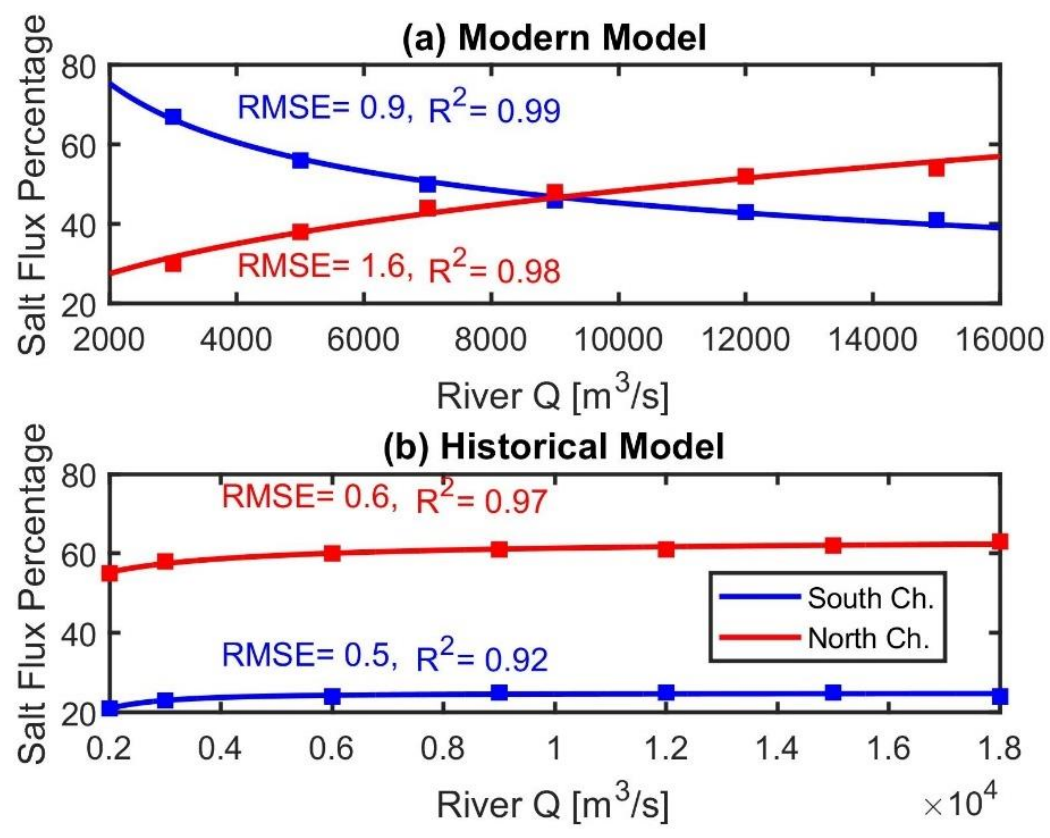

Figure 3-15. Subtidal salt fluxes percentage variation with river discharge (averaged over the spring-neap cycle).

In the MM model, The North Channel conveys more tidal flux during the flood (61\%) than the ebb (55\%). The same pattern also found in the Middle Channel (12\% flood vs. 8\% ebb). In contrast, the South Channel conveys less flux during the flood (27\%) than the ebb (37\%), which indicates a clockwise circulation. This means that salinity flux is imported in the North and the Middle Channels and exported in the South Channel (Figure 3-16a). Similarly, in the HH model, the salt flux rotates clockwise, but the time it returns through the middle and South channels (Figure 3-16b). The flood percentage in the North Channel is $76 \%$ in flood and $60 \%$ in ebb, the South channel flood percentage is $22 \%$ vs. $25 \%$ in ebb, and finally, the Middle Channel flood flux is $2 \%$ compared to $15 \%$ during ebb. 


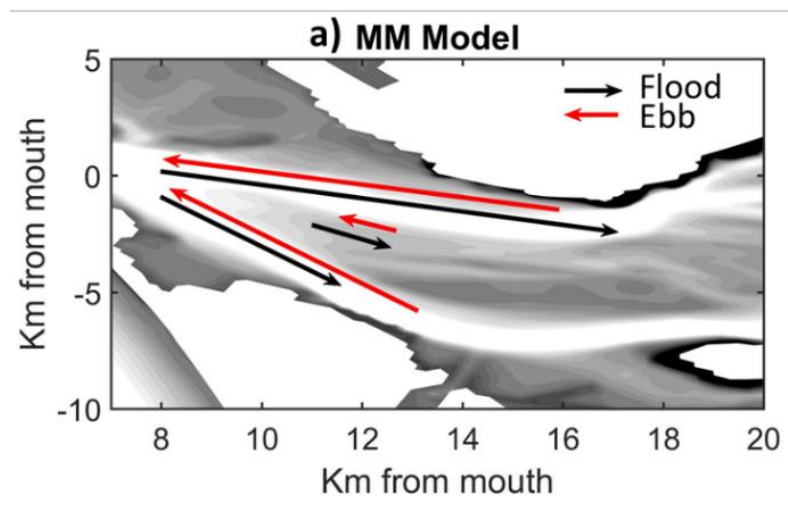

Figure 3-16. Salt flux circulations

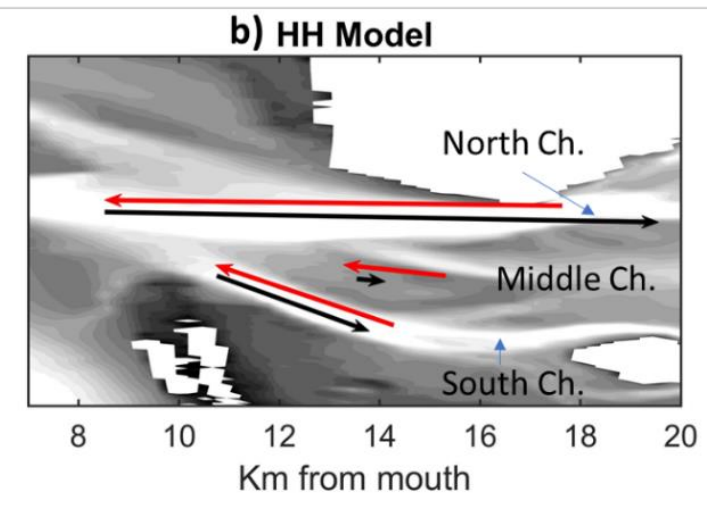

b) HH Model

\subsection{Conclusions}

Flow bifurcation in the LCRE is controlled by the interaction of tidal forcing, river discharge, and channel geometry. In the modern bathymetry model (MB), a larger percentage of river discharge is found to be routed toward the North Channel during periods of high discharge, vs. low flow conditions, because of the asymmetry in water surface slopes between the North and South Channels. This asymmetry is driven by two main factors: the difference in length of the water path along each channel and the nonlinear tidal forcing-river discharge interaction (water level along the estuary is a function of river flow and tides in a non-linear way). These factors produce a mismatch between the two channels in terms of the surface slope.

In the historical bathymetry model (HB), the geometry of the South Channel is less clear because of the presence of the braided channels upstream of Tongue Point. Downstream of that point, the estuary has three channels (North, Middle, and South) that convey river discharge toward the mouth. The tidally averaged surface slope between those 


\section{Chapter 3}

channels was found to be equal, which gives the advantage to the channel geometry to control the water distribution between the channels.

For both models, it was found that the percentage of total non-tidal transport for the channels is proportional to the river discharge and follows a power rule. However, the proportion has a negative trend in the modern model (MB), as it is controlled by the asymmetry in water surface slopes, and is positive in the historical model (HB) since it is proportional to channel geometry. Moreover, the state of the tide controls the channel bifurcation through altering the water surface slopes between the channels, such that the percentage of freshwater in the South Channel is higher in spring tides than neap tide because of the higher water surface slope. The freshwater distribution between the channels has impacted the salt fluxes. Historically, most of the salt was transported through the North Channel since it is more stratified than the South Channel during all river flow. Nowadays, during low river flow, a higher percentage of salt flux is found on the South Channel. Conversely, a higher rate of salt flux goes through the North Channel when the river flow is high because of the stratification. The salt flux lateral circulation has changed as well. The salt flux used to be imported through the North Channel and exported through both the Middle and South Channel. In the modern model, the circulation is the same, but the difference is that the flux is imported in the Middle Channel as well.

Finally, the system alteration has impacted the tidal forcing inside the estuary. The tidal constituent $\mathrm{M}_{2}$ amplitude has increased by $12.5 \%$ at Tongue Point $(\sim 0.11 \mathrm{~m})$ due to channel deepening, mouth squeezing, and river discharge alteration while it has increased 
by $10 \%$ due to channel deepening only. This means the river alteration has elevated $\mathrm{M}_{2}$ by $2.5 \%$ only. The deepening of the channel reduces the velocity, which decreases the effect of friction and hence, increases the tidal amplitude. 


\section{Chapter 4 Changes in the Lower Columbia River Seasonal Cycle of Salinity Intrusion Related to Change in the River Flow Regime and Bathymetry}

\subsection{Introduction}

Estuaries are often defined as the transition region in which freshwater from river flow mixes with saltwater from the ocean, producing a horizontal density gradient and vertical stratification (Wilson, 1977; Hansen \& Rattray, 1966; Pritchard, 1967) Previous literature suggests that salinity intrusion is sensitive to alterations in river flow and bathymetric changes. For example, on the Columbia River Estuary, Chawla et al. (2008) found that the salinity intrusion length doubles when the river flow decreases by $75 \%$, though this result is somewhat sensitive to the zero point chosen. Chant et al. (2018) reported that $15 \%$ increase in the depth of Newark Bay, New Jersey resulted in a doubling of the exchange flow, but caused only a small increase in salinity and longitudinal salinity gradient, possibly because of the limited extent of deep water in the system. In the Hudson River Estuary, salinity intrusion has increased by $30 \%$ over the past century due to channel deepening and decreased river discharge (Ralston \& Geyer, 2019). Also, Mulamba et al. (2019) reported an increase in the lower St. Johns River salinity in Florida in response to sea-level rise.

Many studies have interpreted salinity intrusion using a power-law relation $\left(X \sim Q^{-n}\right)$. For San Francisco Bay, Monismith et al. (2002) found $\mathrm{n}=1 / 7$, while $\mathrm{n}$ was found to be 0.1 for Delaware Bay (Aristizábal \& Chant, 2013). Ralston et al. (2008) found 
a value of $n=0.35$ when accounting for stratification, but 0.4 when using full water depth in the vertical mixing coefficient for the Hudson estuary. However, aside from Hamilton (1981) and Ralston \& Geyer (2019), few studies have analyzed the interaction of historical changes to depth and river flow in altering salinity intrusion and stratification.

In this chapter, I investigate the changes to the Lower Columbia River Estuary (LCRE) salinity intrusion since the $19^{\text {th }}$ century due to the changes in seasonal river hydrograph (flow regulation and diversion) and navigational development (primarily channel deepening and jetty construction). Two questions are addressed:

- How have long-term modifications to the channel depth and river discharge altered the tidal and subtidal transport and distribution of salt within the estuary?

- How have the changes in bathymetry and river hydrograph changed mixing processes, density stratification, and the position of the system on the GeyerMacCready (2014) classification diagram?

For this study, I use records of LCRE river inflow (modern flow, 1966-2016, and historical flow, 1878-1928) for boundary forcing of 3D Delft3D-FM of modern and historical (pre-1900) numerical model grids.

\subsubsection{Columbia River Estuary (CRE)}

The Columbia River is the largest in the northwest (Jay et al., 2007 and Naik \& Jay, 2011) and the second largest in the US (Simenstad et al., 1990). It has a large mean river discharge $\left(7,300 \mathrm{~m}^{3} / \mathrm{s}\right.$, Bottom et al., 2005) with a modern seasonal range of about 2000 to 
$17,000 \mathrm{~m}^{3} \mathrm{~s}^{-1}$. There are also strong tidal currents caused by mixed diurnal and semidiurnal tides with a typical annual range of 1.6-3.7m (Jay et al., 2016). The highly variable tidal energy and fluvial buoyancy input produce large temporal variations and a persistently strong horizontal salinity gradient along the estuary (Jay, 1984; Jay \& Smith, 1990b). Depending on flow and tidal conditions, the estuary typically fluctuates between partially mixed to highly stratified (Jay et al., 2007). The estuary has two main channels (South \& North) and many other braided channels divided by shoals (Sherwood \& Jay, 1990) but most of the flow is confined within the main channels (Jay, 1984), especially in the modern system, which has been highly developed for navigation. At present, most of the river discharge goes through the South Channel while most of the tidal exchange occurs through the North Channel (Jay \& Smith, 1990b).

The LCRE has been highly modified in terms of flow regulation (hydrological modification) and channel development (topographical modification). The topographic modification has included deepening the navigation channel, constructing three jetties at the entrance (total length, $18 \mathrm{~km}$ ), and diking and filling intertidal areas (Sherwood et al., 1990; Simestad et al., 1994). The controlling channel depth in the estuary has doubled (from about 6 to 13m relative to MLLW, Sherwood et al., 1990) to accommodate cargo ships, while the entrance is now $18 \mathrm{~m}$ deep. The construction of jetties has increased the inlet depth and reduced the mouth width by a factor of three (9.7 to $3.2 \mathrm{~km}$ ); see Figure 4-1. Also, diking and filling have reduced the tidal prism by $15 \%$ and caused about a $70 \%$ loss in tidal wetland over the last 140 years (Marcoe \& Pilson, 2017). 
Water management, including irrigation diversion, flood control, and hydropower, started in the 1930s, but integrated system management did not begin until the early 1970s. Flood control and power generation have altered the river hydrograph such that it caused a reduction in spring freshet (by 45-50\%) and an increase in winter, fall, and late summer river discharge. Irrigation and climate change have reduced the mean in annual flow by 17\% (Naik \& Jay, 2005, Figure 4-2). Before modification of the hydrograph, river discharge was ranged from 1,000 to $35,000 \mathrm{~m}^{3} / \mathrm{s}$ in the river above the head of the estuary (Naik \& Jay, 2011), the present range is about $2000-17,000 \mathrm{~m}^{3} / \mathrm{s}$ (Naik \& Jay, 2011; Yeh et al., 2012), with rare floods that may reach $26,000 \mathrm{~m}^{3} / \mathrm{s}$ (Helaire et al., 2019). Although climate change has caused (along with deforestation) earlier spring floods (Sherwood et al., 1990) and a reduction in annual mean discharge of about 7\%, its effect remains less significant than direct engineered modifications (Naik \& Jay, 2011). Hydrologic modifications have altered the system in obvious ways, such as increasing salinity intrusion (the subject of this chapter; see also Naik \& Jay, 2011) and reducing higher elevation wetland habitats in the tidal river (Jay et al., 2016), but also in less obvious ways such as increasing the tidal range (Jay et al., 2016; Talke et al., 2020). Increasing the tidal, changing depth, and any subsequent changes of the tidal velocity range is then a secondary cause of changes to the salinity intrusion, because of the role of wave (tidal) salt fluxes in setting salinity intrusion. 


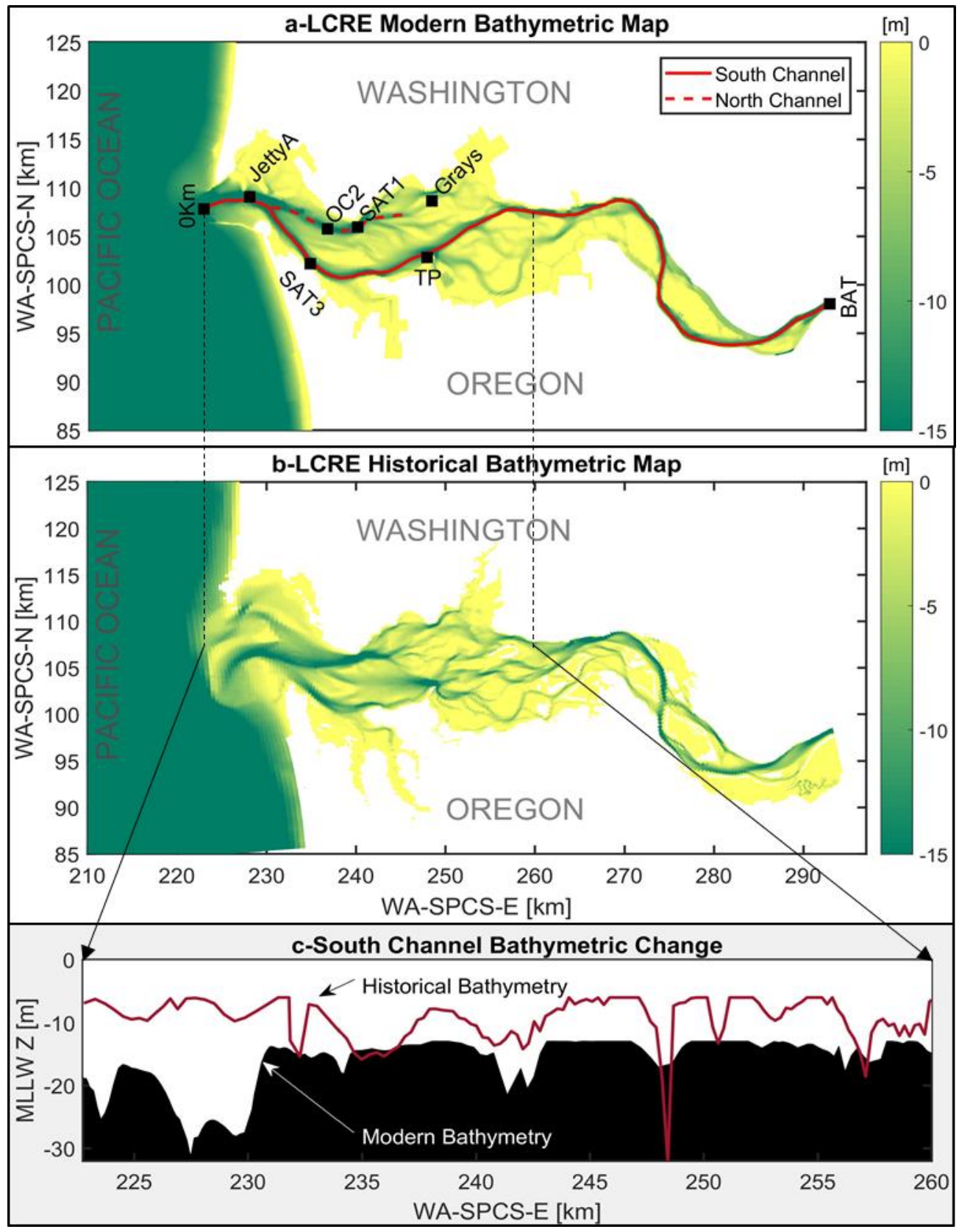

Figure 4-1. Columbia River Estuary (CRE) topographical changes: a-modern bathymetric topography (2008-2010), observation point's locations (OC2, SAT3 \& Tongue Point), North \& South channels layout, and river boundary (BAT), b-historical bathymetric topography (1870-1900), and c-South Channel bathymetric changes. The axes coordinate system referenced to Washington South State Plane Coordinate System (SPCS), E is for easting, and $N$ is for northern. 


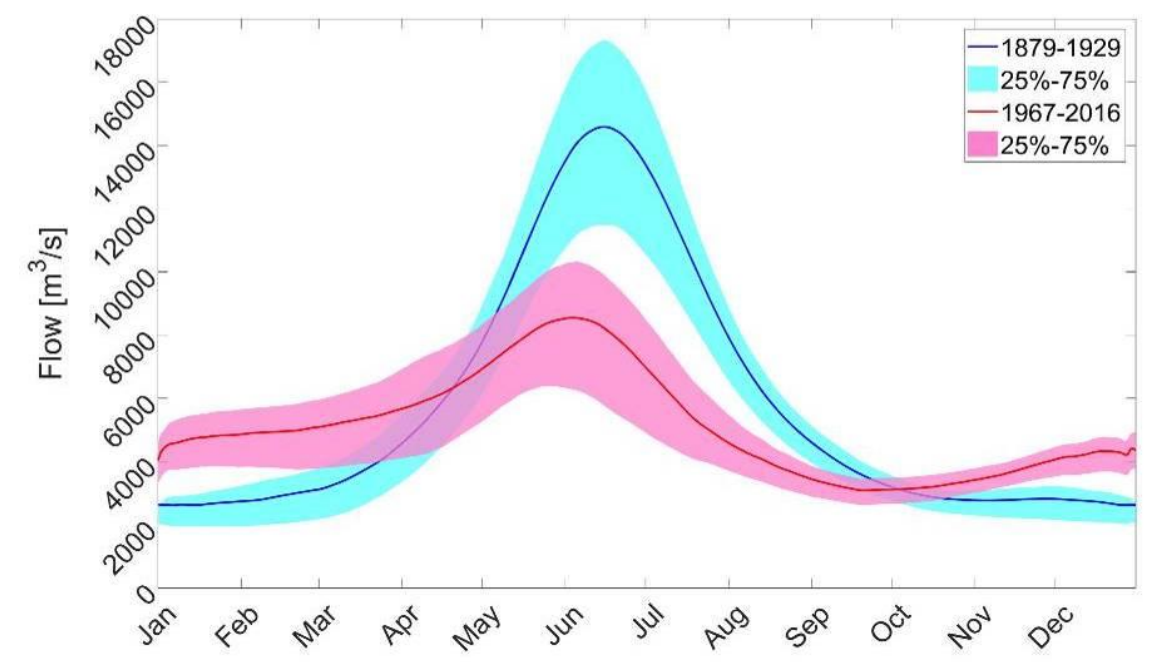

Figure 4-2. Modern vs. historical flow hydrograph (30 days moving average) at The Dalles. The solid lines are the $50^{\text {th }}$ percentile of 50 years while the shaded areas are for the $25^{\text {th }}$ and $75^{\text {th }}$ percentiles.

\subsection{Materials and methods}

\subsubsection{Salinity intrusion theory}

Salt is transported landward due to tidal advection (wave fluxes) and two-layer estuarine circulation (including the gravitational and internal asymmetry modes; (Jay \& Musiak, 1994, 1996), while seaward transport is driven by river discharge. The gravitational circulation (exchange flow) results from the horizontal density gradient between the ocean and the river. Internal asymmetry also produces landward salt fluxes and results from the tidal wave deformation (difference in flood and ebb velocities and mixing). The river flow has a direct effect on salinity intrusion, and high flow is associated with reduced salinity intrusion (Hansen \& Rattray, 1965; 1966; MacCready, 1999; 
MacCready, 2007; Monismith et al., 2002; Geyer \& MacCready, 2014). A theoretical salinity intrusion was presented by Monismith et al. (2002) based on the tidally averaged salt conservation equation, where the net salt flux is zero and the effect of the gravitational circulation is excluded (Hansen \& Rattray, 1965):

$$
X_{S}=\frac{(W \alpha)^{1 / 3}\left(\beta g S_{o}\right)^{2 / 3} H^{3}}{Q^{1 / 3} v_{t}}
$$

where $X_{S}$ is the salinity intrusion length from the mouth of the estuary to the location where the bottom salinity is 2-psu (Monismith et al., 2002; MacWilliams et al., 2015). The channel width is $W, \alpha$ is the constant of proportionality $\left(5.4 \times 10^{-5}\right), \beta$ is the saline expansivity $\left(7.7 \times 10^{-4} p s u^{-1}\right), S_{o}$ is the ocean salinity, $H$ is the local depth, $Q$ is the river discharge, and $v_{t}$ is the eddy diffusion coefficient. This scaling assumes a steadystate, constant width and depth, and that the vertical eddy diffusivity is equal to the eddy viscosity coefficients. It also assumes a uniform eddy viscosity over the water column.

From the scaling in eq 4.1, salinity intrusion varies directly with the third power of channel depth $\left(X_{S} \sim H^{3}\right)$ and inversely with the cubic root of the river discharge $\left(X_{S} \sim Q^{-1 / 3}\right)$. However, estuarine circulation and stratification both can increase salinity intrusion (MacCready \& Geyer, 2010). From the scaling of the tidally averaged along channel momentum and salt equations, the estuarine circulation and stratification can be found as:

$$
U_{E}=\frac{\beta g H^{3}}{48 v_{t}} \frac{\partial s}{\partial x}, \text { and }
$$




$$
\Delta S=U_{E} \frac{H^{2}}{K_{S}} \frac{\partial s}{\partial x},
$$

by relating the eddy viscosity and eddy diffusivity $\left(K_{S}\right)$ to tidal velocity and local depth, $v_{t} \sim u_{t} H$ and $K_{S} \sim v_{t} / S_{c} \sim u_{t} H / S_{c} ; S_{c}$ is Schmidt number (Geyer \& MacCready, 2014), the scaling of the above equations show that $U_{E} \alpha H^{2}, \Delta S \alpha H^{3}$, and $X_{S} \alpha H^{2}$. This means that, theoretically, the salinity intrusion is much more sensitive to changes in bathymetry than to river discharge. A further complication is that depth changes can alter the velocity magnitude. The depth-averaged tidal velocity at the mouth can be found, according to Friedrichs, (2010), from the continuity equation as:

$$
u_{t}=\frac{L \omega A}{H},
$$

where $L$ is estuary length, $\omega$ is the tidal frequency, and $A$ is the tidal amplitude. Thus, the change in tidal amplitude can affect salinity intrusion (Jay \& Naik, 2011; Geyer, 2009). Because of the complexity of many contributors to salinity intrusion, the presence of two estuary channels in the Columbia River Estuary, and a 3D bathymetry, a numerical model is needed to evaluate the changes in salinity intrusion that have occurred since the mid1800s.

\subsubsection{Previous analyses of LCRE salinity intrusion}

Using salinity data observations, Neal (1966) measured the salinity intrusion length in the LCRE and found that during low river flow $\left(\sim 4,000 \mathrm{~m}^{3} / \mathrm{s}\right)$, the intrusion from lower low tide to higher high water was between 28 and 37km, respectively. Moreover, the range 
was $9-24 \mathrm{~km}$ during high river discharge $\left(\sim 17,000 \mathrm{~m}^{3} / \mathrm{s}\right)$. Hamilton (1990) predicted a maximum salinity intrusion length of $50 \mathrm{~km}$ via numerical modeling. The same salinity intrusion length was reported by Jay \& Smith (1990) while a minimum of $20 \mathrm{~km}$ was observed, depending on the tidal stage and river discharge. More recent modeling (e.g., Baptista et al. (2015)) predicted a maximum salinity intrusion of up to $45 \mathrm{~km}$ in the South Channel. However, salinity intrusion in the North Channel is generally greater than in the South Channel, since a large portion of river flow is diverted to the South Channel during high river discharge. In contrast, during low river discharge, the difference in salinity intrusion between channels is small (Jay, 1984).

During low river discharge in the LCRE, salinity intrusion is greater during neap than spring tides. This occurs because the vertical mixing is weaker during neap tides. In contrast, when the river discharge is very high (historical flow), a greater salinity intrusion is expected during spring tides, because of a greater tidal excursion (Jay \& Smith, 1990). However, there is a small variability for spring-neap salinity intrusion on moderate to high river discharge (Jay, 1984). The reason is that the tidal mixing during such flow is unable to overcome the moderate/high stratification (Jay \& Smith, 1990)

\subsubsection{Parameter space theory}

Geyer \& MacCready (2014) proposed a parameter space for estuarine classification based on an analytical solution for the relationship between stratification and the freshwater Froude number for idealized estuaries. In this classification, the effect of river flow is represented by the freshwater Froude number: 


$$
F r_{f}=U_{R} /\left(\beta g s_{o c n} H\right)^{1 / 2},
$$

and the relative strength of tidal mixing vs. stratification effects is represented by the mixing number $M$ :

$$
M^{2}=C_{D} U_{T}^{2} / \omega N_{0} H^{2},
$$

where $U_{R}$ is river flow velocity, $s_{\text {ocn }}$ is the ocean salinity, $H$ is the depth, $C_{D}$ is the drag coefficient, $U_{\mathrm{T}}$ is tidal velocity, $\omega$ is the tidal frequency, and $N_{0}$ is the buoyancy frequency.

$$
N_{0}=\left(\beta g s_{o c n} H\right)^{1 / 2} .
$$

Further, Geyer \& MacCready (2014) propose that complete vertical mixing occurs when

$$
\alpha^{-1 / 2} F r_{f}^{-1 / 3} M^{2} \approx 1,
$$

where $\alpha=3.4$ (Geyer, 2010). Geyer \& MacCready (2014) suggest that each estuary occupies an area inside the diagram given its specific bathymetry and typical tidal/fluvial forcing. From the definitions of the mixing number and freshwater Froude number, it can be concluded that the classification strongly depends on the river flow, tidal velocity, and estuarine depth. Since all three parameters have changed in the LCRE over the last 150 years, I hypothesize that the parameter space occupied by the Columbia River has shifted as well. 


\subsubsection{Methods}

I have built two hydrodynamic models using Delft3D Flexible Mesh; the first one uses the modern bathymetry (2008-2010, Figure 4-1a) and the second uses the historical bathymetry (1868-1901, Figure 4-1-b). From the ocean side, I forced both models with the major tidal constituents $\left(\mathrm{Q}_{1}, \mathrm{P}_{1}, \mathrm{O}_{1}, \mathrm{~K}_{1}, \mathrm{~N}_{2}, \mathrm{M}_{2}, \mathrm{~S}_{2}\right.$, and $\left.\mathrm{K}_{2}\right)$ obtained from the Tide Model Driver (TMD), a tidal prediction software by Oregon State University (Egbert \& Erofeeva, 2002). Oceanside salinity and temperature were obtained from the Hybrid Coordinate Ocean Model (HYCOM) and the global Navy Coastal Ocean Model (NCOM) (after Kärnä et al., 2015; Baptista et al., 2004). The HYCOM model (26 layers) was interpolated to match the LCRE model (36 layers).

The models were forced from the river side using modern (1967-2016) and historical river discharge records (1879-1929). The modern records at the Beaver Army Terminal (BAT) were obtained from the USGS, and the historical records were obtained from the flow estimates of Naik \& Jay $(2005,2011)$. For each era, the $25^{\text {th }}, 50^{\text {th }}$, and $75^{\text {th }}$ percentiles of river flow were extracted. Accordingly, three simulations were run for each river discharge percentile. For example, for the $50^{\text {th }}$ percentile river flow, the simulations represented: the modern bathymetry and the modern river discharge (MM), the historical bathymetry and the historical river discharge $(\mathrm{HH})$, and a hypothetical case where modern bathymetry combined with the historical river discharge $(\mathrm{MH})$. The same was used for the other river flow percentiles such that a total of nine cases that ran for a full year of the simulation were used to represent various conditions of tidal forcing and river discharge. 
The salinity was taken as zero at all times at the landward boundary. The mean daily water temperatures for the Columbia River were obtained from combined sources: USGS station 453845121562000 at Bonneville Dam (https://www.streamnet.org/) for the period 19382018. Wind data were obtained from the National Data Buoy Center (NDBC) station 46029 (Columbia River Bar) to represent the offshore area for the period 1984-2016, while wind data from the National Oceanic and Atmospheric Administration (NOAA) at Astoria Tongue Point (TP), OR-station 9439040 was used to cover the inside region of the estuary (2005 - 2016). For both water temperature and wind data, I used the mean of the available period, and the same date used for both models (historical and modern). Because of the steep topography along the LCRE, actual winds are highly variable and likely differ in many locations from the values used.

Averaging over a long period enables a climatological approach, such that the mean seasonal response of the system is simulated. I therefore implicitly assumed that wind forcing and water temperature have not changed over time. By holding these forcing factors constant, the factors producing long-term changes are reduced to just bathymetry and river flow alterations, which is a more tractable problem. However, it is known that water temperature is increasing in the Columbia River (Bottom et al., 2005), and it is possible that wind/wave forcing is also increasing (Ruggiero et al., 2011). Further, there are well-known variations in wind/temperature associated with El Nino and the Pacific Decadal oscillation (Newman et al., 2016). A detailed investigation of these factors, and how they have changed over time, is beyond the scope of this modeling effort; for now, I 
note that some of the subtidal variations in water level that occur in data, but not the model, may be related to the use of climatological averages (see calibration, results, and discussion thereof).

\subsection{Calibration of historical and modern models}

Both models (historical and modern bathymetry) were calibrated to available water levels. In addition, the modern model was calibrated/compared to measured salinities and velocities. The model was also compared to the model results -- salinities and velocities - of Kärnä et al. (2015). The calibration/validation of water levels can be found in (3.3). Here I show calibration results for salinities and velocities of the modern model only as there is no historical data. The good agreement with modern salinity measurements (see below) improves our confidence in the historical hindcast. Four measures of model quality were employed: The coefficient of determination $\left(\mathrm{R}^{2}\right)$, the mean root square error (RMSE), the Nash-Sutcliffe coefficient (NS), and the skill coefficient (SK). For NS and SK, one means a perfect match between the model and the observation, while zero is no match at all.

Time series and profiles of velocity and salinity were collected in the North Channel (OC2 on Figure 1) during May and October 2012 and used to calibrate the SELFE numerical model (Kärnä et al., 2015). The observation data and the modeled data from (Kärnä et al., 2015) are available online at (http://dx.doi.org/10.5281/zenodo.13782); see Sanford et al. (2015). Using the salinity time series data for high flow (spring) and low flow (fall) at the OC2 location, I found a close agreement in terms of $\mathrm{R}^{2}$ and NS. The 
modern model calibration results show that $\mathrm{R}^{2}$ and NS are about 0.9 between the modeled and observed salinity data during high flow conditions and 0.93 during low river flow (Figure 4-3a \& Figure 4-3b). These scenarios are compared to the Kärnä et al. (2015) model in Figure 4-3c \& Figure 4-3d. The statistical comparison shows good agreement between the model and the observations for both salinity and velocity. Compared with the two measured conditions, the salinity results show minimum values of $R^{2}=0.91$, NS $=0.9$, $\mathrm{SK}=0.97$, and maximum RMSE $=3.4 \mathrm{psu}$. These results compare favorably with the values of $\mathrm{R}^{2}=0.85, \mathrm{NS}=0.83, \mathrm{SK}=0.96$, and maximum $\mathrm{RMSE}=4.2 \mathrm{psu}$ reported by Kärnä et al. (2015)(Table 4-1). Results (Figure 4-3, Table 4-1) therefore show that the Delft3D-FM model is better than the Kärnä et al. (2015) model at reproducing measured velocity and salinity patterns. Model data in the FM model are clustered more closely around the 1:1 line than in the Kärnä et al. (2015) model, with fewer outliers (compare Figure 4-3b to Figure 4-3d, for example). Particularly at high flow, salinity (and therefore salinity intrusion) shows less variance and outliers. The good fit to data in the modern model increases our confidence that the historical model is reasonably modeling historical intrusion patterns. 


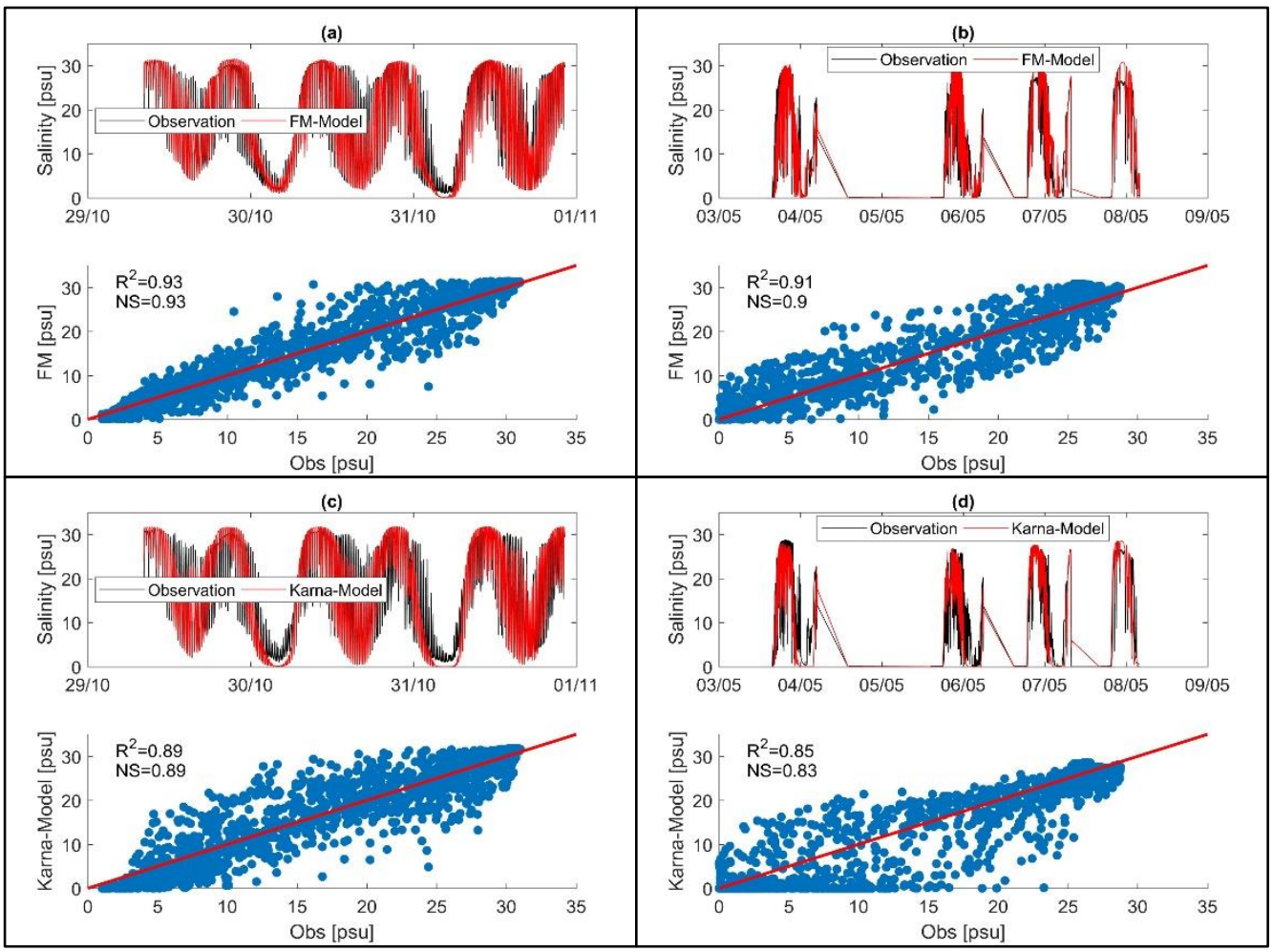

Figure 4-3. Observed vs. modeled salinity comparison, FM-models (top panels: a \& b). Karna et al. 2015 model (bottom panels: $c \& d$ ). Left panels for low flow (fall: $a \& c$ ) while right panels for high flow (spring: $b \& d)$.

Table 4-1. Model Calibration Statistics: 22 is the coefficient of determination, RMSE is the mean root square error, NS is the Nash-Sutcliff coefficient, and SK is the skill coefficient (one indicates there is the perfect match between the model and the observation, while zero is no match at all)

\begin{tabular}{|c|c|c|c|c|c|c|c|c|c|}
\hline & \multirow{2}{*}{$\begin{array}{l}\text { River } \\
\text { Flow }\end{array}$} & \multicolumn{4}{|c|}{ FM-model } & \multicolumn{4}{|c|}{ Kärnä et al., (2015)-model } \\
\hline & & $\mathrm{R}^{2}$ & RMSE & $\mathrm{NS}$ & SK & $\mathrm{R}^{2}$ & RMSE & NS & SK \\
\hline \multirow[t]{2}{*}{ Salinity } & High & 0.91 & 3.38 & 0.90 & 0.97 & 0.85 & 4.23 & 0.83 & 0.96 \\
\hline & Low & 0.93 & 2.79 & 0.93 & 0.98 & 0.89 & 3.79 & 0.89 & 0.97 \\
\hline Velocity & Low & 0.94 & 0.25 & 0.92 & 0.98 & 0.95 & 0.23 & 0.92 & 0.98 \\
\hline
\end{tabular}

*velocities of high flow are not available on the in-situ data

The modern model was also calibrated to selected salinity measurements made by the Center for Coastal Margin Observation and Prediction (CMOP) stations that are 
distributed along the estuary (see locations marked Jetty A, SAT3, SAT1, and Grays in Figure 4-1). Depending on the availability of the data, the salinity extracted from our model was calibrated at the top, middle, and bottom of the water column (Figure 4-4). This figure shows calibrations during high river discharge conditions in Figure 4-4 (a1 to a3) and low discharge in Figure 4-4 (b1 to b3) at SAT3; other stations appear in Figure 4-4 (c1-c3). The statistical results for Figure 4-4 range from 0.7-0.8 for $\mathrm{R}^{2} \& \mathrm{NS}$ and 2-4.5psu for the RMSE.

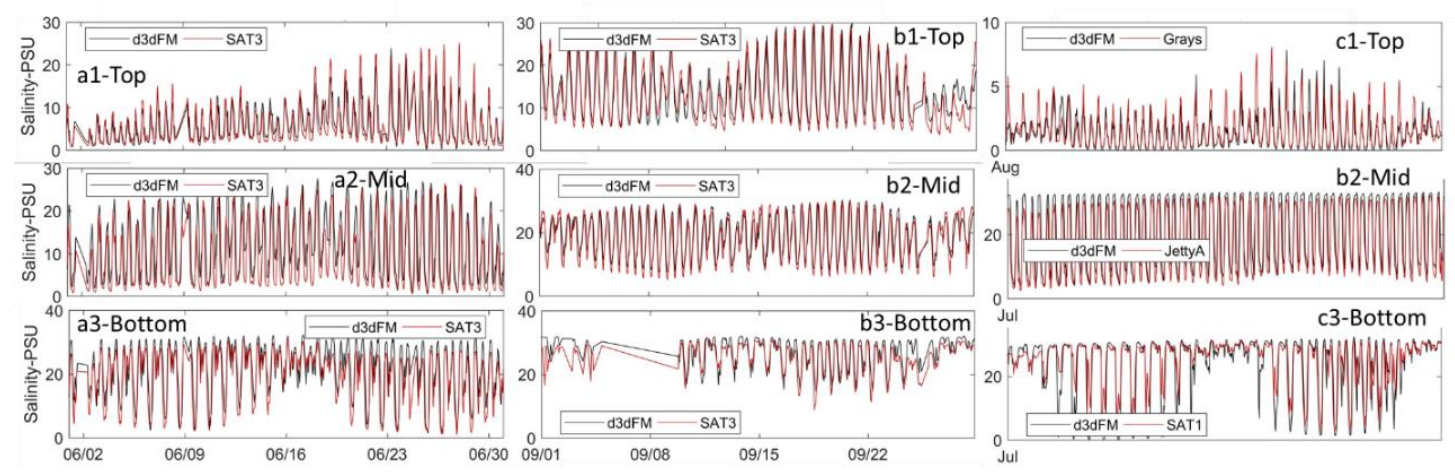

Figure 4-4. Calibration of the CMOP stations

\subsection{Results}

\subsubsection{Salinity intrusion}

Comparison of the historical and modern models (MM, MH and $\mathbf{H H}$ ) shows that hourly estimates of the $\mathrm{X} 2(2 \mathrm{psu})$ isohaline follow the seasonal pattern of the river hydrograph for each case, but are modulated by the tidal signal on daily and monthly tidal time scales (Figure 4-5). Comparison of Figure 4-5a (MM) and Figure 4-5b (MH) illustrates the effect of the changing hydrograph on salinity since both the $\mathbf{M M}$ and $\mathbf{M H}$ 
models are based on modern bathymetry. A significant seasonal change in salinity intrusion can be found during winter and spring. A maximum decrease $(\sim 10 \mathrm{~km})$ in the intrusion length observed in hourly model data occurs during winter because modern discharge is significantly larger $(50 \%)$ than historical discharge (Figure 4-5). By contrast, salinity intrusion during the spring-freshet is greater than it used to be by up to $4 \mathrm{~km}$ because the modern freshet is only $44 \%$ as large as it was historically. Considering all tidal phases, the salinity intrusion range is $8-40 \mathrm{~km}$ for the modern $50^{\text {th }}$ percentile run (MM case) while it was 5-45 km for the historical flow (MH case; see Table 4-2). The larger variability in the tidally varying $\mathrm{X} 2$ intrusion during historical discharge conditions stems from the overall greater variability in discharge over a year. The average historical hydrograph varied from 2,500 to $14,500 \mathrm{~m}^{3} / \mathrm{s}$, while the modern hydrograph varies from 3,000 to $8,500 \mathrm{~m}^{3} / \mathrm{s}$ (see white lines in Figure 4-5a and Figure 4-5b). Despite the 40\% greater range, however, the overall difference in $\mathrm{X} 2$ range is only $11 \%$; the relative insensitivity of salinity intrusion to discharge changes, as shown later, is driven by the approximately $\mathrm{Q}^{-1 / 3}$ relationship between salinity intrusion and flow (see also Equation 4.1).

The effect of the bathymetric change is observed by comparing cases (b) MH and (c) HH in Figure 4-5. The two cases show the same seasonal pattern of salinity intrusion because hydrological forcing is the same; however, much less salinity intrusion is observed in the $\mathbf{H H}$ case. The salinity intrusion for the $50^{\text {th }}$ percentile run was shifted landward from 3-30 $\mathrm{km}$ in the $\mathbf{H H}$ case to $5-45 \mathrm{~km}$ due to changes in the bathymetry since the $1800 \mathrm{~s}$, (Table 4-2). As shown below, the deepening of the channel made the system more stratified 
and pushed intrusion further landward, for the same historical hydrograph. The combined effect of both river flow alteration and channel deepening is demonstrated by comparing a-MM and c-HH in Figure 4-5. As shown, the salinity intrusion has shifted landward from 3-30 $\mathrm{km}$ to $8-40 \mathrm{~km}$ for the mean flow. Therefore, the decreased dynamic range in river discharge (which tends to decrease the range of salinity intrusion, both by increasing lowflow and decreasing high flow) somewhat counteracts the tendency of channel deepening and other bathymetric changes to move salt further landward. Overall, however, the results still suggest an upstream movement of the maximum salinity intrusion.

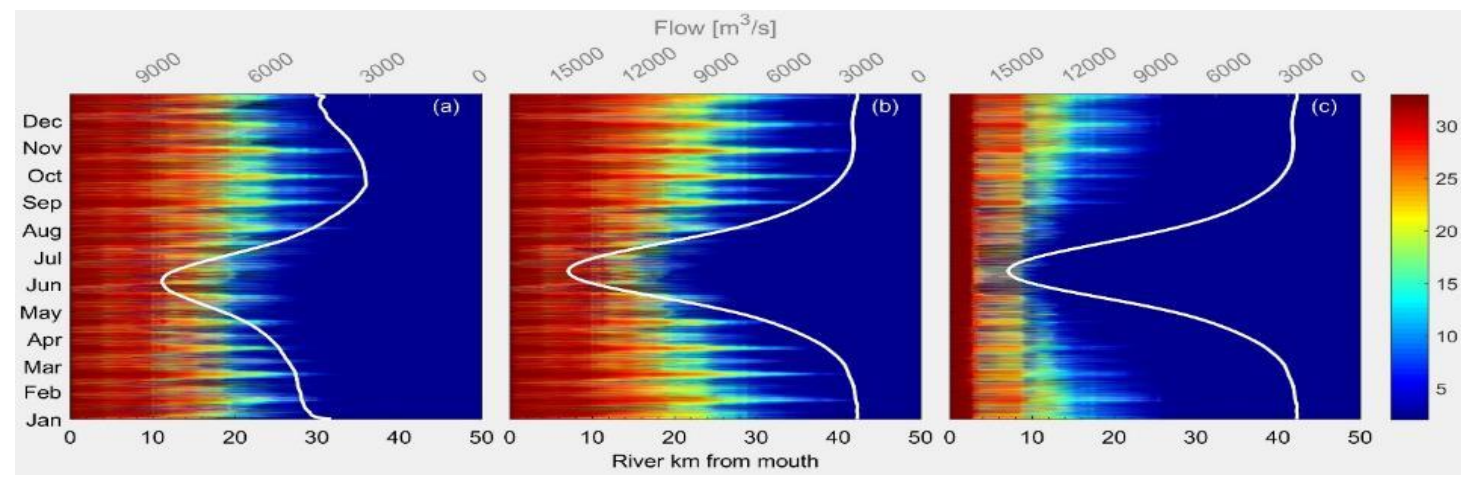

Figure 4-5. Instantaneous (hourly) Salinity intrusion seasonal variation of the South Channel. The 2-psu isohaline is the limit between blue color and the other colors. a) $M M, b) \mathrm{MH}$, and c) $H H$. The white curve is the river hydrograph.

Higher salinity intrusion is correlated with lower river discharge. The salinity intrusion variation based on the $25^{\text {th }}$ percentile of discharge (i.e., a relatively dry year) suggests that the tidally varying intrusion (hourly time scale) could reach up to $55 \mathrm{~km}$ for the modern case (MM model) compared to a maximum of $35 \mathrm{~km}$ in the historical scenario (HH model) under the 25th percentile discharge (Table 4-2). Hence, during low-flow 
conditions (25th percentile discharge), as much as $10 \mathrm{~km}$ of landward intrusion has occurred as a result of flow management and bathymetric change. Conversely, on a wet year $\left(75^{\text {th }}\right.$ percentile or river discharge), only a $4 \mathrm{~km}$ increase in salinity intrusion has occurred (Table 4-2).

Table 4-2. Maximum and minimum hourly salt intrusion in km from the mouth of the CRE (using 2-psu isohaline) for the three cases (MM, MH, and HH), using mean flow, 25th, and 75th percentiles of flow

\begin{tabular}{|c|c|c|c|c|c|c|c|c|c|}
\hline $\begin{array}{c}\text { Salinity } \\
\text { intrusion } \\
(\mathbf{k m})\end{array}$ & \multicolumn{3}{|c|}{$\begin{array}{c}\text { Modern bathymetry } \\
\text { \& Modern flow } \\
(\mathbf{M M})\end{array}$} & \multicolumn{3}{|c|}{$\begin{array}{c}\text { Modern bathymetry } \\
\text { \& Historical flow } \\
(\mathbf{M H})\end{array}$} & \multicolumn{3}{|c|}{$\begin{array}{c}\text { Historical bathymetry } \\
\text { \& Historical flow } \\
(\text { HH) }\end{array}$} \\
\cline { 2 - 10 } & $25^{\text {th }}$ & $50^{\text {th }}$ & $75^{\text {th }}$ & $25^{\text {th }}$ & $50^{\text {th }}$ & $75^{\text {th }}$ & $25^{\text {th }}$ & $50^{\text {th }}$ & $75^{\text {th }}$ \\
\hline Min & 11 & 8 & 6 & 7 & 5 & 2 & 5 & 3 & 2 \\
\hline Max & 45 & 40 & 34 & 48 & 45 & 44 & 35 & 30 & 29 \\
\hline
\end{tabular}

To better understand the net effect of flow and depth variation on the salinity intrusion, a tidally averaged salinity intrusion for each scenario was considered (Figure 4-6). The range of tidally averaged intrusion was pushed landward from $6-27 \mathrm{~km}(\mathbf{H H})$ to $12-43 \mathrm{~km}(\mathbf{M H})$ due only to bathymetric change. The combined effect of flow management and bathymetric alteration has increased X2 by 14-36km (MM vs. HH), see (Figure 4-6). In the deeper channel cases (MM \& $\mathbf{M H}$ ), as shown below, the salinity intrusion pushed further landward than for the shallower channel $(\mathbf{H H})$ because of stratification. The timing of maximum salinity intrusion has also shifted, due to river discharge hydrograph alteration (Figure 4-2). The historical maximum intrusion occurred in early January but occurs in September in the modern model. For the $25^{\text {th }}$ and $75^{\text {th }}$ percentile discharge, the same timereversal was noted. The salinity intrusion results shown are for typical historical and modern flow patterns, but the actual salinity intrusion depends on year-to-year variation. 
Different years have very different flow patterns, with the extremes of mean annual flow varying by a factor of about 2.7 between 1878 and the present (Naik and Jay, 2011).

Furthermore, a change in the spring-neap intrusion was noticed due to the bathymetric and flow variation. The spring-neap transition has changed such that a mean of $\sim 7 \mathrm{~km}$ variation between successive spring-neap cycles occurs in the MM model compared to $\sim 5 \mathrm{~km}$ in the $\mathbf{H H}$ model (Figure 4-6). Changes in the spring-neap transition between the MM and $\mathbf{H H}$ model are caused by both discharge changes and bathymetry changes. The effect of bathymetry can be isolated by comparing the MM and MH runs. Here, I see that under historical river flow, the modern spring-neap transition would be slightly enhanced, with an average of $10 \mathrm{~km}$. Therefore, I conclude that bathymetric change is the primary driver of weekly and monthly variability in intrusion (while discharge dominates the seasonal variability). The increased variability of salinity intrusion over a two-week and monthly time scale occurs due to greater salinity stratification caused by channel deepening, see section 4.4.2. However, it remains true that LCRE shows maximum salinity intrusion on neap tides for most flow conditions. Only for the highest flows in the HH case does the maximum salinity intrusion shift to spring tides, a situation suggested by Jay \& Smith (1990). 


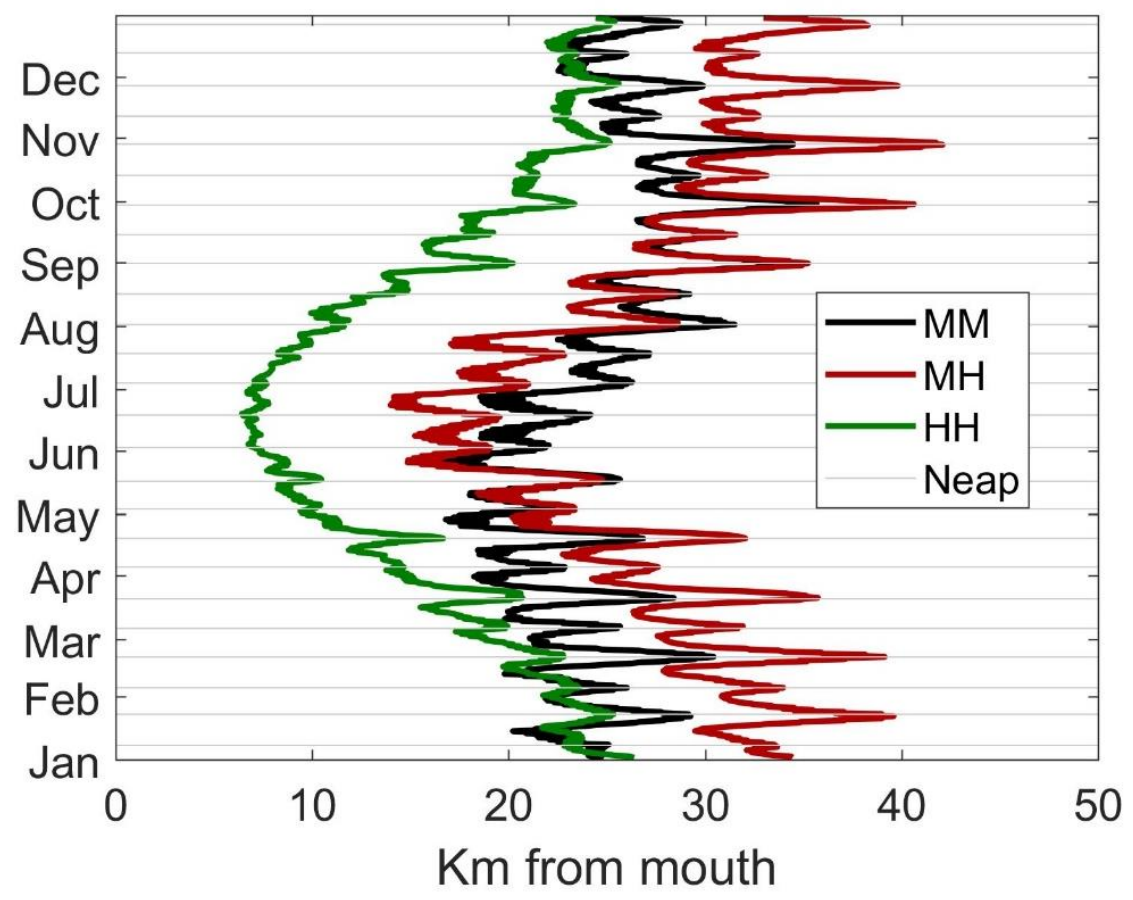

Figure 4-6. Tidally averaged salt intrusion based on the mean flow, gray lines mark the neap tide

\subsubsection{Salinity intrusion sensitivity to the river flow.}

Theory suggests that the salinity intrusion $\left(X_{S}\right)$ is inversely proportional to the river flow $(Q)$ as $X_{S} \sim Q^{-n}$, where $\mathrm{n}=1 / 3$. Using the river discharge portion that passes through the South Channel only (see Chapter3), the value of the exponent $\mathrm{n}$ was found to be $\sim 0.42$ for both river flow scenarios on modern bathymetry (models MM and MH). As might be expected, changing the seasonal flow magnitude and distribution does not affect this relation. However, changing the bathymetry does alter the salinity intrusion-river discharge relation. For simulations run on historical bathymetry (case $\mathbf{H H}$ ), the exponent $\mathrm{n}$ is found to be 0.56 , rather than 0.42 (Figure 4-7a). Therefore, changing channel bathymetry has not 
only pushed the salinity intrusion further landward but may have reduced its sensitivity to river flow as well. These results are different when assuming the whole river discharge is passing through the South Channel. Using BAT river discharge, rather than accounting for flow bifurcation between the north and south channels (see Chapter 3), produces $n=0.33$ for both MM \& MH models and $n=0.46$ for the HH model (Figure 4-7b). Therefore, the change in the flow sensitivity has been caused in part by the change in the redistribution of flow between the North and South Channels.

A possible reason for the difference in exponent $n$ between time periods is methodological, rather than physical. Since the exponent is fit with nonlinear regression, it is quite sensitive to the (somewhat arbitrary) position of the coordinate system. The modern 'River mile zero' is defined by the Army Corps of Engineers to be at the intersection of the shipping channel and a line that bisects the seaward limit of the North and South Jetty. When the origin (X0) is moved further seaward in our nonlinear regression, the exponent $\mathrm{n}$ increases, and vice versa (Figure 4-7c). Since the historical entrance to the estuary is landward of the present-day $\mathrm{X} 0$, it is therefore likely that our estimated coefficient value $\mathrm{n}$ is at least somewhat of an artifact of how one fits a line. When the origin of Clatsop spit is used, the historical n-value is 0.42 . These results are consistent with the boundary of the estuary having moved further seaward since the 1800s. However, there is significant uncertainty about the correct location to put the estuary boundary, and therefore the correct functional dependence of the exponent $\mathrm{n}$. For example, if I move the 
origin of the modern model landward by $8 \mathrm{~km}$, one could obtain the $n=1 / 3$ theoretical relationship.
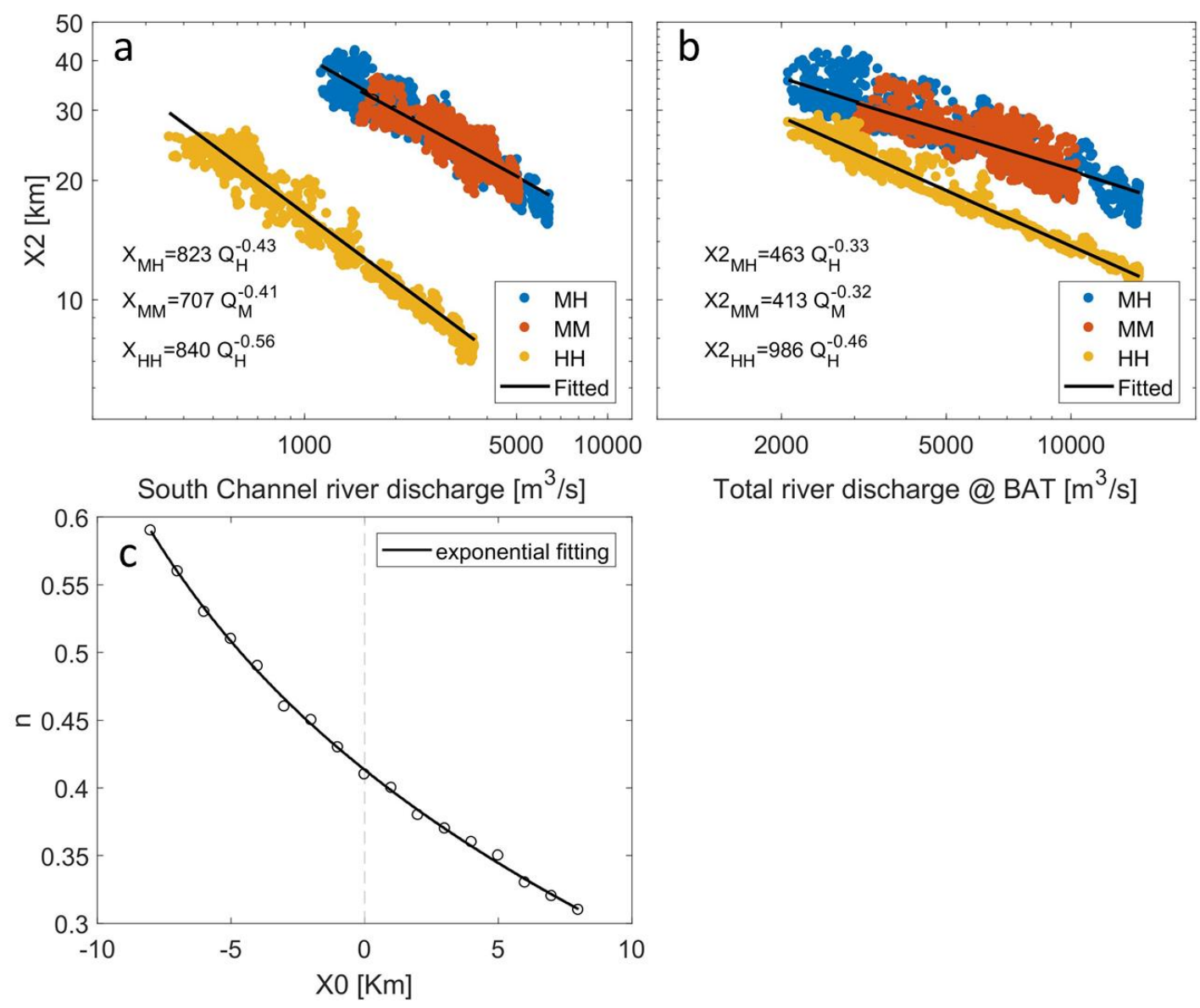

Figure 4-7. (a) River discharge tidally averaged intrusion relation at the South Channel, where X=0km (at the mouth) is obtained from the corps of engineers (see Figure 4-1-a). $Q_{H}$ refers to the historical hydrograph while $Q_{M}$ is the modern one. (b) river discharge power $(n)$ sensitivity to zero $\mathrm{km}(\mathrm{XO})$ selection.

Salinity intrusion is also sensitive to stratification, such that the vertical mixing is restricted in the presence of high stratification, which leads to greater intrusion (Monismith, et al., 2002). Model results confirm that greater salinity intrusion is associated with larger 
stratification during neap tides (Figure 4-8, region B). However, larger river flow can increase the salinity gradient which pushes the salinity intrusion towards the ocean (Geyer \& MacCready, 2014). This results in a strongly stratified system with a short intrusion length that is close to the river mouth (Figure 4-8, region A). The reverse is also true, such that during low river flow the salinity flux can reach further upstream (Figure 4-8, region C).

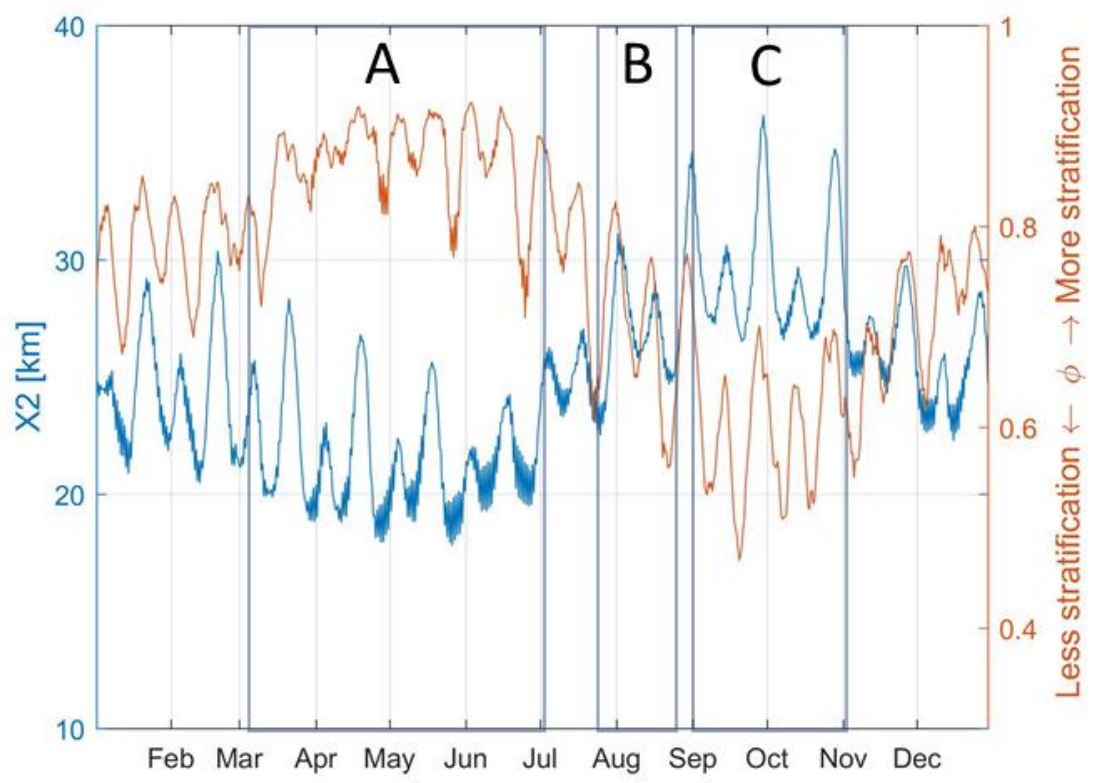

Figure 4-8. South Channel stratification -salinity intrusion relation for the modern model (MM). The blue curve is tidally averaged salinity intrusion (X2) time series. The orange is a tidally averaged stratification index $(\emptyset)$. Region A represents a high flow period, region C represents a low flow, and region $B$ shows the correlation between $X 2 \& \emptyset$ 


\subsubsection{Stratification}

Stratification changes were analyzed using the stratification index $(\varnothing)$ which is the difference in the bottom to top salinity divided by the bottom salinity (zero indicates well mixed, while one means strongly stratified). I define the system as 'stratified' when the index is greater than 0.5 stratification (i.e $\varnothing>0.5$ ). For the South Channel and the mean flow scenario, it is found that the $\mathbf{H H}$ model is stratified about 59\% throughout the whole year of the simulation period (hourly estimates), while the $\mathbf{M H}$ model is stratified $77 \%$ of the time (Figure 4-9b and Figure 4-9c). This increase in stratification is due to bathymetric change only since both models have the same river discharge but different bathymetry. Likewise, the MM model is found to be stratified about $92 \%$ of the time during the simulation year (Figure 4-9a). In other words, deepening the channel and altering the river hydrograph have increased the likelihood of exceeding the $\emptyset=0.5$ threshold from 59\% to 92\% (18\% due to bathymetric change and $15 \%$ due to river flow change). The system alteration has made the system stratified most of the year except during very low flow periods (Figure 4-9a), though it was historically strongly stratified mostly during above average flows (Figure 4-9c). The chage in stratification is primarily because of the seasonal redistribution of the flow during the modern periods for hydropower generation and flood control, as more water is released during winter for power generation (Naik \& Jay, 2011). The increased discharge during low-flow periods leads to more stratification. Secondary causes of altered river flow (and hence salinity stratification) include deforestation and climate change (more precipitation falls as rain in winter and the spring snowmelt is earlier; 
Matheussen et al., 2000; Hamlet et al., 2013), and irrigation withdrawal, which reduces mean flow, most strongly at the end of the spring freshet (Naik \& Jay, 2011).

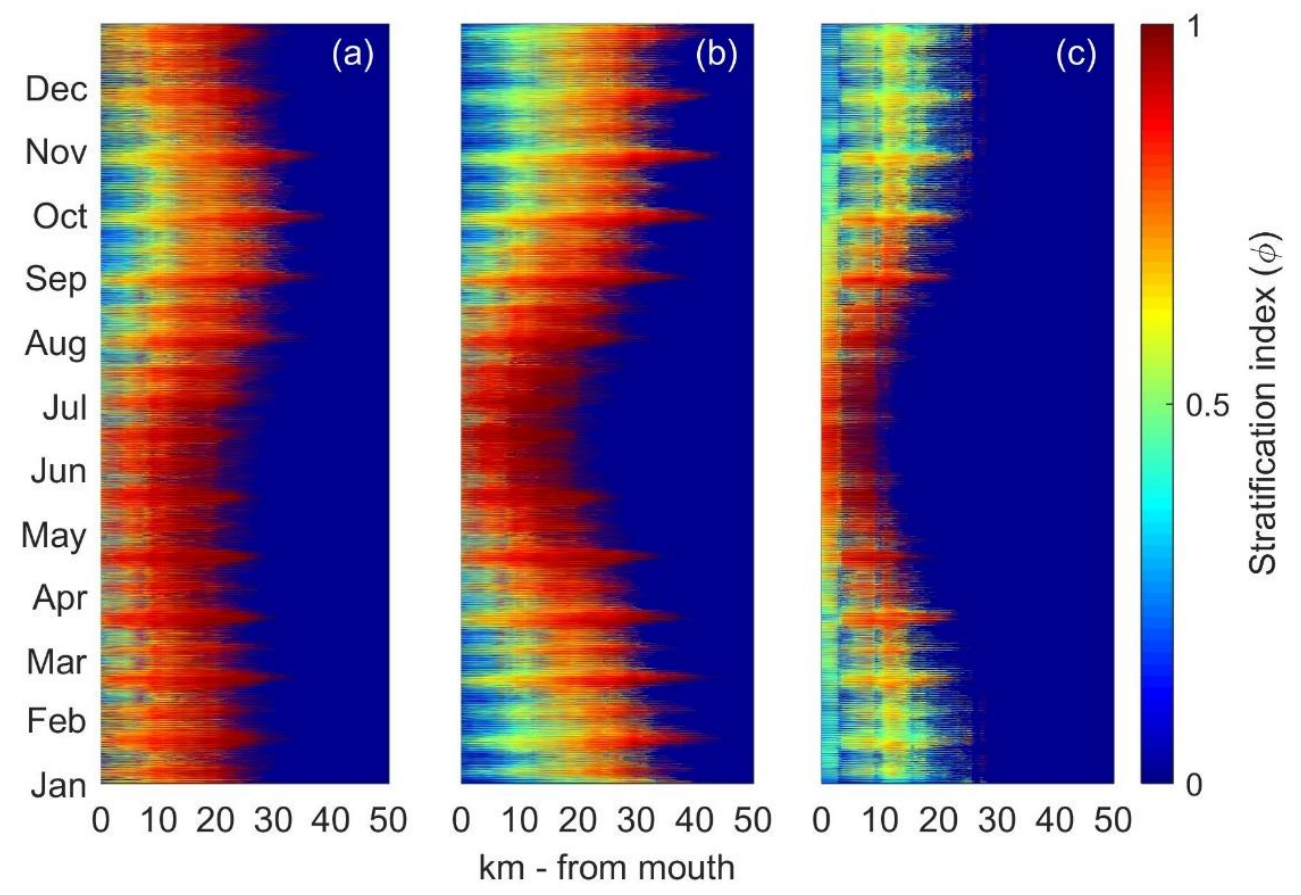

Figure 4-9. South Channel stratification. (a) MM, (b) MH and (c) HH.

\subsubsection{Parameter space evaluation}

To show the aggregate change of altered tides, depth, and river forcing on the salinity dynamics of the Columbia River estuary, I employ the non-dimensional parameter space plot developed by Geyer \& MacCready (2014). Plotting model results onto the Geyer \& MacCready parameter space is challenging in an estuary with irregular geometry since it is unclear what representative depth, width, and tidal velocity to use. The choice of a specific depth, width, and tidal velocity could move the location of an estuary from one 
regime to another. To overcome this problem, I apply both Eulerian and Lagrangian approaches and qualitatively compare the resultant parameter space to actually modeled results. In this way, I ensure that a forcing condition that is placed, for example, in the "highly stratified" parameter space, is actually highly stratified over a modeled tidal period.

The Eulerian method is applied at three locations along the South Channel of the estuary: at the mouth (rkm0), in the middle of the estuary (SAT3, rkm13), and Tongue point (rkm29), see Figure 4-1-a for locations. At each location, the mixing time scale $\left(T_{m}\right)$ was found from the relation $T_{m}=H^{2} / K_{m}$ and compared to a half-tidal cycle time scale $(T)$. Note that the bottom boundary layer would likely reach the surface if $T_{m}<T$. The local depth is $H$, and $K_{m}$ is the eddy viscosity coefficient as averaged from model results over the water column at each station. The mixing time scale $\left(T_{m}\right)$ was found for each flood and ebb period during high flow $(9,000 \mathrm{CMS})$ and low flow $(3,000 \mathrm{CMS})$ periods. The local depth and eddy viscosity coefficient were averaged over a half-tidal cycle, see Figure 4-10. The estuary is considered completely mixed if mixing time is less than the half-tidal time for all three stations. In the Geyer \& MacCready (2014) parameter space plot (Figure 2-2 and also below), the mixed condition is the parameter space located to the right of the diagonal red line.

The Lagrangian method uses the 2-psu isohaline to define a time-varying region over which to evaluate the freshwater Froude number (Equation 4.2) and the Mixing number (Equation 4.3). The water depth (H), channel width (W), and tidal velocity are spatially averaged over the region in between the mouth and the 2-psu isohaline in $2.5 \mathrm{~km}$ 
intervals (Figure 4-11). Then (H) and (W) are averaged over the duration of both the flood and ebb tide, and the tidal velocity is estimated as the root-mean-square of hourly-spaced model output.

A comparison of the Lagrangian and Eulerian methods of estimating tidally averaged Froude and mixing numbers shows that they both agree with the vertical salinity structure profile. An example of this analysis is the vertical salinity structure plots of the modern model (MM) during high river discharge (9,000 CMS, mean; Figure 4-12). Each plot represents either the end of a flood period $(\mathrm{F})$ or the end of an ebb (E) while the numbers in Figure 4-12 represent the day of that month (June). For both flood and ebb, the estuary is found to be mostly stratified during the whole month except for the five tidal periods that are enclosed by a green rectangle in Figure 4-12. The analyses of high $(9,000 \mathrm{CMS})$ and low $(3,000 \mathrm{CMS})$ river discharge simulation data showed that the Eulerian method matched the Lagrangian approach in 93\% of cases (i.e., it is in the same bin in the parameter space). The occasional mismatch occurs when the Eulerian approach slightly overestimates the mixing time scale. This may result from averaging the local depth and eddy viscosity coefficient over a half-tidal cycle. For the historical model (HH) analysis, I found full consistency between the Eulerian and the Lagrangian approaches for the high flow, and 88\% matches between Lagrangian and Eulerian for the low flow condition. 

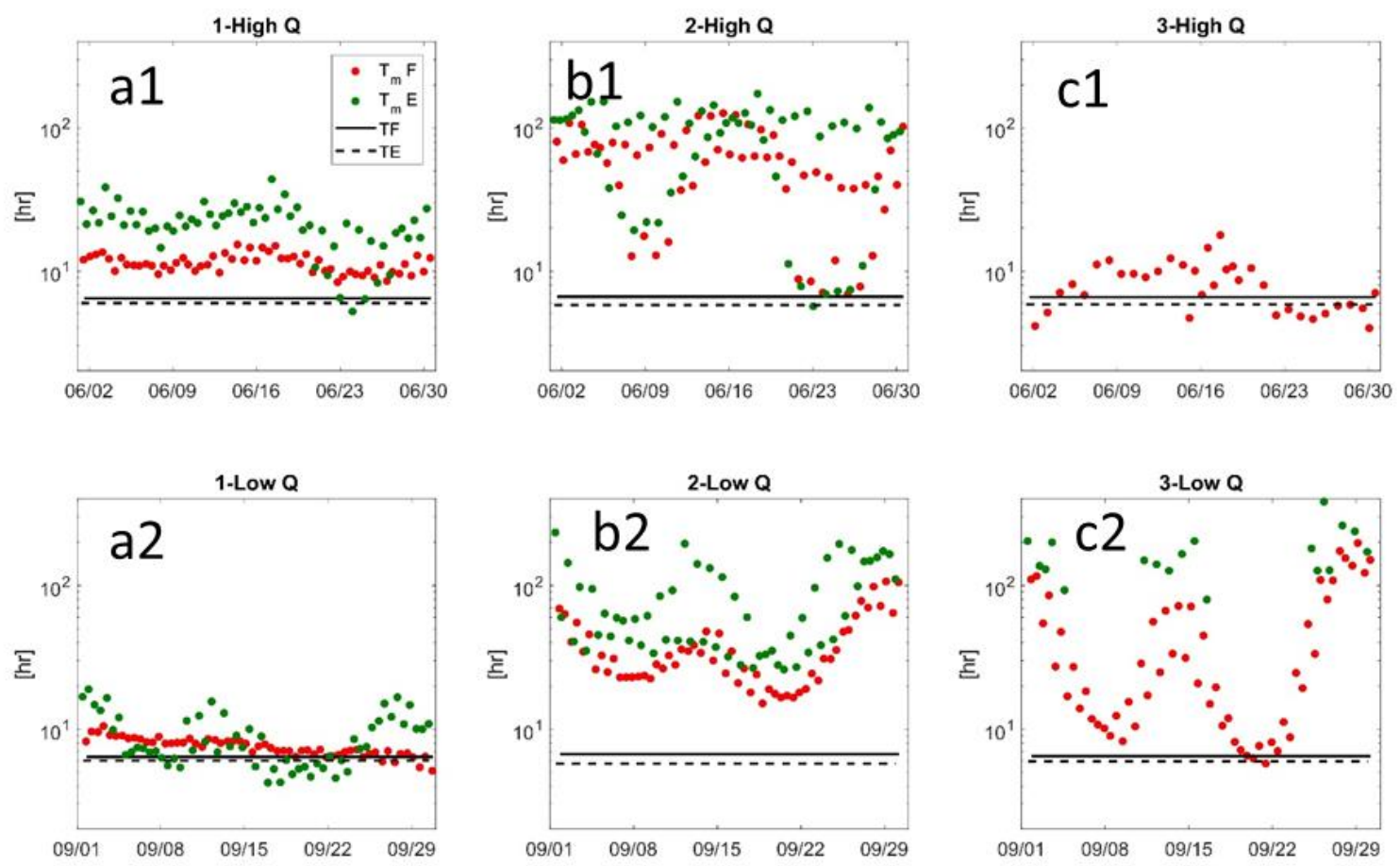

Figure 4-10. Eulerian Approach, (1) is the RKMO location at the mouth, (2) is the SAT3 location (11.5km from the mouth), and (3) is the Tongue point location (25Km from the mouth). The red dots are for the end of the flood, while the green ones are for the end of the ebb period. The black solid line is the mean flood time and the dashed line is the mean ebb time. Finally, the top row is for the high flow conditions and the lower panel is for the low flow period.

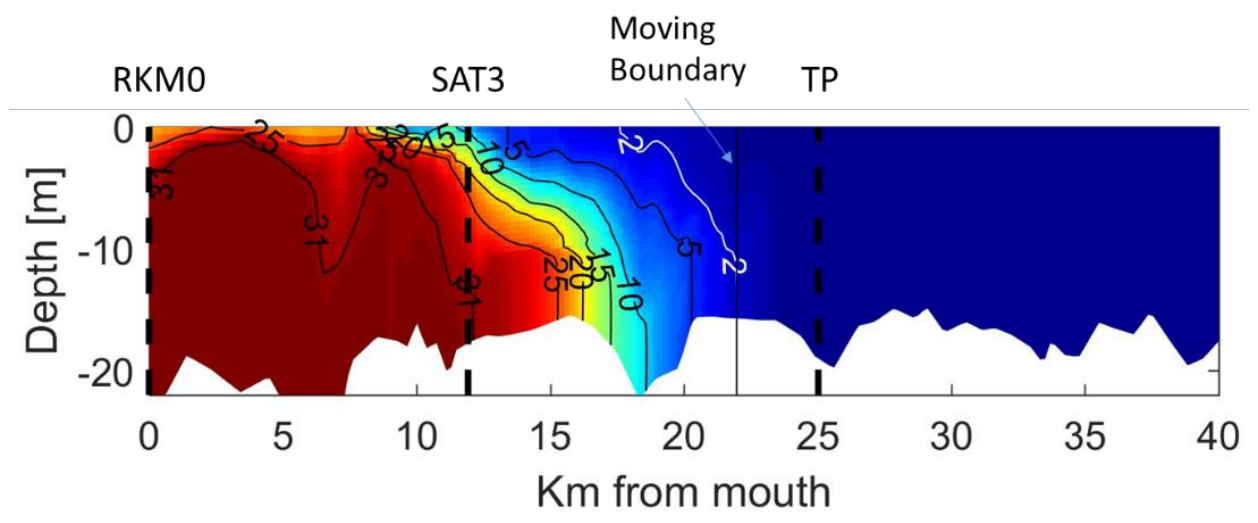

Figure 4-11. Eulerian vs. Lagrangian approaches. The three Eulerian locations are RKM0, SAT3, and Tongue point (TP). The Lagrangian approach is from Rkm0 to the white line (2psu isohaline moving boundary). 

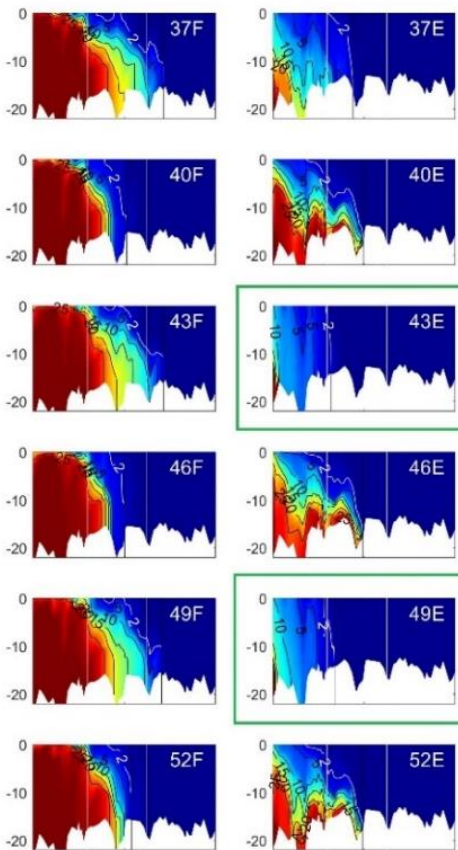
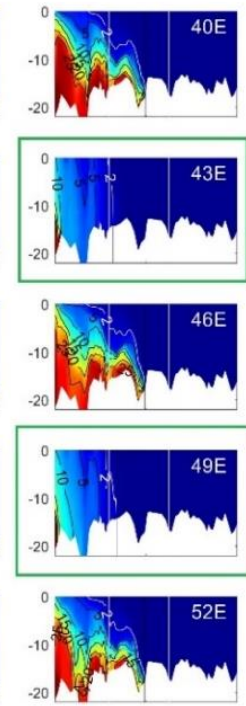
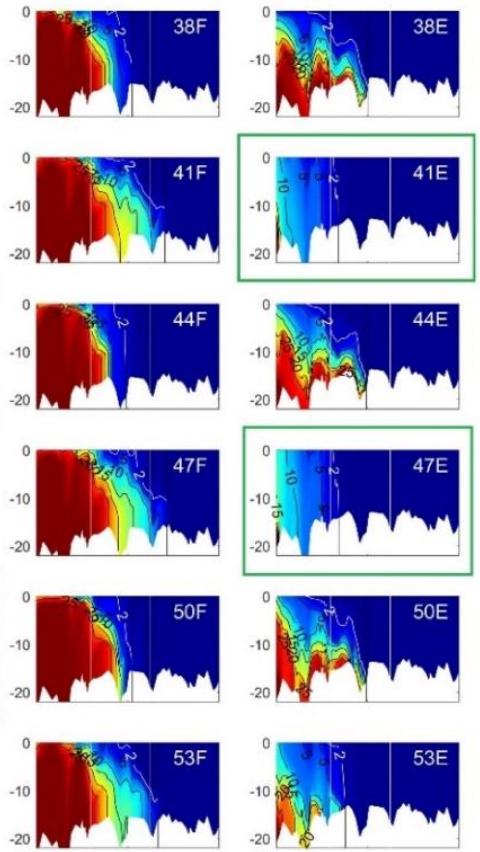
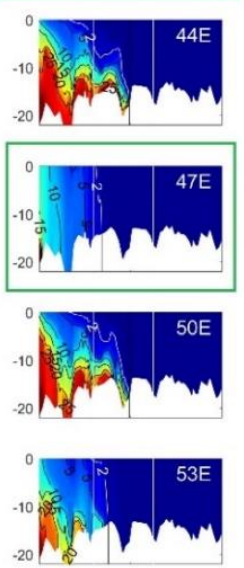
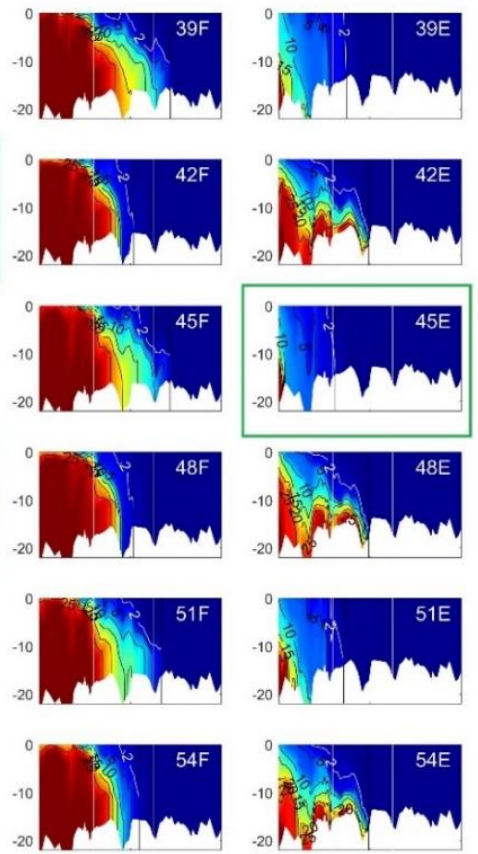

Figure 4-12. Vertical salinity structure of the modern model (MM) for the South Channel during the high flow period. $F \& E$ denote the spatial structure at the end of flood and ebb periods; numbers represent the number of floods/ebbs since the beginning of the month. Green rectangles enclose the situation where the total vertical mixing is likely to happen.

After applying the Eulerian \& Lagrangian approaches for quality control, the model data for both modern model (MM case) and historical model (HH case) were plotted on the Geyer \& MacCready (2014) parameter space using the Lagrangian approach (as shown in Figure 4-13). Each point in Figure 4-13 represents the end of each flood and each ebb for the whole simulation year. In the modern model (MM case), it is found that the estuary occupies the strongly stratified regime $50 \%$ of the time, the salt wedge regime $34 \%$ of the time, the partially mixed region $10 \%$ of the time, and the time-independent salt wedge $6 \%$ of the time. By comparison, in the historical model (HH case), the percentages are 50\%, $4 \%, 41 \%$, and $4 \%$, respectively. Thus, changes in the river discharge and bathymetry have 
caused the modern system (MM case) to spend more time in the salt wedge regime but less time in the partially mixed zone than the historical system (HH case).

Although the total river discharge $\left(\mathrm{Q}_{\mathrm{T}}\right)$ range is higher in the $\mathbf{H H}$ model, the percentage of freshwater going through the South Channel (Qs) is lower in the MM model. Because of the higher discharge and the greater cross-sectional area (A), the river velocity $\left(\mathrm{U}_{\mathrm{R}}\right)$ range in the $\mathbf{M M}$ model is larger than in the $\mathbf{H H}$ model (Table 4-3). Hence, the $\mathbf{M M}$ model occupies the salt wedge zone (determined by $F r_{f} \sim U_{R} / H^{1 / 2}$, from equation 4.2) more frequently despite the bathymetric changes. Likewise, even though the tidal velocity ( $\mathrm{U}_{\mathrm{T}}$ ) range in the MM model is larger than in the $\mathbf{H H}$ model (Table 4-3), the range of mixing number is still larger in the $\mathbf{H H}$ model because of its shallower depth $\left(\mathrm{M} \sim \mathrm{U}_{T} / H^{3 / 4}\right.$, from equation 4.3). Hence, the $\mathbf{M M}$ model spends a lower percentage of time in the partially mixed regime. 

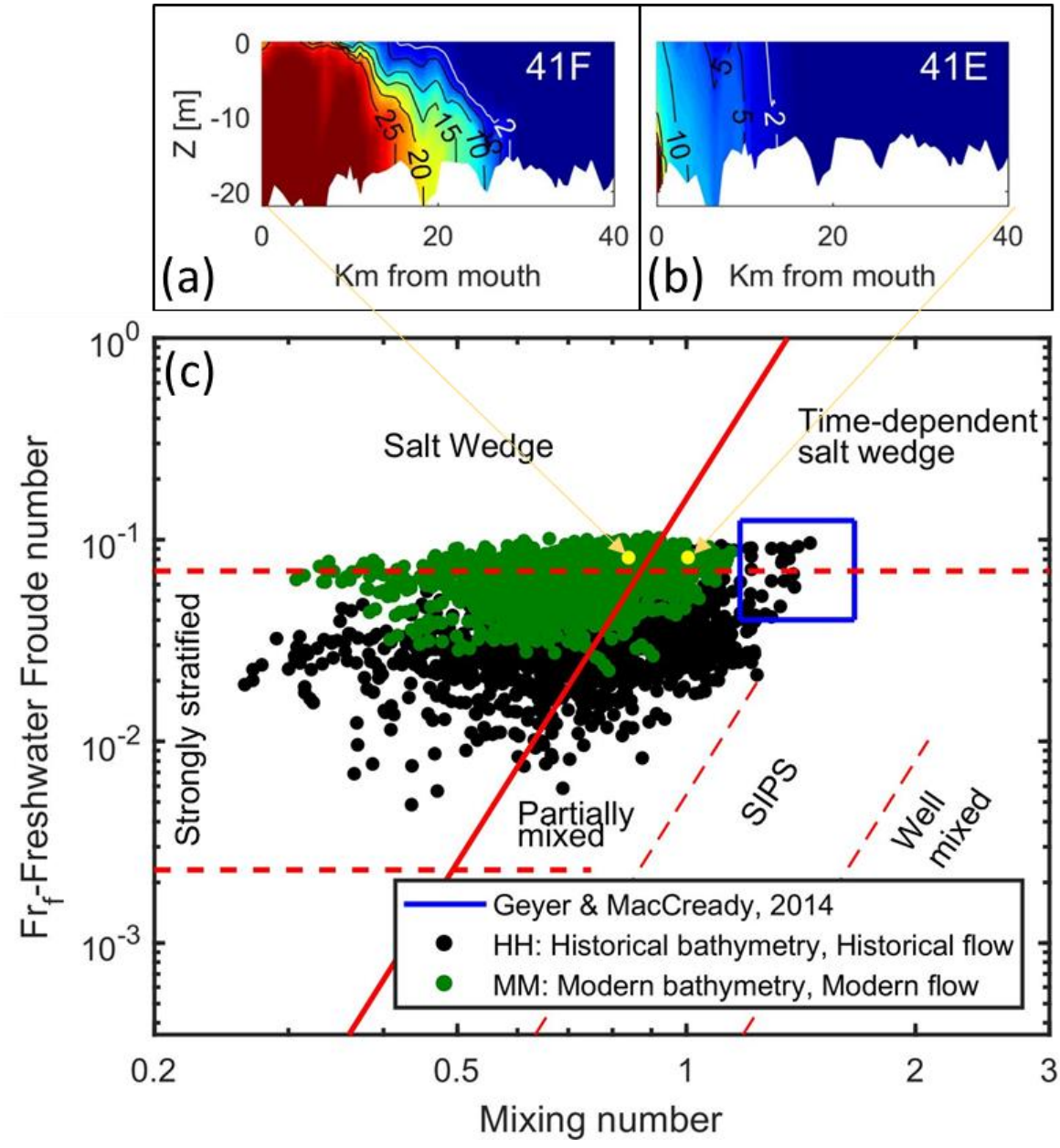

Figure 4-13. Parameter space for the modern and historical models, where (a) \& (b) represent the Lagrangian approach for flood and ebb of the 41 tidal cycles during June (high flow period), and (c) is the presentation of modeling results of modern and historical models

Table 4-3. The effective variables and ranges in the parameter space: $Q_{T}$ is the river discharge at the BAT, $Q_{S}$ is the freshwater in the South Channel, $H$ is the water depth range, $A$ is the cross-section area, $U_{T}$ is the tidal velocity range, and $U_{R}$ is the river velocity range in the South Channel.

\begin{tabular}{|l|c|c|}
\hline & MM model & HH-model \\
\hline $\mathbf{Q}_{\mathbf{T}}\left[\mathbf{m}^{3} / \mathbf{s}\right]$ & $2,000-10,000$ & $1,400-15,000$ \\
\hline $\mathbf{Q}_{\mathbf{s}}\left[\mathbf{m}^{3} / \mathbf{s}\right]$ & $1,100-5,200$ & $160-3,750$ \\
\hline $\mathbf{H}[\mathbf{m}]$ & $11-15$ & $6.5-11$ \\
\hline $\mathbf{A}\left[\mathbf{m}^{2}\right]$ & $(2.4-4.3) \times 10^{4}$ & $(1.7-3.9) \times 10^{4}$ \\
\hline $\mathbf{U}_{\mathbf{T}}[\mathbf{m} / \mathbf{s}]$ & $0.33-1.3$ & $0.23-1.05$ \\
\hline $\mathbf{U}_{\mathbf{R}}[\mathbf{m} / \mathbf{s}]$ & $0.04-0.17$ & $0.008-0.12$ \\
\hline
\end{tabular}




\subsection{Conclusions}

Both river flow and bathymetrical variation can affect salinity intrusion in estuaries. The analysis of river flow effects on LCRE salinity intrusion shows that the time series profiles of salinity intrusion follow the same pattern of the river flow hydrograph. However, a significant seasonal change in salinity intrusion is found during winter and spring. Less salinity intrusion occurs during winter while greater intrusion takes place in spring because modern discharge is significantly larger in winter and much smaller in magnitude during spring-freshet than historical river flow. Moreover, the change in the bathymetry of the estuary caused by deepening the South Channel made the system more stratified, so that the intrusion pushed further landward.

The combined effect of both river flow alteration $\left(50^{\text {th }}\right.$ percentile) and bathymetric change suggests an increase of about $10 \mathrm{~km}$ in maximum hourly salinity intrusion into the system. Additionally, the time of occurrence of maximum intrusion has shifted from early January to the end of September, as it corresponds to the minimum river flow. Furthermore, a change in the spring-neap intrusion was noticed due to the bathymetric variation, such that there is more salinity intrusion variation between spring and neap in the modern model than in the historical one, though there was greater seasonal variability in neap-spring transitions historically. The deeper channel's salinity intrusion pushed further landward than the shallower channel because of the neap-spring transition in stratification. The bathymetric changes to the CRE have not only affected the timing and salinity intrusion 
position, but also the intrusion-river flow sensitivity, on account of the change in water distribution between the South and North Channels.

Finally, the location and the range of the LCRE has changed on the Geyer and MacCready (2104) diagram. Given that the scales are logarithmic, small visual changes in Figure 4-13 are quite significant in process terms - on the whole, the system is now more stratified than it was historically. For both models, historical and modern, the estuary occupies four regimes in the parameter space: Salt wedge, time-dependent salt wedge, strongly stratified, and partially mixed. However, the estuary has changed in two major regimes such that it used to spend more time in the partially mixed and less time in the salt wedge regimes. Though the river flow alteration has contributed slightly to the regime changes as the change in the channel geometry has balanced the flow alteration, these regime changes are due to mainly to bathymetric changes.

In this research, I have shown the use of historical and modern bathymetry and flow with corresponding numerical model grids to evaluate changes in salinity intrusion patterns in the LCRE over the past $\sim 150$ years. By studying salinity intrusion over a year, I have expanded on previous short-term scale models of the LCRE and provided a broader overview of the system hydrodynamics due to variable tide and fluvial forcing. Finally, I have demonstrated the importance of the variable selection (depth, width, and tidal velocity) on the estuarine classification by utilizing different (Eulerian and Lagrangian) approaches. 


\section{Chapter 5 After the Earthquake and Climate Change: How Sudden Relative Sea- Level Changes May Alter Salinity Intrusion in the Columbia River Estuary?}

\subsection{Introduction}

The estuarine depth of the Lower Columbia River Estuary (LCRE) is increasing over time. This depth alteration can be man-made (dredging) or natural (sea-level rise or sudden land subsidence). In this chapter, I will explore the effect of possible future depth changes on the LCRE estuarine hydrodynamics. The Cascadia Subduction Zone (CSZ) is a $1000 \mathrm{~km}$ long fault along a subduction zone between Northern California and British Columbia, Canada (Clague, 1997). It is thought that mega- earthquakes (greater than M8.5) recur about every 400-600 years (Atwater et al., 2005). The last known mega-earthquake in the northwest occurred over 300 years ago (January 1700). The effects of the tsunami waves associated with this earthquake have been found in sediments up to Rkm 56 up the Columbia River (Atwater et al., 2005). In addition to a tsunami wave, average land subsided by up to $0.5 \mathrm{~m}$ along the Oregon coast (Hawkes, et al., 2011; Mori et al, 2011). The maximum wave height resulting from the M8.7-9.2 earthquake could range from $4 \mathrm{~m}$ to $25 \mathrm{~m}$ along the shoreline of Bandon, Oregon as predicted via simulation by Witter et al. (2013). A simulation of a hypothetical tsunami at the Columbia River mouth by Yeh et al (2012) used a maximum tsunami amplitude of $5.6 \mathrm{~m}$ at the mouth. The wave height was modeled to decrease to $\sim 1.5 \mathrm{~m}$ by Astoria Tongue Point and to about $0.35 \mathrm{~m}$ near Beaver Army Terminal ( $\mathrm{Rkm}$ 86). Further, the subsidence in the LCRE resulting from the M9 
earthquake could lower the land by $2 \mathrm{~m}$ at the coast and $1.5 \mathrm{~m}$ at Astoria with small or negligible change further upstream (Kalmbacher \& Hill, 2015; OSSPAC, 2013).

There are three tectonic plates on the Pacific Northwest that are in continuous horizontal movement and could cause a major earthquake: The Pacific Plate, the North American plate, and the Juan De Fuca plate (Dipietro, 2013). The result of these movements causes a spatially variable uplift of the Oregon coastal zone. Talke et al. (2020) reported uplift activity of $\sim 1.5 \mathrm{~mm} / \mathrm{yr}$ near the coast of the Columbia River and uplift of 0.35-0.4 mm/yr in the Tongue Point; a similar pattern was reported by Burgette et al. (2009). Variable coastal uplift is confirmed through an analysis of sea-level data, leveling surveys, and Global Navigation Satellite System (GNSS) data (Burgette et al., 2009; Talke et al., 2020).

The projection of sea-level rise in Oregon (including causes both global and local) suggested by NRC (2012) suggests that sea-level rise could reach up to $1.43 \mathrm{~m}$ by 2100 . Additionally, a potential earthquake $>=8$ in magnitude could raise the regional relative sealevel (RSL) another 1-2m over these projected values, through land subsidence (Pfeffer et al., 2008). Based off of my previous simulations which shows that depth increases cause increased salinity intrusion (Chapter 4), I hypothesize that future increased depth would increase salinity intrusion. Further, sea-level rise could impact estuarine habitats by alter salinity, water levels, and inundation of shallow water habitat. Tidal marshes, for example, could convert to tidal flats or lagoons because of changes in their elevation range (Horton et al., 2018). 
The potential for sudden land subsidence, projected coastal sea-level rise, and predicted changes to river hydrology (more winter flow, less spring and summer flow) have motivated this study. In this chapter, I test both the effect of a constant sea-level rise and a linearly varying bathymetry on salinity intrusion and tides, as possible scenarios, and compare them to a validated simulation of the present-day situation. Both these scenarios are plausible given current projections, and in fact may occur together, making the effects worse. These scenarios constrain the order of magnitude changes that might occur. However, any morphodynamic changes that result from the tsunami and its aftermath are not modeled, and could merit further consideration in the future.

\subsection{Theory}

A theoretical model of salinity intrusion was presented by Monismith et. al. (2002), based on the cross-sectionally and tidally averaged salt conservation equation (Hansen \& Rattray, 1965) as:

$$
X_{2}=\frac{(W \alpha)^{1 / 3}\left(\beta g S_{o}\right)^{2 / 3} H^{3}}{Q^{1 / 3} v_{t}},
$$

Equation 5.1 assumes steady-state, constant depth, vertical eddy diffusivity is equal to the eddy viscosity, and assumes that tidally averaged circulation is the primary mechanism of salinity intrusion. The variable $X_{2}$ is the salinity intrusion length from the mouth of the estuary toward the upstream point at which the bottom salinity is 2-psu (Monismith et al., 2002; MacWilliams et al., 2015). $W$ is the width, $\alpha$ is the constant of proportionality 
$\left(5.4 \times 10^{-5}\right), \beta$ is the saline expansivity $\left(7.7 \times 10^{-4}\right.$ psu-1), $S_{o}$ is ocean salinity, $H$ is the local depth, $Q$ is the river flow, and $v_{t}$ is the eddy diffusion coefficient. Assuming that $v_{t}$ scales as $u_{t} H$, where $u_{t}$ is the tidal velocity, then the salinity intrusion scale become:

$$
X_{2}=\frac{(W \alpha)^{1 / 3}\left(\beta g S_{o}\right)^{2 / 3} H^{2}}{Q^{1 / 3} U_{t}}
$$

The scaling in equation 5.1 shows that the salinity intrusion scales as water column depth squared $\left(H^{2}\right)$, holding the other parameters constant (especially river discharge). In this theory, estuarine circulation $\left(U_{E}\right)$ and stratification $(\Delta S)$ scale as follows (MacCready \& Geyer, 2010):

$$
\begin{gathered}
U_{E}=\frac{g H^{3} \beta}{48 v_{t}} \frac{\partial s}{\partial x}, \\
\Delta S=U_{E} \frac{H^{2}}{K_{S}} \frac{\partial s}{\partial x},
\end{gathered}
$$

where $K_{S}$ is the eddy diffusivity. Using $v_{t} \sim u_{t} H$ and $K_{S} \sim v_{t} / S_{c} \sim u_{t}\left(H / S_{c}\right)\left(S_{c}\right.$ is Schmidt number), the estuarine circulation and stratification scaling equation can be written as:

$$
\begin{gathered}
U_{E}=\frac{g H^{2} \beta}{48 u_{t}} \frac{\partial s}{\partial x}, \\
\Delta S=U_{E} \frac{H S_{c}}{u_{t}} \frac{\partial s}{\partial x}, \text { or } \quad \Delta S=\frac{\beta g S_{c}}{48 u_{t}^{2}}\left(\frac{\partial s}{\partial x}\right)^{2} H^{3},
\end{gathered}
$$

The scaling above suggests that the estuarine circulation and stratification are proportional to $H^{2}$ and $H^{3}$, respectively. Monismith et al. (2002) \& Ralston et al. (2008) approximate $\frac{\partial s}{\partial x}$ to be $\frac{s_{0}}{X_{2}}$ for the steady-state salt balance, so that estuarine circulation and stratification equations can be written as:

$$
U_{E}=\frac{g H^{2} \beta}{48 u_{t}} \frac{S_{0}}{X_{2}}, \quad \text { or } \quad U_{E}=\frac{1}{48}\left(\frac{g \beta S_{o} Q}{W \alpha}\right)^{1 / 3}
$$




$$
\Delta S=\frac{\beta g S_{c}}{48 u_{t}^{2}}\left(\frac{S_{0}}{X_{2}}\right)^{2} H^{3}, \quad \text { or } \quad \Delta S=\frac{S_{c}\left(S_{0} Q\right)^{2 / 3}}{48 H(\beta g W \alpha)^{1 / 3}}
$$

The last two equations suggest that estuarine circulation is independent of depth during steady-state conditions, and stratification is proportional to $H^{-1}$.

For the Hudson River Estuary, the results of Ralston \& Geyer, (2019) agreed with the scaling in equation 5.7, in that the estuarine circulation is independent of channel depth (i.e., when the channel deepened, the salinity intrusion increased but there was no change in estuarine circulation). However, they found that stratification increased with increasing depth, which contradicted the steady-state balance in equation 5.8. This area of estuarine circulation theory remains unresolved.

\subsection{Methods}

The effects of relative sea-level rise and possible earthquake-induced land subsidence on tidal properties and salinity intrusion were simulated using a 3D hydrodynamic model. The model was calibrated earlier in Sections 3.3 and 4.3. Six possible scenarios were considered. The base case (B-2019) represents the current bathymetry and no rise in sea-level, case B-2100 simulates a $0.21 \mathrm{~m}$ sea-level rise, and B2300 simulates $1.5 \mathrm{~m}$ sea-level rise. For each of the sea-level rise cases, I made an additional simulation which represented the effect of spatially variable land subsidence caused by a subduction-zone earthquake (Table 5-1). All cases were simulated using a river discharge boundary condition that applied two constant flow conditions $\left(3,000 \mathrm{~m}^{3} / \mathrm{s}\right.$, labeled "LO" 
and $15,000 \mathrm{~m}^{3} / \mathrm{s}$, labeled "HI"). Each discharge was applied for two weeks to equilibrate the model, and then the model was run for a month to cover two full neap-spring cycles.

The projections of relative sea-level rise in 2100 and 2300 were selected based on the projections of Kopp et al. (2017) with a high greenhouse emission scenario (Figure 51). They projected a SLR with high (RCP8.5), moderate (RCP45), and low (RCP2.6) greenhouse emission scenarios. The relative sea-level rise utilized is the 50th percentile projection of the worst-case scenario (i.e., the model with high greenhouse emissions, Figure 5-1a). The Earthquake-induced land subsidence scenario is based on a hypothetical change in depth that is $2 \mathrm{~m}$ at the coast, zero at the upstream boundary (Kalmbacher \& Hill, 2015), and 1.5m at Astoria for a magnitude 9 earthquake (OSSPAC, 2013), see Figure 5-2

Table 5-1. Simulation scenarios for the constant river discharge.

\begin{tabular}{|c|c|c|}
\hline Case & $\begin{array}{c}\text { Sea-level Rise } \\
{[\mathbf{m}]}\end{array}$ & Subsidence \\
\hline B-2019 & 0 & No \\
\hline B-2100 & 0.21 & No \\
\hline B-2300 & 1.50 & No \\
\hline T-2019 & 0 & Yes \\
\hline T-2100 & 0.21 & Yes \\
\hline T-2300 & 1.50 & Yes \\
\hline
\end{tabular}




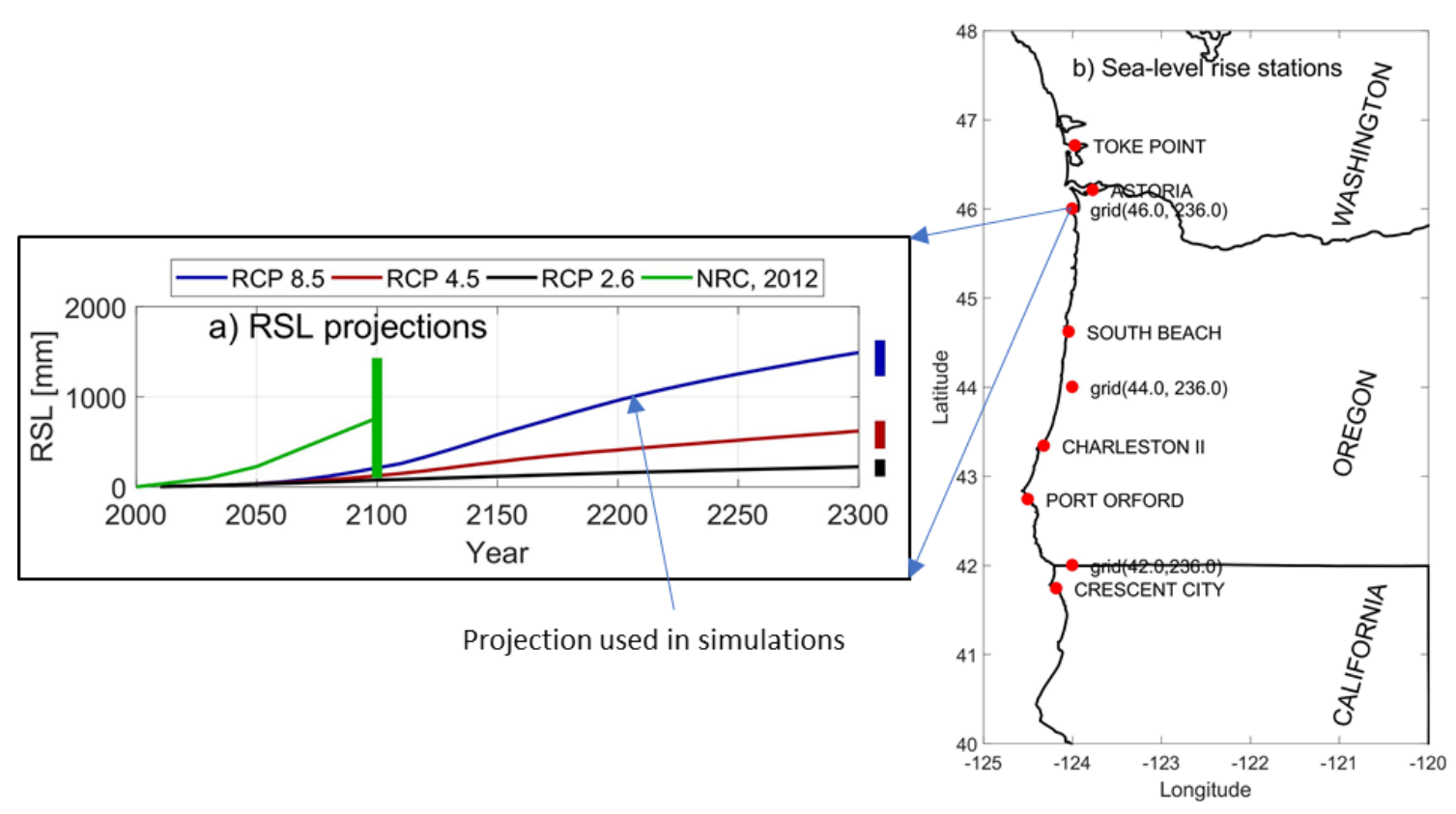

Figure 5-1. (a) Projected relative sea-level rise scenarios near CRE with 5 and $95 \%$ confidence interval, RCP8.5 is a sub-model with a high greenhouse emissions scenario, RCP4.5 is a moderate greenhouse emissions scenario, and RCP2.6 is a low greenhouse emissions scenario. The green plot is from NRC, 2012 predictions. (b) Sea-level rise stations along the west coast (Kopp et al., 2017). 

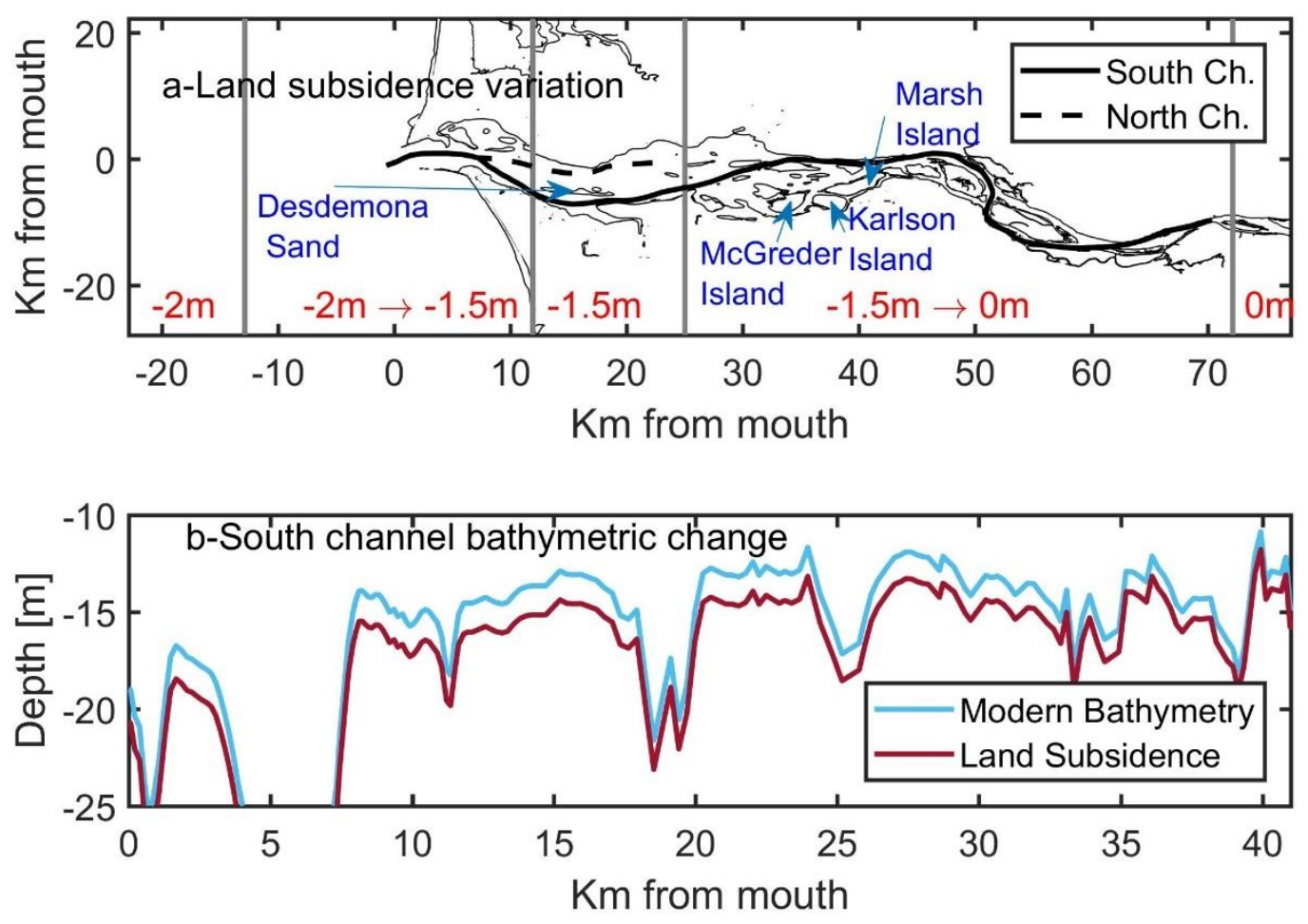

Figure 5-2. Projected subsidence scenario in the LCRE a result of a Cascadia zone subduction earthquake; the scenario is $2 \mathrm{~m}$ subsidence at the coast, zero at the upstream model boundary (Rkm 86), and $1.5 \mathrm{~m}$ at Astoria, after Kalmbacher \& Hill (2015).

I also assessed the impact of hydrological changes on the sessional variation of salinity intrusion. First, projected future river discharge conditions were extracted from USBR (2016) which predicts the potential hydrologic impacts of climate change in the Columbia River Basin. Their projected scenarios for the Columbia River above The Dalles are presented in Table 5-2. The tabulated data shows the percentage of changes in river hydrograph from the 1990s to the 2040s and 2080s. From this projection, I have chosen the minimum values of the 2080s to represent the future change in the hydrograph, where 
the Winter discharge increases by $26 \%$ and spring freshet reduces by $17 \%$ (Figure 5-3). Note that this does not consider any changes in the management of the system. To account for changed river flow, four more simulations were conducted to represent the combined effect of SLR and river hydrograph on salinity intrusion (Table 5-3).

Table 5-2.Hydrologic modeling for the Columbia River above The Dalles [after the Bureau of Reclamation, (2016)]

\begin{tabular}{|c|c|c|}
\hline $\begin{array}{c}\text { Change from 1990s } \\
(\mathbf{1 9 8 0 - 2 0 0 9 )}\end{array}$ & $\begin{array}{c}\mathbf{2 0 4 0 s} \\
\mathbf{( 2 0 3 0 - 2 0 5 9 )}\end{array}$ & $\begin{array}{c}\mathbf{2 0 8 0 s} \\
\mathbf{( 2 0 7 0 - 2 0 9 9 )}\end{array}$ \\
\hline Mean Annual Runoff (\%) & -5 to +10 & -4 to +15 \\
\hline Mean Dec-Mar Runoff $(\%)$ & +13 to +44 & +26 to +91 \\
\hline Mean Apr-Jul Runoff $(\%)$ & -8 to +8 & -17 to +10 \\
\hline
\end{tabular}

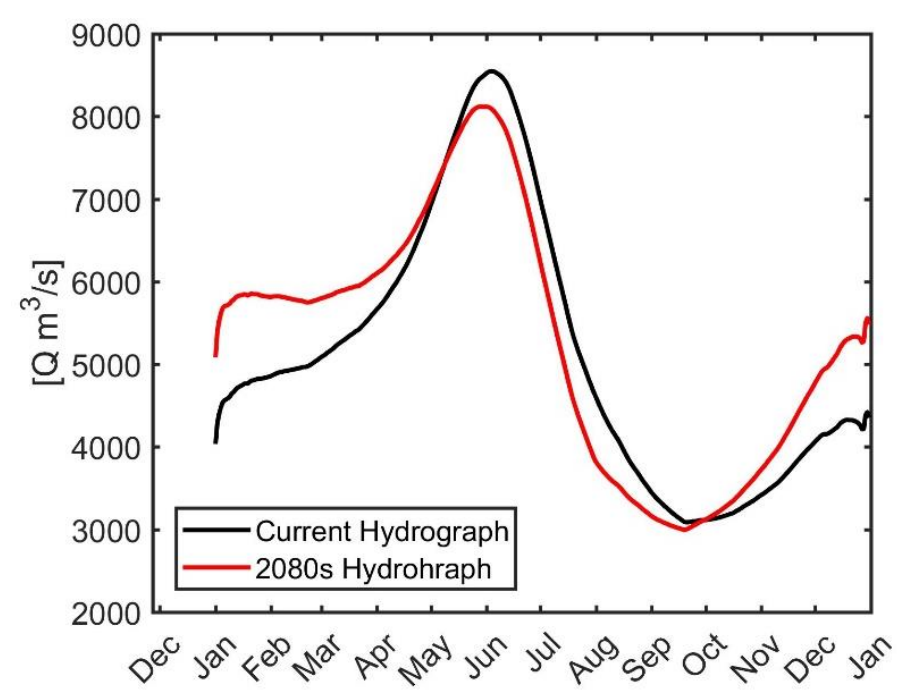

Figure 5-3. Future hydrograph changes (Winter increases by $26 \%$ and spring freshet reduced by $17 \%$ ) 
Table 5-3. Simulation scenarios for a variable river discharge

\begin{tabular}{|c|c|c|c|}
\hline & $\begin{array}{c}\text { River } \\
\text { hydrograph }\end{array}$ & SLR $[\mathrm{m}]$ & Description \\
\hline P-2019 & Present & 0 & Recent river hydrograph w/o any SLR \\
\hline F-2019 & Future & 0 & Future river hydrograph w/o any SLR \\
\hline F-2100 & Future & 0.21 & Future river hydrograph w/ Future SLR \\
\hline F-2300 & Future & 1.50 & Future river hydrograph w/ Future SLR \\
\hline
\end{tabular}

\subsection{Results}

\subsubsection{Tidal changes}

Increases in depth are simulated to cause an increase in tidal amplitudes everywhere within the estuary, consistent with past measurements and models (Talke et al., 2020; Helaire, et al., 2019). The effect of depth change applied equally everywhere is illustrated in the comparison of Figure 5-4a to Figure 5-4b (low river discharge) and Figure 5-4c to Figure 5-4-d (high river discharge). Consistent with past studies (Jay et al., 2011; Moftakhari et al., 2013; Talke \& Jay, 2020) higher river discharge tends to dampen the tidal amplitude (Figure 5-4a \& Figure 5-4c or Figure 5-4b \& Figure 5-4d). The comparison among all cases including sea-level rise and/or Earthquake-induced land subsidence can be illustrated using Figure 5-4e and Figure 5-4f for low and high river discharges, respectively. In addition to increased tidal range $\left(\mathrm{M}_{2}\right.$ amplitude), the location of the maximum tide has shifted into the upstream for all cases in response to the increased depth.

Results show that $0.21 \mathrm{~m}$ RSL has a slight effect on $\mathrm{M}_{2}$, but a $1.5 \mathrm{~m}$ RSL rise causes an increase in $\mathrm{M}_{2}$ of 5-6\%. The $\mathrm{M}_{2}$ amplitude maximum is pushed $\sim 4.1 \mathrm{~km}$ and $4.2 \mathrm{~km}$ further upstream for low and high river discharge, respectively. The earthquake-induced 
land subsidence case has a similar effect as $1.5 \mathrm{~m} \mathrm{RSL}$ on $\mathrm{M}_{2}$ as $1.5 \mathrm{~m} \mathrm{RSL}$ (5-6\% increase and 2.6-4.2km propagation), see Table 5-4. The combined effect of 1.5m RSL rise and land subsidence is simulated to increase the peak of $\mathrm{M}_{2}$ amplitude by $11 \%(0.11 \mathrm{~m})$ with landward propagation of the $\mathrm{M}_{2}$ maximum by about $10 \mathrm{~km}$ during the low-flow simulation.
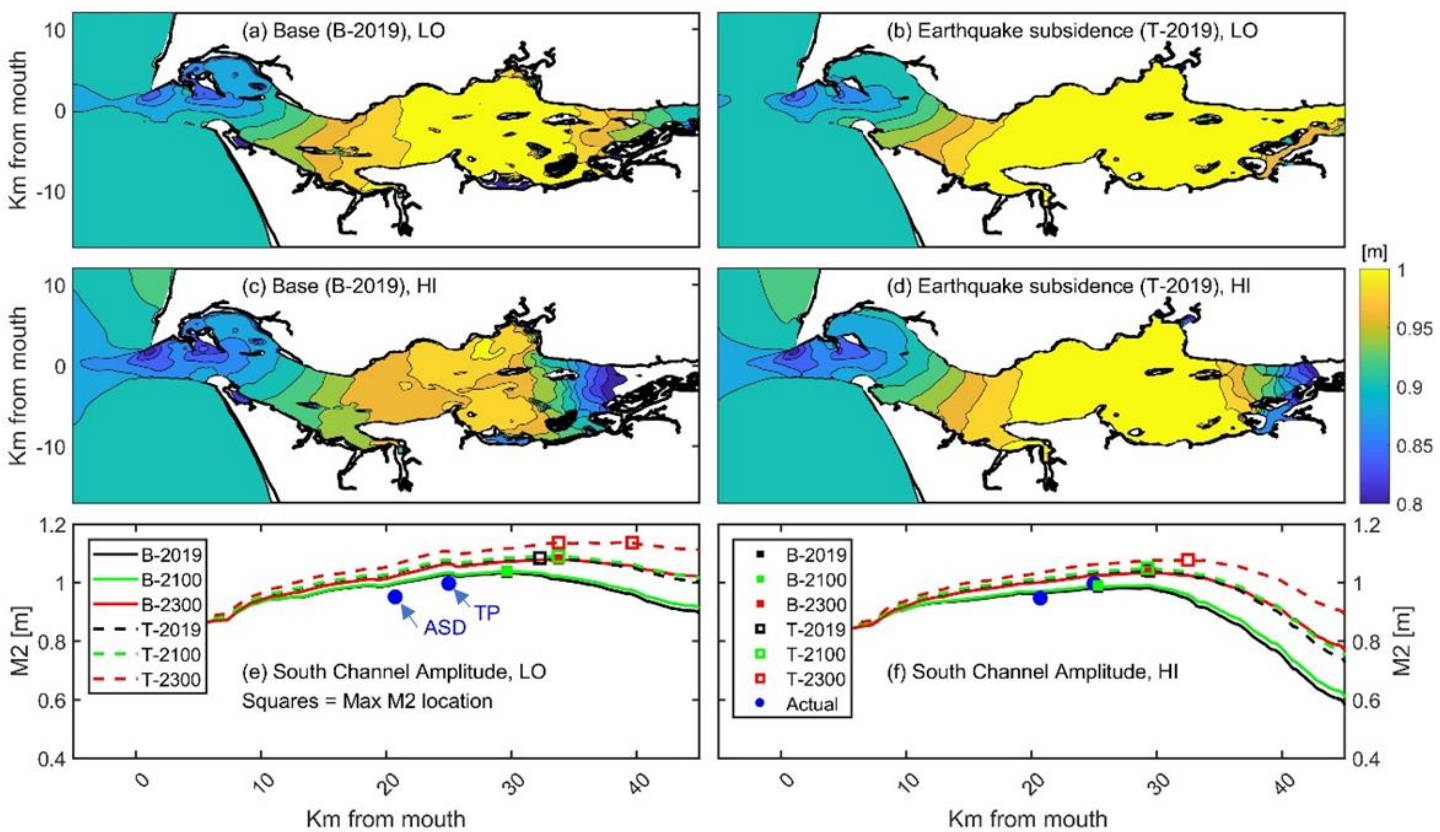

Figure 5-4. Changes in tides forth scenarios indicated; squares represent the location of maximum amplitude. For South Channel location, see Figure 5-2. 
Table 5-4. Sea-level rise and earthquake-induced land subsidence effects on $M_{2}$ amplitude and location of Maximum $\mathrm{M}_{2}$ inside the South Channel of the estuary. Mean water depth is during low flow, averaged over neap-spring, and averaged spatially along the South Channel.

\begin{tabular}{|c|c|c|c|c|c|c|c|}
\hline Cases & $\begin{array}{c}\text { Location } \\
\text { from } \\
\text { mouth } \\
{[\mathrm{km}]}\end{array}$ & $\begin{array}{c}\text { Max } M_{2} \\
\text { location } \\
\text { shift }[\mathrm{km}]\end{array}$ & $\begin{array}{c}\mathbf{M}_{2} \\
\text { Amplitude } \\
{[\mathrm{m}]}\end{array}$ & $\begin{array}{c}\text { Increase } \\
\text { in } \\
\mathbf{M}_{2} \\
{[\mathrm{~cm}]}\end{array}$ & $\begin{array}{c}c \mathrm{M}_{2} \\
\text { Increment } \\
\text { percentage }\end{array}$ & $\begin{array}{l}\text { Mean } \\
\text { depth, } \\
H[\mathrm{~m}]\end{array}$ & $\begin{array}{l}\Delta \boldsymbol{H} \\
{[\mathrm{m}]}\end{array}$ \\
\hline \multicolumn{8}{|c|}{ Low Q } \\
\hline B-2019 & 29.7 & - & 1.03 & - & - & 18 & - \\
\hline B-2100 & 29.7 & 0 & 1.04 & 1 & $1 \%$ & 18.2 & 0.2 \\
\hline B-2300 & 33.8 & 4.1 & 1.08 & 5 & $5 \%$ & 19.5 & 1.5 \\
\hline T-2019 & 32.3 & 2.6 & 1.08 & 5 & $5 \%$ & 19.3 & 1.3 \\
\hline T-2100 & 33.8 & 4.1 & 1.09 & 6 & $6 \%$ & 19.6 & 1.6 \\
\hline T-2300 & 39.7 & 10 & 1.14 & 11 & $11 \%$ & 20.8 & 2.8 \\
\hline \multicolumn{3}{|c|}{ High Q } & & & & & \\
\hline B-2019 & 25.3 & - & 0.98 & - & - & 18.3 & - \\
\hline B-2100 & 25.3 & 0 & 0.99 & 1 & $1 \%$ & 18.5 & 0.2 \\
\hline B-2300 & 29.5 & 4.2 & 1.04 & 6 & $6 \%$ & 19.7 & 1.4 \\
\hline T-2019 & 29.3 & 4 & 1.04 & 6 & $6 \%$ & 19.6 & 1.3 \\
\hline T-2100 & 29.3 & 4 & 1.05 & 7 & $7 \%$ & 19.8 & 1.5 \\
\hline T-2300 & 32.5 & 7 & 1.08 & 10 & $10 \%$ & 21 & 2.7 \\
\hline
\end{tabular}

\subsubsection{Salinity Intrusion}

Salinity intrusion is greatly impacted by channel depth as suggested by salinity intrusion scaling in equation (5.1). The channel deepening effect is observed by the comparison of the baseline case and the subsidence case (without any sea-level rise) in Figure 5-5. Results suggest that the salinity intrusion would advance by $3.2 \mathrm{~km}$ landward during spring (compare Figure 5-5a with Figure 5-5c) and 4.6km during neap tides (compare Figure 5-5b with Figure 5-5d). The advance of salinity intrusion is in response to the land subsidence, which in turn increased the local depth inside the estuary. The larger depth has reduced the bed stress by about $0.06 \mathrm{~N} / \mathrm{m}^{2}$ and $0.08 \mathrm{~N} / \mathrm{m}^{2}$ for spring and neap (averaged along the South Channel), respectively, compared to the base case (current bathymetry). The reduction in bed stress enhances the stratification (see section 4.4.2) and 
reduces the vertical mixing, hence increasing salinity intrusion. The discrepancies between spring and neap intrusion are due to the higher spring tidal energy which enhances mixing and reduces the intrusion compared to neap tides (see Figure 4-6).
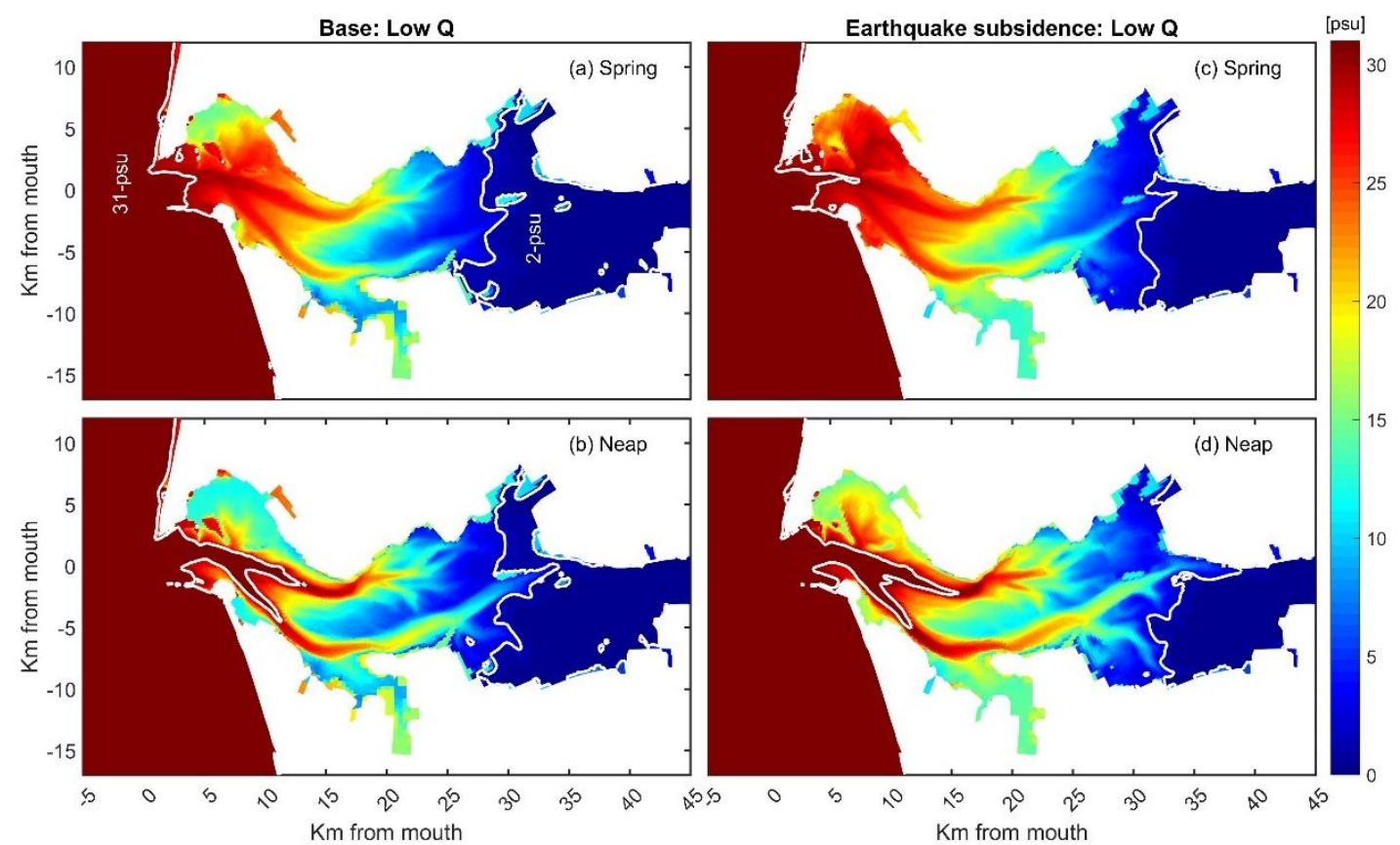

Figure 5-5. Salinity intrusion maps, white contours represent 31-psu \& 2-psu isohalines.

A similar increase in salinity intrusion is found in other sea-level rise scenarios, or when earthquake-induced subsidence and SLR occur together. The worst-case scenario (Figure 5-6b) is associated with the higher sea-level rise case $(1.5 \mathrm{~m})$ combined with the land subsidence case during neap tides (T-2300). In this scenario, the X2 (2psu) isohaline intrudes by $9.3 \mathrm{~km}$ landward during neap/low river flow conditions of $3000 \mathrm{~m}^{3} / \mathrm{s}$, from 34.4 $\mathrm{km}$ to $43.6 \mathrm{~km}$ from the mouth. 

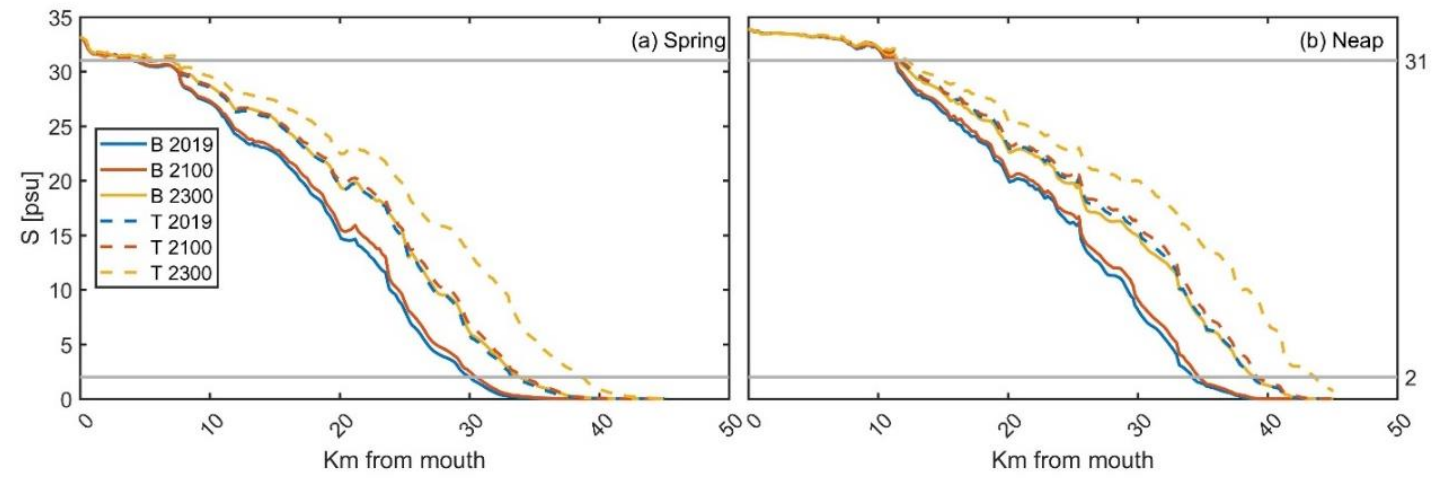

Figure 5-6. Tidally averaged bottom salinity profile along the South Channel

A statistical comparison (Table 5-5) shows that there is little change in salinity intrusion for $0.21 \mathrm{~m}$ SLR $(0.6 \mathrm{~km}$ increase in X2) but a substantial increase could happen in the case of $1.5 \mathrm{~m}$ SLR or sudden land subsidence resulting from a major earthquake (9magnitude) or both of them combined. For $1.5 \mathrm{~m}$ sea-level rise, the spring salinity intrusion could increase by about $3.8 \mathrm{~km}$ and $4.6 \mathrm{~km}$ for neap tides. This is nearly the same change in the intrusion as when land subsidence occurs without any SLR $(3.2 \mathrm{~km} / \mathrm{spring} \&$ $4.6 \mathrm{~km} / \mathrm{neap})$. In other words, the change in salinity intrusion that might occur in the next 300-years could happen nearly instantaneously, if a subsidence zone earthquake were to occur and cause the simulated subsidence.

Results show that other salinity isohalines have also propagated upstream. This can be seen in the 31-psu isohaline in Table 5-5, such that for 1.5m SLR, X31 advanced about $1.1 \mathrm{~km}$ during spring tides but only $0.2 \mathrm{~km}$ during neap tides. The land subsidence case pushed the 31 -psu isohaline upstream by $3.2 \mathrm{~km}$ and $0.4 \mathrm{~km}$ during spring and neap tides, respectively. 
Simulations, therefore, suggest that the subsidence case has slightly more impact on the horizontal salinity gradient than the sea-level rise case. Both the B2300 case and the land subsidence case are modeled to have a $1.5 \mathrm{~m}$ increase in water level snear Astoria, which is closer to the position of the $\mathrm{X} 2$ isohaline. Given similar depths, tides, and river flow, salinity intrusion behaves similarly. However, near the mouth, the $0.5 \mathrm{~m}$ greater depth in the earthquake subsidence scenario leads to a greater intrusion of the X31 isohaline. As a result, the gradient of salinity is slightly larger in the subsidence case, in the mid-estuary.

Table 5-5. Tidally averaged Salinity intrusion in the South Channel during spring (SP) and neap (NE) tides and low river discharge $(Q)$.

\begin{tabular}{|c|c|c|c|c|c|c|c|c|c|}
\hline \multicolumn{10}{|c|}{ 2-psu Salinity Intrusion (X2) } \\
\hline \multirow{2}{*}{ Base } & \multicolumn{4}{|c|}{$\mathrm{X}[\mathrm{Km}]$} & \multirow{2}{*}{ Tsunami } & \multicolumn{4}{|c|}{$\mathrm{X}[\mathrm{Km}]$} \\
\hline & SP & Diff. & $\mathbf{N E}$ & Diff. & & SP & Diff. & NE & Diff. \\
\hline B-2019 & 30.0 & 0 & 34.3 & 0 & T-2019 & 33.2 & 3.2 & 38.9 & 4.6 \\
\hline B-2100 & 30.6 & 0.6 & 34.9 & 0.6 & T-2100 & 34.3 & 4.3 & 39.3 & 5.0 \\
\hline B-2300 & 33.8 & 3.8 & 38.9 & 4.6 & T-2300 & 38.5 & 8.5 & 43.6 & 9.3 \\
\hline \multicolumn{10}{|c|}{ 31-psu salinity Intrusion (X31) } \\
\hline B-2019 & 4.2 & 0 & 11.4 & 0 & T-2019 & 7.4 & 3.2 & 11.8 & 0.4 \\
\hline B-2100 & 4.2 & 0 & 11.4 & 0 & T-2100 & 7.4 & 3.2 & 11.8 & 0.4 \\
\hline B-2300 & 5.3 & 1.1 & 11.6 & 0.2 & T-2300 & 7.6 & 3.4 & 12.3 & 0.9 \\
\hline
\end{tabular}

The net salinity intrusion (X2) changes, excluding the neap/tide variation, show that the intrusion could increase by $0.7 \mathrm{~km}$ for $0.21 \mathrm{~m}$ SLR and $4.6 \mathrm{~km}$ for $1.5 \mathrm{~m}$ SLR. The salinity intrusion could propagate about $4.6 \mathrm{~km}$ upstream for a land subsidence case and about $9 \mathrm{~km}$ for the combined effect of land subsidence and SLR (Figure 5-7). 

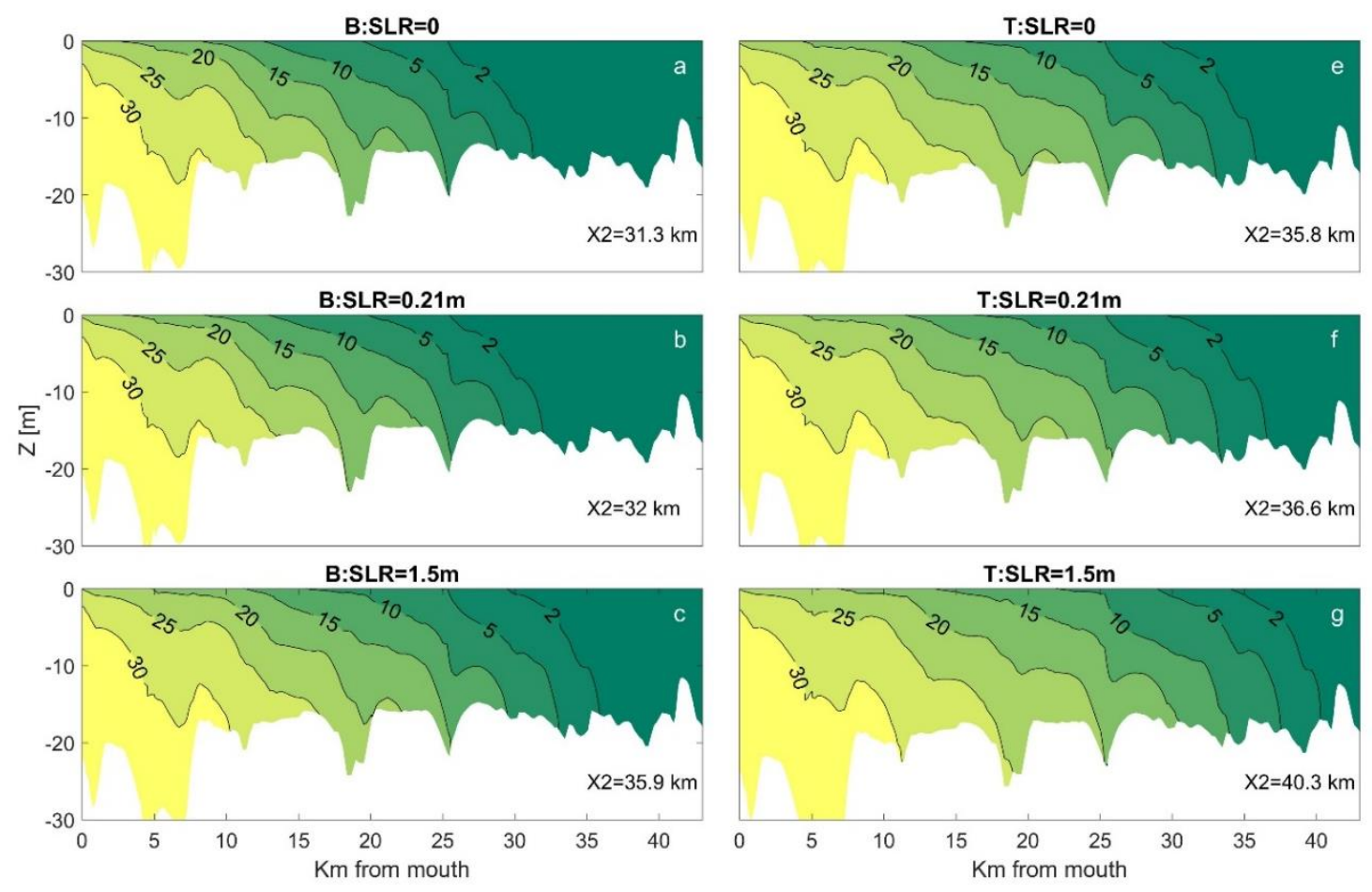

Figure 5-7. South Channel average salinity transaction (averaged over the spring-neap cycle)

\subsubsection{SLR \& future hydrograph}

Simulation results suggest that a change in future river discharge may also affect salinity intrusion. Further, any fluvial effects also interact with the change caused by increased depth (see section 4.4.1), by altering the freshwater distribution and increasing local depth. As shown in section 4.4.1, the temporal pattern of salinity intrusion in the South Channel follows the same pattern of the river discharge. The maximum salinity intrusion length (X2mx) occurs around October (low river flow period) while minimum intrusion length (X2mn) is in June (high Q) corresponding to the annual spring freshet (Figure 5-8). 
The alteration of river discharge by increasing the winter flow by $17 \%$ and decreasing the spring freshet up to $26 \%$ produces a slight impact on salinity intrusion. This alteration pushed the minimum tidally averaged salinity intrusion of $0.6 \mathrm{~km}$ (landward) and reduced $\mathbf{X} 2 \mathbf{m x}$ by $0.7 \mathrm{~km}$ only. The combined effect of both future hydrograph and $0.21 \mathrm{~m}$ SLR also has a small effect, and increases $\mathbf{X} 2 \mathbf{m n}$ by $1.2 \mathrm{~km}$ and $\mathbf{X} \mathbf{2 m x}$ by $0.4 \mathrm{~km}$. The largest effect is for $1.5 \mathrm{~m}$ SLR and the future hydrograph. For this condition, salinity intrusion could be $9.1 \mathrm{~km} \& 5 \mathrm{~km}$ for $\mathbf{X 2} \mathbf{m n}$ and $\mathbf{X 2 m x}$, respectively (Table 5-6).

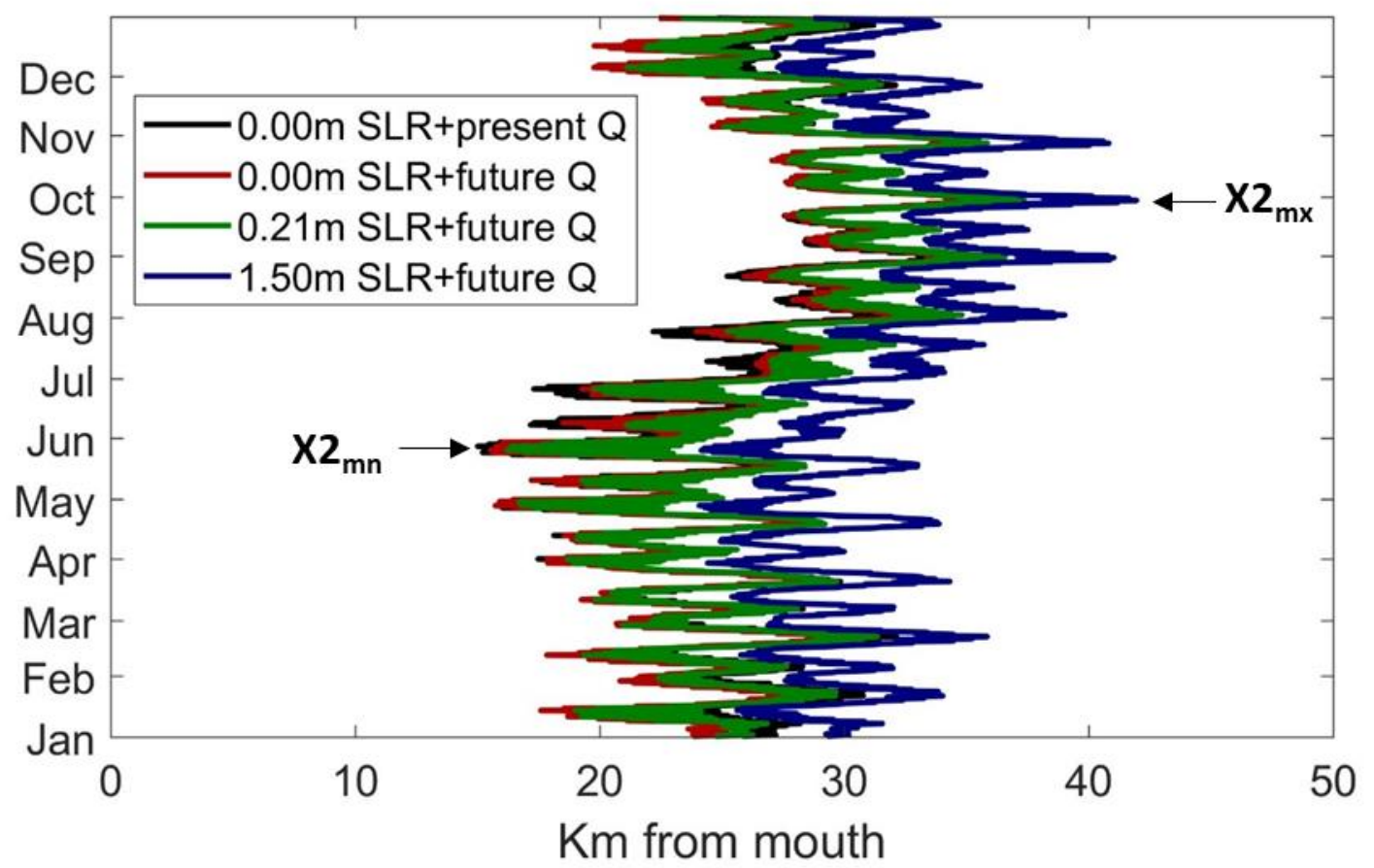

Figure 5-8. Tidally averaged salinity intrusion (X2) along the South Channel 
Table 5-6. Maximum and minimum limits of X2 for river discharge and SLR interaction (+ for percentage increase, and-for decrease)

\begin{tabular}{|c|c|c|c|c|c|}
\hline Case & Description & Min. X2 [km] & \% & Max. X2 [km] & \% \\
\hline P-2019 & 0m SLR + Present Q & 15.0 & -- & 37.0 & -- \\
\hline F-2019 & 0m SLR + Future Q & 15.6 & +4 & 36.7 & -1 \\
\hline F-2100 & 0.21m SLR + Future Q & 16.2 & +8 & 37.4 & +1 \\
\hline F-2300 & 1.50m SLR + Future Q & 24.1 & +60 & 42.0 & +13 \\
\hline
\end{tabular}

\subsubsection{Impact of SLR on habitats}

Sea-level rise and/or land subsidence can alter the shallow water habitat by increasing salinity intrusion length (X2), water depth, tidal range, and inundation. The water depth comparison of recent bathymetry (B-2019) with $1.5 \mathrm{~m}$ sea-level rise showed that the mean water depth over four islands within the LCRE (Figure 5-2) would increase as a result of SLR. Moreover, the habitat near the mouth has a larger depth change than those in the upstream. The mean water depth over Desdemona Sands could increase by $1.48 \mathrm{~m}$, while simulations suggest only a $0.65 \mathrm{~m}$ increase on Marsh Island during low river discharge (Figure 5-9 \& Table 5-7).

The projected river discharge changes also help in raising the water depth over those habitats. The river influence is also function of river mile, but in the opposite sense of the SLR effect. The maximum effect of river discharge starts at the river boundary upstream and then decreases in the ocean direction; the depth increases by $0.12 \mathrm{~m}$ near the river boundary due to elevated river and decreases toward the ocean. Near the mouth, the river discharge does not affect the habitat's water depth (Figure 5-9). The change in water depth could alter the habitat classification and the plants and animals that live on/in it (Horton et al., 2018). 


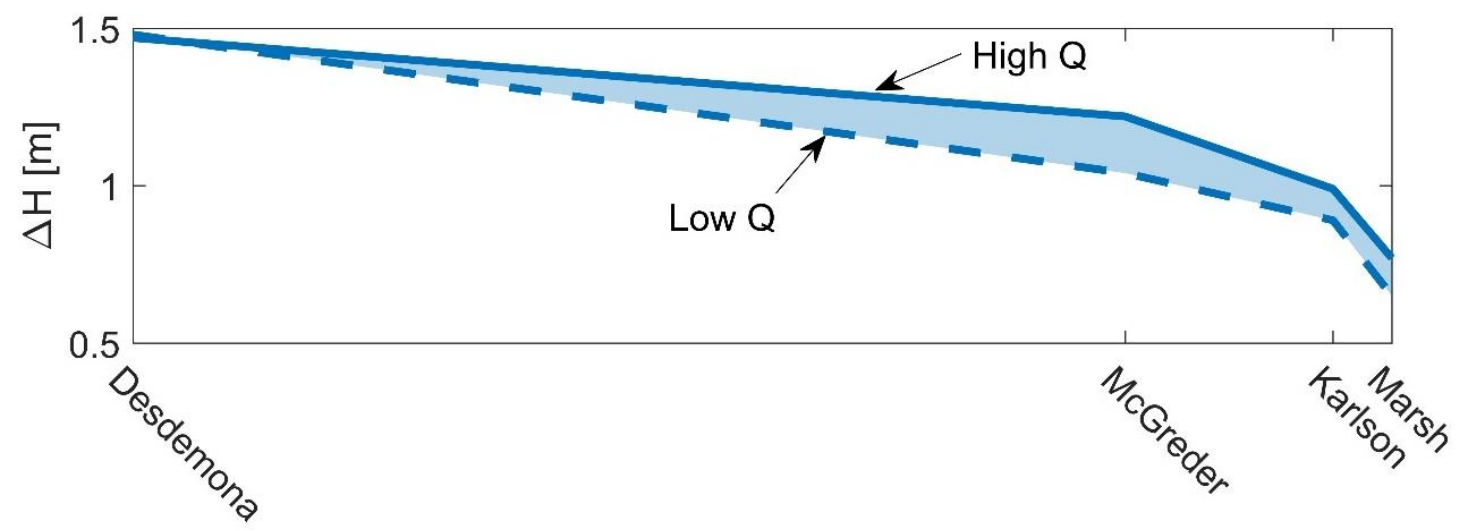

Figure 5-9. Change in water depth in shallow water habitats. Shading represents the range between low (3,000 CMS) and high river discharge (15,000 CMS).

Table 5-7. Water depth (averaged during spring-neap cycle) increment due to SLR and river discharge variation.

\begin{tabular}{|c|c|c|c|c|c|c|}
\hline & $\begin{array}{c}\text { River } \\
\text { Q }\end{array}$ & Case & $\begin{array}{c}\text { Desdemona } \\
\text { Sand [m] }\end{array}$ & $\begin{array}{l}\text { McGreder } \\
\text { Island [m] }\end{array}$ & $\begin{array}{c}\text { Karlson } \\
\text { Island [m] }\end{array}$ & $\begin{array}{c}\text { Marsh } \\
\text { Island [m] }\end{array}$ \\
\hline \multirow{6}{*}{ 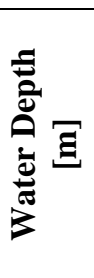 } & \multirow{3}{*}{ High } & B2019 & 1.43 & 0.53 & 0.27 & 0.11 \\
\hline & & B2300 & 2.90 & 1.75 & 1.26 & 0.88 \\
\hline & & $\Delta \mathrm{H}$ & 1.47 & 1.22 & 0.99 & 0.77 \\
\hline & \multirow{3}{*}{ Low } & B2019 & 1.25 & 0.41 & 0.17 & 0.05 \\
\hline & & B2300 & 2.73 & 1.45 & 1.06 & 0.7 \\
\hline & & $\Delta \mathrm{H}$ & 1.48 & 1.04 & 0.89 & 0.65 \\
\hline
\end{tabular}

\subsection{Conclusion}

Numerical simulation of the Lower Columbia River shows that climate change represented by river hydrograph alteration and/or water depth change from SLR or land subsidence has important implications for tidal properties and salinity intrusion.

A hypothetical SLR of $0.21 \mathrm{~m}$ has no significant impact on salinity intrusion and tidal hydrodynamics inside the LCRE. On the other hand, a future $1.5 \mathrm{~m}$ SLR has a 
substantial impact on the estuarine hydrodynamics as measured by the $\mathrm{M}_{2}$ tidal constituent. $\mathrm{M}_{2}$ increased by $0.01 \mathrm{~m}$ for $0.21 \mathrm{~m}$ SLR without changing the location of maximum $\mathrm{M}_{2}$. However, $\mathrm{M}_{2}$ increased by $0.05 \mathrm{~m}$ for $1.5 \mathrm{~m}$ SLR and the location of maximum $\mathrm{M}_{2}$ advanced by about $4 \mathrm{~km}$ landward. Sudden land subsidence that might occur from a potential major earthquake (M9) along the Oregon coast was simulated to produce a similar dynamic response in salinity intrusion and tidal amplitude to the $1.5 \mathrm{~m}$ sea-level rise case.

The tidal analysis of both cases showed an increase in $\mathrm{M}_{2}$ amplitude by $5 \%(0.05 \mathrm{~m})$ in the South Channel. Moreover, the location of maximum $\mathrm{M}_{2}$ inside the estuary has moved upstream by $\sim 4 \mathrm{~km}$ for the SLR case and $3.5 \mathrm{~km}$ for the subsidence case. The combined effect of both scenarios can double the effect of each case such that it can increase $M_{2}$ by $11 \%(0.11 \mathrm{~m})$ and push its maximum up to $10 \mathrm{~km}(34 \%)$ landward for low flow conditions.

Salinity intrusion analysis showed the same trend for both SLR and subsidence scenarios (B-2300 \& T-2019). Simulations suggest that X2 may advance by $\sim 4 \mathrm{~km}$ during spring and neap tides for both cases. However, the discrepancy between the two cases is in the horizontal salinity gradient. In comparison, the subsidence case caused a higher salinity gradient than the SLR case since it can push the 31psu isohaline (X31), because of the deeper water column at the mouth of the estuary. The deeper depth reduces the bed stress and lessens vertical mixing.

Alteration of the river hydrograph by $+17 \%$ in winter and $-26 \%$ during spring freshet produced a small effect on salinity intrusion, such that winter X2 advanced by $0.6 \mathrm{~km}$ while spring freshet $\mathrm{X} 2$ reduced by $0.7 \mathrm{~km}$. However, $1.5 \mathrm{~m}$ of SLR plus the future 
hydrograph change produced a much greater effect. Together, these joint alterations increased $\mathrm{X} 2$ by $9 \mathrm{~km}$ and5 $\mathrm{km}$ during low and high river discharge seasons, respectively.

Finally, future changes have a strong impact on shallow-water habitats, not only through the increase of salinity intrusion but also because of water depth changes. The water depth variation of the habitats $(\Delta H)$ has a maximum value near the mouth and decreases toward the upstream. 


\subsection{Summary}

\section{Chapter 6 Summary and Conclusion}

This study analyzed the effect of long-term changes in the Lower Columbia River Estuary (LCRE) that have occurred in the past 150 years on its estuarine hydrodynamics and transport. The bathymetry of the estuary has been changing since the middle of the 19th century as a result of navigation channel improvement and maintenance to accommodate increasingly large cargo ships. Additionally, large scale changes have included the construction of jetties, islands, and other navigational structures, and the reclamation and diking of shallow water habitat along the estuary. The other major change is hydrological--water withdrawal for agriculture and river flow management. Together, these have reduced the spring freshet for (flood control and irrigation) and increased the winter release of water for power generation.

In this thesis, I have investigated via numerical modeling the variation in freshwater distribution between the two main channels (South \& North) inside the estuary, and also the tidal changes. The importance of these variables (buoyancy and tidal forcing) comes from their influence on estuarine hydrodynamics, especially salinity intrusion. The second question addressed was, 'How has salinity intrusion changed over the past century due to the system alteration (hydrological and morphological)?'. The natural and man-made alteration will likely continue as a result of land development and climate change. The final research chapter, therefore, addressed the following question: What will happen in the future to the estuarine hydrodynamics as a result of future river management, future sea- 
level rise, and a sudden land drop from a potential mega-earthquake along the Pacific Northwest?

\subsection{Conclusion}

Considering the forgoing research questions, I have used 3D-hydrodynamic models to simulate the historical bathymetry, historical river hydrograph, and modern bathymetry, modern river hydrograph. These models were calibrated intensively under barotropic and baroclinic conditions.

The results from the first research question (Ch.3) suggest that the river discharge distribution between the North and South channels is a function of tidal forcing, river discharge, and channel geometry. In the modern model conditions, the slope plays a major role in water distribution between the two channels. This asymmetry is driven by the length difference of water paths along each channel and by the non-linear interaction between the tidal forcing and river discharge. On the other hand, in the historical model, Manning's roughness coefficient and surface slope of both channels were found to be equal, hence the water bifurcation was controlled by the channel's geometry. The effect of tidal range on bifurcation was also noticed in the spring-neap variation, such that the percentage of freshwater in the South channel is higher on spring tides than on neap tides since spring tides tend to elevate the water surface slope. A further effect of system alteration was found on the tidal constituents such that modeled $\mathrm{M}_{2}$ is elevated by $0.11 \mathrm{~m}$ near Astoria Tongue Point mainly due to channel deepening. 
The second research question (Ch.4) investigation revealed a significant seasonal change in salinity intrusion. Relative to the historical model, a larger intrusion was found in the modern model during summer due to spring-freshet reduction while the intrusion reduced during winter in response to larger modern winter flows. However, channel deepening has increased the stratification and helped propagate salinity intrusion further landward. The combined effect of the $50^{\text {th }}$ percentile of river flow alteration and channel deepening suggests an increase of about $10 \mathrm{~km}$ in maximum tidally varying salinity intrusion into the system, which occurs during low river flows and neap tides. Additionally, the time of occurrence of maximum intrusion has shifted from early January to the end of September, consistent with changes in the seasonality of minimum river flow.

The results also suggest a major change in the power law relating the $\mathrm{X} 2$ salinity intrusion distance to river flow $\left(X 2 \sim Q^{-n}\right)$. This change is mainly due to a change in river discharge distribution between the North and South Channel in the historical and modern estuary (discussed in Ch.3). Finally, the parameter-space examination showed that the estuary used to be more often partially mixed and act less salt wedge regime due to the bathymetrical change (on the whole the system is now more stratified than it was historically). The river flow change has a minor effect on the classification change since it has been balanced by the change in channel geometry.

An analysis the future changes to the system and in the event of rapid tectonic subsidence (Ch.5) showed that a 1.5m SLR and a linear bathymetrical change profile has a similar effect on salinity intrusion and tidal changes. In each case, the major tidal 
component $\left(\mathrm{M}_{2}\right)$ is predicted to increase by around $0.05 \mathrm{~m}$ and the maximum $\mathrm{M}_{2}$ is predicted to advance $\sim 4 \mathrm{~km}$ landward. The combined effect of both scenarios can approximately double the effect of the individual changes such that it can increase $\mathrm{M}_{2}$ amplitude by $0.11 \mathrm{~m}$ and push its point of maximum amplitude about $10 \mathrm{~km}$ landward for low flow conditions.

Similarly, both cases showed an advance of about $4 \mathrm{~km}$ of salinity intrusion (X2), though the salinity gradient became larger in the land subsidence case than the SLR case. In other words, the change in salinity intrusion that might occur in the next 300-years due to SLR could occur much sooner if an earthquake occurs. The worst-case scenario is the combination of the two extreme cases (1.5m SLR and land subsidence) such that the effect on $\mathrm{M}_{2}$ and $\mathrm{X} 2$ is more than double compared to each individual case. Moreover, a future $1.5 \mathrm{~m}$ SLR and a future decrease in river flow can push X2 up to $9 \mathrm{~km}$ landward during low river discharge seasons. The future changes would probably impact the shallow-water habitat as well. Simulation results showed an increase in water depth $(1.5-0.8 \mathrm{~m})$ along the estuarine habitat (near the mouth and near the river boundary in the upstream, respectively).

\subsection{Future steps and recommendations}

Future studies could enhance my modeling results by expanding the hydrodynamic grid further into the ocean $(200-300 \mathrm{~km})$, and overall investigate the possible influence of changed oceanic conditions (such as any changes to upwelling) on the oceanic salinity and 
water temperature condition. Further investigation is also needed to address the relationship between salinity intrusion and channel depth (more simulations with different depths). The effect of the mouth modification (depth and width) on the hydrodynamics needs to be examined closely as well. More effort is needed to study the effect of salinity intrusion and climate change on water temperature variation, since water temperature is an important factor (like salinity) in the estuarine environment. Finally, future studies might study the effect of river discharge change, bathymetric change, and jetty constructions on plume dynamics. 


\section{References}

Abood, K. A. (1974). Circulation in the Hudson Estuary. Annals of the New York Academy of Sciences, 250(1), 39-111. https://doi.org/10.1111/j.1749-6632.1974.tb43895.x

Aristizábal, M., \& Chant, R. (2013). A Numerical Study of Salt Fluxes in Delaware Bay Estuary. Journal of Physical Oceanography, 43(8), 1572-1588. https://doi.org/10.1175/JPO-D-12-0124.1

Atwater, B. F., Musumi-Rokkaku, S., Satake, K., Tsuji, Y., Ueda, K., \& Yamaguchi, D. K. (2005). The orphan tsunami of 1700_Japanese clues to a parent earthquake in North America (First Edit). Professional Paper. https://doi.org/10.3133/pp1707

Baptista, A. M., Seaton, C., Wilkin, M. P., Riseman, S. F., Needoba, J. A., Maier, D., ... Simon, H. M. (2015). Infrastructure for collaborative science and societal applications in the Columbia River estuary. Frontiers of Earth Science, 9(4), 659-682. https://doi.org/10.1007/s11707-015-0540-5

Baptista, A. M., Zhang, Y., Chawla, A., \& Zulauf, M. (2004). A cross-scale model for 3D baroclinic circulation in estuary-plume- shelf systems: II . Application to the Columbia River, 1-56.

Becherer, J., Stacey, M. T., Umlauf, L., \& Burchard, H. (2015). Lateral Circulation Generates Flood Tide Stratification and Estuarine Exchange Flow in a Curved Tidal Inlet. Journal of Physical Oceanography, 45(3), 638-656. https://doi.org/10.1175/JPO-D-14-0001.1

Bell, G. W., \& Eggleston, D. B. (2003). Behavioral responses of free-ranging blue crabs to episodic hypoxia. I. Movement . Marine Ecology Progress Series, 259, 215-225.

Bottom, D. L., Simenstad, C. A., Burke, J., Baptista, A. M., Jay, D. A., Jones, K. K., ... Schiewe., M. H. (2005). Impacts of climate change on Oregon's coasts and estuaries. NOAA Technical Memorandum NMFS-NWFSC-68.

Bromirski, P. D., Miller, A. J., Flick, R. E., \& Auad, G. (2011). Dynamical suppression of sea-level rise along the Pacific coast of North America: Indications for imminent acceleration. Journal of Geophysical Research: Oceans, 116(7), 1-13. https://doi.org/10.1029/2010JC006759

Bürger, G., Schulla, J., \& Werner, A. T. (2011). Estimates of future flow, including extremes, of the Columbia River headwaters. Water Resources Research, 47(10), 118. https://doi.org/10.1029/2010WR009716

Burgette, R. J., Weldon, R. J., \& Schmidt, D. A. (2009). Interseismic uplift rates for western Oregon and along-strike variation in locking on the Cascadia subduction zone. Journal of Geophysical Research: Solid Earth, 114(1), 1-24. https://doi.org/10.1029/2008JB005679

Buschman, F. A., Hoitink, A. J. F., Van Der Vegt, M., \& Hoekstra, P. (2010). Subtidal 
flow division at a shallow tidal junction. Water Resources Research, 46(12), 1-12. https://doi.org/10.1029/2010WR009266

Chant, R. J., Sommerfield, C. K., \& Talke, S. A. (2018). Impact of Channel Deepening on Tidal and Gravitational Circulation in a Highly Engineered Estuarine Basin. Estuaries and Coasts, 41(6), 1587-1600. https://doi.org/10.1007/s12237-018-0379-6

Chawla, A., Jay, D. A., Baptista, A. M., Wilkin, M., \& Seaton, C. (2008a). Seasonal variability and estuary-shelf interactions in circulation dynamics of a river-dominated estuary. Estuaries and Coasts, 31(2), 269-288. https://doi.org/10.1007/s12237-0079022-7

Chawla, A., Jay, D. A., Baptista, A. M., Wilkin, M., \& Seaton, C. (2008b). Seasonal Variability and Estuary - Shelf Interactions in Circulation Dynamics of a Riverdominated Estuary, 269-288. https://doi.org/10.1007/s12237-007-9022-7

Church, J. A., \& White, N. J. (2011). Sea-Level Rise from the Late 19th to the Early 21st Century. Surveys in Geophysics, 32(4-5), 585-602. https://doi.org/10.1007/s10712011-9119-1

Clague, J. J. (1997). Evidence for large earthquakes at the Cascadia subduction zone. Reviews of Geophysics, 35(4), 439-460. https://doi.org/10.1029/97RG00222

Cohen, S. J., Miller, K. A., Hamlet, A. F., \& Avis, W. (2000). Climate change and resource management in the Columbia river basin. Water International, 25(2), 253-272. https://doi.org/10.1080/02508060008686827

Dangendorf, S., Marcos, M., Wöppelmann, G., Conrad, C. P., Frederikse, T., \& Riva, R. (2017). Reassessment of 20th century global mean sea-level rise. Proceedings of the National Academy of Sciences, 114(23), 5946-5951. https://doi.org/10.1073/pnas.1616007114

Dijkstra, Y. M., Schuttelaars, H. M., \& Burchard, H. (2017). Generation of exchange flows in estuaries by tidal and gravitational eddy viscosity-shear covariance (ESCO). Journal of Geophysical Research: Oceans, 122, 4217-4237. https://doi.org/10.1002/2016JC012379

Dipietro, J. A. (2013). Landscape Evolution in the United States. Elsevier, Amsterdam.

Egbert, G. D., \& Erofeeva, S. Y. (2002). Efficient inverse modeling of barotropic ocean tides. Journal of Atmospheric and Oceanic Technology, 19(2), 183-204. https://doi.org/10.1175/1520-0426(2002)019<0183:EIMOBO>2.0.CO;2

Friedrichs, C. T. (2010). Barotropic tides in channelized estuaries. In A. Valle-Levinson (Ed.), Contemporary Issues in Estuarine Physics (pp. 27-61). Cambridge: Cambridge University Press. https://doi.org/10.1017/CBO9780511676567.004

Friedrichs CT, Aubrey DG. 1994. Tidal propagation in strongly convergent channels. J. Geophys. Res. 99:3321-36 
Ganju, N. K., Brush, M. J., Rashleigh, B., Aretxabaleta, A. L., del Barrio, P., Grear, J. S., ... Vaudrey, J. M. P. (2016). Progress and Challenges in Coupled HydrodynamicEcological Estuarine Modeling. Estuaries and Coasts, 39(2), 311-332. https://doi.org/10.1007/s12237-015-0011-y

Geyer, W. Rockwell, \& MacCready, P. (2014). The Estuarine Circulation. Annual Review of Fluid Mechanics, 46(1), 175-197. https://doi.org/10.1146/annurev-fluid-010313141302

Geyer, W R. (2010). Estuarine salinity structure and circulation. In A. Valle-Levinson (Ed.), Contemporary Issues in Estuarine Physics (pp. 12-26). Cambridge: Cambridge University Press. https://doi.org/DOI: 10.1017/CBO9780511676567.003

Godin, G. (1985). Modification of river tides by the discharge. J. Waterw, Port, Coast. Ocean Engin, I(2), 257-274.

Godin, G. (1999). The propagation of tides up rivers with special considerations on the upper Saint Lawrence river. Estuarine, Coastal and Shelf Science, 48(3), 307-324. https://doi.org/10.1006/ecss.1998.0422

Gong, W., \& Shen, J. (2011). The response of salt intrusion to changes in river discharge and tidal mixing during the dry season in the Modaomen Estuary, China. Continental Shelf Research, 31(7-8), 769-788. https://doi.org/10.1016/j.csr.2011.01.011

Gonzales, F. I. (1984). A Case Study of Wave-Current-Bathymetry Interactions at the Columbia River Entrance. Pacific Marine Environmental Laboratory/NOAA, Seattle, WA 98115. Retrieved from https://doi.org/10.1175/15200485(1984)014\%3C1065:ACSOWI\%3E2.0.CO;2

Hamilton, P. (1990). Modelling salinity and circulation for the Columbia River Estuary. Progress in Oceanography, 25(1-4), 113-156. https://doi.org/10.1016/00796611(90)90005-M

Hamlet, A. F., Elsner, M. M. G., Mauger, G. S., Lee, S. Y., Tohver, I., \& Norheim, R. A. (2013). An overview of the columbia basin climate change scenarios project: Approach, methods, and summary of key results. Atmosphere - Ocean, 51(4), 392415. https://doi.org/10.1080/07055900.2013.819555

Hansen, D. V., \& Rattray, M. (1966). New dimensions in estuary classification. Limnol. Oceanogr., (July), 11, 319-326.

Hansen, Donald V., \& Rattray, M. (1965). Gravitational circulation in straits and estuaries. Journal of Marine Research, 23, 104-122. https://doi.org/10.1098/rspb.2009.2214

Hansen, Donald V., \& Rattray, M. (1966). Lno19661130319, (July).

Hawkes, A. D., Horton, B. P., Nelson, A. R., Vane, C. H., \& Sawai, Y. (2011). Coastal subsidence in Oregon, USA, during the giant Cascadia earthquake of AD 1700. Quaternary Science Reviews, 30(3-4), 364-376. https://doi.org/10.1016/j.quascirev.2010.11.017 
Hay, C. C., Morrow, E., Kopp, R. E., \& Mitrovica, J. X. (2015). Probabilistic reanalysis of twentieth-century sea-level rise. Nature, 517(7535), 481-484. https://doi.org/10.1038/nature14093

Helaire, L. T., Talke, S. A., Jay, D. A., \& Mahedy, D. (2019). Historical Changes in Lower Columbia River and Estuary Floods: A Numerical Study. Journal of Geophysical Research: Oceans, 124(11), 7926-7946. https://doi.org/10.1029/2019JC015055

Helaire, L.T. (2016). Modeling of Historic Columbia River Flood Impacts Based on Delft3D Simulations

Hickson, R. E., \& Rodolf, F. W. (1951). History of Columbia River jetties. Proceedings of the First Conference on Coastal Engineering, 283-298.

Hoitink, A. J. F., \& Jay, D. A. (2016). Tidal river dynamics: Implications for deltas. Reviews of Geophysics, 54(1), 240-272. https://doi.org/10.1002/2015RG000507

Horton, B. P., Shennan, I., Bradley, S. L., Cahill, N., Kirwan, M., Kopp, R. E., \& Shaw, T. A. (2018). Predicting marsh vulnerability to sea-level rise using Holocene relative sea-level data. Nature Communications, 9(1), 4-10. https://doi.org/10.1038/s41467018-05080-0

Hudson, A. S., Talke, S. A., Branch, R., Chickadel, C., Farquharson, G., \& Jessup, A. (2017). Remote measurements of tides and river slope using an airborne lidar instrument. Journal of Atmospheric and Oceanic Technology, 34(4), 897-904. https://doi.org/10.1175/JTECH-D-16-0197.1

Jay, D. (1984). Circulatory processes in the Columbia River estuary., (May).

Jay, D. A. (1991), Green's law revisited: Tidal long-wave propagation in channels with strong topography, J. Geophys. Res., 96(C11), 20585-20598, doi:10.1029/91JC01633.

Jay, D. A., \& Musiak, J. D. (1994). Particle trapping in estuarine tidal flows. Journal of Geophysical Research, 99(C10). https://doi.org/10.1029/94jc00971

Jay, D. A., \& Musiak, J. D. (1996). Internal tidal asymmetry in channel flows: Origins and consequences, 50, 211-249. https://doi.org/10.1029/ce050p0211

Jay, D A, \& Smith, J. D. (1990). Circulation, Density Distribution and Neap-Spring Transitions in the Columbia River Estuary. Progress in Oceanography, 25(1-4), 81112. https://doi.org/10.1016/0079-6611(90)90004-L

Jay, David A. (2009). Evolution of tidal amplitudes in the eastern Pacific Ocean. Geophysical Research Letters, 36(4), 1-5. https://doi.org/10.1029/2008GL036185

Jay, David A., Borde, A. B., \& Diefenderfer, H. L. (2016). Tidal-Fluvial and Estuarine Processes in the Lower Columbia River: II. Water Level Models, Floodplain Wetland Inundation, and System Zones. Estuaries and Coasts, 39(5), 1299-1324. https://doi.org/10.1007/s12237-016-0082-4 
Jay, David A., Leffler, K., \& Degens, S. (2011). Long-Term Evolution of Columbia River Tides. Journal of Waterway, Port, Coastal and Ocean Engineering, 137(4), 182-191. https://doi.org/10.1061/(ASCE)WW.1943-5460.0000082

Jay, David A., Orton, P. M., Chisholm, T., Wilson, D. J., \& Fain, A. M. V. (2007). Particle trapping in stratified estuaries: Application to observations. Estuaries and Coasts, 30(6), 1106-1125. https://doi.org/10.1007/BF02841400

Jay, David A., \& Smith, D. J. (1990). Weakly Stratified and Partially Mixed , Narrow Estuaries. Estuaries, 95(89), 733-748.

Kalmbacher, K. D., \& Hill, D. F. (2015). Effects of Tides and Currents on Tsunami Propagation in Large Rivers : Columbia River, United States. Journal of Waterway, Port, Coastal, and Ocean Engineering, 141(5), 1-8. https://doi.org/10.1061/(ASCE)WW.1943-5460.0000290.

Kärnä, T., Baptista, A. M., Lopez, J. E., Turner, P. J., McNeil, C., \& Sanford, T. B. (2015). Numerical modeling of circulation in high-energy estuaries: A Columbia River estuary benchmark. Ocean Modelling, 88, 54-71. https://doi.org/10.1016/j.ocemod.2015.01.001

Kopp, R. E., Deconto, R. M., Bader, D. A., Hay, C. C., Radley, M., Kulp, S., ... Strauss, B. H. (2017). Earth's Future Evolving Understanding of Antarctic Ice-Sheet Physics and Ambiguity in Probabilistic Sea-Level Projections Earth's Future.

Kukulka, T., \& Jay, D. A. (2003a). Impacts of Columbia River discharge on salmonid habitat: 1. A nonstationary fluvial tide model. Journal of Geophysical Research C: Oceans, 108(9), 9-1. https://doi.org/10.1029/2002jc001382

Kukulka, T., \& Jay, D. A. (2003b). Impacts of Columbia River discharge on salmonid habitat: 2. Changes in shallow-water habitat. Journal of Geophysical Research, 108(C9), 3294. https://doi.org/10.1029/2003JC001829

Lee, S.-Y., Hamlet, A. F., \& Grossman, E. E. (2016). Impacts of Climate Change on Regulated Streamflow, Hydrologic Extremes, Hydropower Production, and Sediment Discharge in the Skagit River Basin. Northwest Science, 90(1), 23-43. https://doi.org/10.3955/046.090.0104

Leffler, K. E., \& Jay, D. A. (2009). Enhancing tidal harmonic analysis: Robust (hybrid L1 I L2) solutions. Continental Shelf Research, 29(1), 78-88. https://doi.org/10.1016/j.csr.2008.04.011

Lenanton, R. C. J., \& Potter, I. C. (1987). Estuaries (p. 10:28). Springer-Verlag. https://doi.org/10.2307/1352022

Lutz, G. A., Hubbell, D. W., \& Stevens Jr, H. H. (1975). Discharge and flow distribution, Columbia river estuary. Geological Survey Professional Paper 433-P.

MacCready, P. (1999). Estuarine adjustment to changes in river flow and tidal mixing. Journal of Physical Oceanography, 29(4), 708-726. https://doi.org/10.1175/1520- 
0485(1999)029<0708:EATCIR>2.0.CO;2

MacCready, P. (2007). Estuarine Adjustment. Journal of Physical Oceanography, 37(8), 2133-2145. https://doi.org/10.1175/JPO3082.1

MacCready, P. (2011). Calculating Estuarine Exchange Flow Using Isohaline Coordinates. Journal of Physical Oceanography, 41(6), 1116-1124. https://doi.org/10.1175/2011JPO4517.1

MacCready, P., \& Geyer, W. R. (2010). Advances in Estuarine Physics. Annual Review of Marine Science, 2(1), 35-58. https://doi.org/10.1146/annurev-marine-120308081015

MacCready, P., Geyer, W. R., \& Burchard, H. (2018). Estuarine Exchange Flow Is Related to Mixing through the Salinity Variance Budget. Journal of Physical Oceanography, 48(6), 1375-1384. https://doi.org/10.1016/j.expneurol.2017.07.017

MacWilliams, Michael L. Bever, Aaron J. Gross, Edward S. Ketefian, G. S. and K. W. J. (2015). Three-Dimensional Modeling of Hydrodynamics and Salinity in the San Francisco Estuary: An Evaluation of Model Accuracy, X2, and the Low-Salinity Zone. San Francisco Estuary and Watershed Science, 26(1), 217-220. https://doi.org/10.5811/westjem.2011.5.6700

Marcoe, K., \& Pilson, S. (2017). Habitat change in the Lower Columbia River and Estuary, 1870-2019. J Coast Conserv. https://doi.org/10.1007/s11852-017-0523-7

Merrifield, M. A., Thompson, P. R., \& Lander, M. (2012). Multidecadal sea-level anomalies and trends in the western tropical Pacific. Geophysical Research Letters, 39(13). https://doi.org/10.1029/2012GL052032

Miranda L., Andutta F.P., Kjerfve B., de C. F. B. M. (2017). Estuary Classification. In: Fundamentals of Estuarine Physical Oceanography. Ocean Engineering \& Oceanography, vol 8. Singapore: Springer, Singapore. https://doi.org/10.1007/978981-10-3041-3_3

Moftakhari, H. R., Jay, D. A., Talke, S. A., Kukulka, T., \& Bromirski, P. D. (2013). A novel approach to flow estimation in tidal rivers. Water Resources Research, 49(8), 4817-4832. https://doi.org/10.1002/wrcr.20363

Monismith, S. G., Kimmerer, W., Burau, J. R., \& Stacey, M. T. (2002). Structure and FlowInduced Variability of the Subtidal Salinity Field in Northern San Francisco Bay. Journal of Physical Oceanography, 32(11), 3003-3019. https://doi.org/10.1175/1520-0485(2002)032<3003:SAFIVO>2.0.CO;2

Mori, N., Takahashi, T., Yasuda, T., \& Yanagisawa, H. (2011). Survey of 2011 Tohoku earthquake tsunami inundation and run-up. Geophysical Research Letters, 38(18), 611. https://doi.org/10.1029/2011GL049210

Mulamba, T., Bacopoulos, P., Kubatko, E. J., \& Pinto, G. F. (2019). Sea-level rise impacts on longitudinal salinity for a low-gradient estuarine system. Climatic Change, 152(3- 
4), 533-550. https://doi.org/10.1007/s10584-019-02369-x

Naik, P. K., \& Jay, D. A. (2005). Estimation of Columbia River virgin flow: 1879 to 1928. Hydrological Processes, 19(9), 1807-1824. https://doi.org/10.1002/hyp.5636

Naik, P. K., \& Jay, D. A. (2011). Distinguishing human and climate influences on the Columbia River: Changes in mean flow and sediment transport. Journal of Hydrology, 404(3-4), 259-277. https://doi.org/10.1016/j.jhydrol.2011.04.035

Nash, J. E., \& Sutcliffe, J. V. (1970). River flow forecasting through conceptual models part I - A discussion of principles. Journal of Hydrology, 10(3), 282-290. https://doi.org/10.1016/0022-1694(70)90255-6

Newman, M., Alexander, M. A., Ault, T. R., Cobb, K. M., Deser, C., Di Lorenzo, E., ... Smith, C. A. (2016). The Pacific decadal oscillation, revisited. Journal of Climate, 29(12), 4399-4427. https://doi.org/10.1175/JCLI-D-15-0508.1

Nidzieko, N. J. (2010). Tidal asymmetry in estuaries with mixed semidiurnal/diurnal tides. Journal of Geophysical Research: Oceans, 115(8), 1-13. https://doi.org/10.1029/2009JC005864

NRC. (2012). Sea-Level Rise for the Coasts of California, Oregon, and Washington. National Academies Press. https://doi.org/10.17226/13389

Oey, L.-Y. (1984). On steady salinity distribution and circulation in partially mixed and well mixed estuaries. Journal of Physical Oceanography. https://doi.org/http://dx.doi.org/10.1175/15200485(1984)014<0629:OSSDAC>2.0.CO;2

Osborn, R. P. (2012). CLIMATE CHANGE AND THE COLUMBIA RIVER TREATY, $75-123$.

OSSPAC. (2013). The Oregon Resilience Plan: Reducing Risk and Improving Recovery for the Next Cascadia Earthquake and Tsunami.

Parker, B. B. (1991). The relative importance of the various nonlinear meachanisms in a wide range of tidal interactions (review), in Tidal Hydrodynamics (pp. 237-268). New York: John Wiley.

Pawlowicz, R., Beardsley, B., \& Lentz, S. (2002). Classical tidal harmonic analysis with error analysis in MATLAB using T_TIDE. Computers \& Geosciences (Vol. 28). https://doi.org/10.1016/S0098-3004(02)00013-4

Pfeffer, W. T., Harper, J. T., \& O’Neel. (2008). Kinematic Constraints on Glacier Contributions to 21st-Century Sea-Level Rise. Science, 321, 1340. https://doi.org/10.1126/science.1159099

Pritchard, D. (1967). What is an estuary: a physical viewpoint. American Association for the Advancement of Science. Retrieved from http://hdl.handle.net/1969.3/24383 
Putra, S. S., Wegen, M. v.d., Reyns, J., Dam, A. v., Solomatine, D. P., \& Roelvink, J. A. (2015). Multi Station Calibration of 3D Flexible Mesh Model: A Case Study of the Columbia Estuary. Procedia Environmental Sciences, 28(SustaiN 2014), 297-306. https://doi.org/10.1016/j.proenv.2015.07.038

Ralston, D. K. (2010). Structures, variability, and salt flux in a strongly forced salt wedge estaury, 115, 1-21. https://doi.org/10.1029/2009JC005806

Ralston, D. K., \& Geyer, W. R. (2019). Response to Channel Deepening of the Salinity Intrusion, Estuarine Circulation, and Stratification in an Urbanized Estuary. Journal of Geophysical Research: Oceans, 124(7), 4784-4802. https://doi.org/10.1029/2019JC015006

Ralston, D. K., Geyer, W. R., \& Lerczak, J. A. (2008). Subtidal Salinity and Velocity in the Hudson River Estuary: Observations and Modeling. Journal of Physical Oceanography, 38(4), 753-770. https://doi.org/10.1175/2007JPO3808.1

Ramamurthy, A. S., and Satish, M. G. (1988). "Division of flow in short open channel branches." J. Hydraul. Eng., 114(4), 428-438.10.1061/(ASCE)07339429(1988)114:4(428), Google Scholar

Rice, K. C., Hong, B., \& Shen, J. (2012). Assessment of salinity intrusion in the James and Chickahominy Rivers as a result of simulated sea-level rise in Chesapeake Bay, East Coast, USA. Journal of Environmental Management, 111, 61-69. https://doi.org/10.1016/j.jenvman.2012.06.036

Robinson, A. H. W. (1960). Ebb-flood Channel Systems in Sandy Bays and Estuaries. Geography, 45(3), 183-199.

Ruggiero, P., Brown, C. A., Komar, P. D., Allan, J. C., Deborah, A., Lee, H., ... Moritz, H. (2011). Chapter 6. Impacts of Climate Change on Oregon's Coasts and Estuaries in "Oregon Climate Change Assessment Report." North. Washington , DC.

San, N., Bay, F., Monismith, S. T. G., \& Kimmerer, W. I. M. (2002). Structure and FlowInduced Variability of the Subtidal Salinity Field in Northern San Francisco Bay.

Sanford, T. B., McNeil, C., Shcherbina, A. Y., Litchendorf, T. M., Karna, T., Lopez, J. E., \& Baptista, A. M. (2015). CMOP 2012 AUV-WP Columbia River estuary benchmark data set. https://doi.org/10.5281/ZENODO.13782

Sassi, M. G., Hoitink, A. J. F., De Brye, B., Vermeulen, B., \& Deleersnijder, E. (2011). Tidal impact on the division of river discharge over distributary channels in the Mahakam Delta. Ocean Dynamics, 61(12), 2211-2228. https://doi.org/10.1007/s10236-011-0473-9

Sheng Y P, T. W., \& Wang, P. (1988). Coastal and Estuarine Hydrodynamic Modeling in Curvilinear Grids. ASCE, (Proc of the 21st ICCE), 2655-2665.

Sherwood, C. R., Jay, D. A., Harvey, R. B., Hamilton, P., \& Simenstad, C. A. (1990). Historical changes in the Columbia River Estuary. Progress in Oceanography, 25(1- 


\section{4), 299-352. https://doi.org/10.1016/0079-6611(90)90011-P}

Sherwood, R., \& Jay, D. A. (1990). Historical changes in the Columbia River Estuary, 25, 299-352.

Simenstad, C., \& Sherwood, C. (1990). Columbia river estuary studies : An introduction to the estuary, a brief history, and prior studies, (August 2014). https://doi.org/10.1016/0079-6611(90)90002-J

Simpson, J. H., Brown, J., Matthews, J., \& Allen, G. (1990). Tidal Straining, Density Currents, and Stirring in the Control of Estuarine Stratification. Estuaries, 13(2), 125. https://doi.org/10.2307/1351581

Swart, R. de. (2015). Salinity intrusion and tidal propagation in estuarine channel networks with different channel lengths. Utrecht.

Talke, S. A., Mahedy, A., Jay, D. A., Lau, P., Hilley, C., \& Hudson, A. (2019). Sea-level, tidal and river flow trends in the Lower Columbia River Estuary , 1853- present. Journal of Geophysical Research C: Oceans.

Talke, S. A., Mahedy, A., Jay, D. A., Lau, P., Hilley, C., \& Hudson, A. (2020a). Sea-Level, Tidal, and River Flow Trends in the Lower Columbia River Estuary, 1853-present. Journal of Geophysical Research: Oceans, 125(3), 1-29. https://doi.org/10.1029/2019jc015656

Talke, S. A., Mahedy, A., Jay, D. A., Lau, P., Hilley, C., \& Hudson, A. (2020b). Sea-Level, Tidal, and River Flow Trends in the Lower Columbia River Estuary, 1853-present. Journal of Geophysical Research: Oceans, 125(3), 1-29. https://doi.org/10.1029/2019JC015656

Templeton, W. J., \& Jay, D. A. (2013). Lower columbia river sand supply and removal: Estimates of two sand budget components. Journal of Waterway, Port, Coastal and Ocean Engineering, 139(5), 383-392. https://doi.org/10.1061/(ASCE)WW.19435460.0000188

U.S. Army, C. of E. (2012). U.S. Port and Inland Waterways Modernization: Preparing for Post-Panamax Vessels. Institute for Water Resources.

USBR. (2016). Columbia River Basin, Climate Impact Assessment, (March).

USGS. (1981). River basins of the United States: the Columbia. General Information Product. Washington, D.C. https://doi.org/10.3133/70039373

USGS. (2016). National Water Information System data available on the World Wide Web (USGS Water Data for the Nation) accessed [June 10, 2012]. https://doi.org/10.5066/F7P55KJN

Valle-Levinson, A. (2010). Definition and classification of estuaries. In A. Valle-Levinson (Ed.), Contemporary Issues in Estuarine Physics (pp. 1-11). Cambridge: Cambridge University Press. https://doi.org/DOI: 10.1017/CBO9780511676567.002 
Vermeer, M., \& Rahmstorf, S. (2009). Global sea-level linked to global temperature. Proceedings of the National Academy of Sciences (Vol. 106). https://doi.org/10.1073/pnas.0907765106

Wang, T., Geyer, W. R., \& MacCready, P. (2017). Total Exchange Flow, Entrainment, and Diffusive Salt Flux in Estuaries. Journal of Physical Oceanography, 47(5), 12051220. https://doi.org/10.1175/JPO-D-16-0258.1

Warner, J. C., Geyer, W. R., \& Lerczak, J. A. (2005). Numerical model of an estuary: \{ \{\}A comprehensive skill assessment\{\}\}. Journal of Geophysical Research-Oceans, 110(C5), C05001. https://doi.org/10.1029/2004jc002691

Warner, M. D., Mass, C. F., \& Salathé, E. P. (2015). Changes in Winter Atmospheric Rivers along the North American West Coast in CMIP5 Climate Models. Journal of Hydrometeorology, 16(1), 118-128. https://doi.org/10.1175/JHM-D-14-0080.1

Wei, X., Schramkowski, G. P., \& Schuttelaars, H. M. (2016). Salt Dynamics in WellMixed Estuaries: Importance of Advection by Tides. Journal of Physical Oceanography, 46(5), 1457-1475. https://doi.org/10.1175/JPO-D-15-0045.1

Wilson, R. E. (1977). A Model of Dynamics in the Lower Potomac River Estuary. Chesapeake Science, 18(2), 177-187. https://doi.org/doi.org/10.2307/1350859

Witter, R. C., Zhang, Y. J., Wang, K., Priest, G. R., Goldfinger, C., Stimely, L., ... Ferro, P. A. (2013). Simulated tsunami inundation for a range of cascadia megathrust earthquake scenarios at bandon, oregon, USA. Geosphere, 9(6), 1783-1803. https://doi.org/10.1130/GES00899.1

Xiao, H., Huang, W., Johnson, E., Lou, S., \& Wan, W. (2014). Effects of Sea-Level Rise on Salinity Intrusion in St. Marks River Estuary, Florida, U.S.A. Journal of Coastal Research, 68(Fall), 89-96. https://doi.org/10.2112/SI68-012.1

Yeh, H., Tolkova, E., Jay, D., Talke, S., \& Fritz, H. (2012). Tsunami hydrodynamics in the Columbia River. Journal of Disaster Research, 7(5), 604-608. https://doi.org/10.20965/jdr.2012.p0604

Zhang, W., Feng, H., Hoitink, A. J. F., Zhu, Y., Gong, F., \& Zheng, J. (2017). Tidal impacts on the subtidal flow division at the main bifurcation in the Yangtze River Delta. Estuarine, Coastal and Shelf Science, 196, 301-314. https://doi.org/10.1016/j.ecss.2017.07.008

Zimmerman, J. T. F. (1986). The tidal whirlpool: A review of horizontal dispersion by tidal and residual currents. Netherlands Journal of Sea Research, 20(2-3), 133-154. https://doi.org/10.1016/0077-7579(86)90037-2 